\title{
How Much Does Household Collateral Constrain Regional Risk Sharing?
}

\author{
Hanno Lustig* \\ UCLA and NBER \\ Stijn Van Nieuwerburgh ${ }^{\dagger}$ \\ New York University Stern School of Business
}

August 4, 2005

\begin{abstract}
The covariance of regional consumption varies cross-sectionally and over time. Household-level borrowing frictions can explain this aggregate phenomenon. When the value of housing falls, loan collateral shrinks, borrowing (risk-sharing) declines, and the sensitivity of consumption to income increases. Using panel data from 23 US metropolitan areas, we find that in times and regions where collateral is scarce, consumption growth is about twice as sensitive to income growth. Our model aggregates heterogeneous, borrowing-constrained households into regions characterized by a common housing market. The resulting regional consumption patterns quantitatively match the data.
\end{abstract}

\footnotetext{
*corresponding author: email:hlustig@econ.ucla.edu, Dept. of Economics, UCLA, Box 951477 Los Angeles, CA 90095-1477

${ }^{\dagger}$ email: svnieuwe@stern.nyu.edu, Dept. of Finance, NYU, 44 West Fourth Street, Suite 9-120, New York, NY 10012. First version May 2002. The material in this paper circulated earlier as "Housing Collateral and Risk Sharing Across US Regions." (NBER Working Paper). The authors thank Thomas Sargent, David Backus, Dirk Krueger, Patrick Bajari, Timothey Cogley, Marco Del Negro, Robert Hall, Lars Peter Hansen, Christobal Huneuus, Matteo Iacoviello, Patrick Kehoe, Martin Lettau, Sydney Ludvigson, Sergei Morozov, Fabrizio Perri, Monika Piazzesi, Luigi Pistaferri, Martin Schneider, Laura Veldkamp, Pierre-Olivier Weill, and Noah Williams. We also benefited from comments from seminar participants at NYU Stern, Duke, Stanford GSB, University of Iowa, Université de Montreal, University of Wisconsin, UCSD, LBS, LSE, UCL, UNC, Federal Reserve Bank of Richmond, Yale, University of Minnesota, University of Maryland, Federal Reserve Bank of New York, BU, Wharton, University of Pittsburgh, Carnegie Mellon University GSIA, Kellogg, University of Texas at Austin, Federal Reserve Board of Governors, University of Gent, UCLA, University of Chicago, Stanford, the SED Meeting in New York, and the North American Meeting of the Econometric Society in Los Angeles. Special thanks to Gino Cateau for help with the Canadian data. Stijn Van Nieuwerburgh acknowledges financial support from the Stanford Institute for Economic Policy research and the Flanders Fund for Scientific Research. Keywords: Regional risk sharing, housing collateral JEL F41,E21
} 


\section{Introduction}

The cross-sectional correlation of consumption in US metropolitan areas is much smaller than the correlation of labor income or output. This quantity anomaly has been documented in international (e.g. Backus, Kehoe and Kydland (1992), and Lewis (1996)) and in regional data (e.g. Atkeson and Bayoumi (1993), Hess and Shin (2000) and Crucini (1999)), but these unconditional moments hide a surprising amount of time variation in the correlation of consumption across US metropolitan areas. This novel dimension of the quantity anomaly is the focus of our paper, and we propose a housing collateral mechanism to explain it.

On average, US regions share only a modest fraction of total region-specific income risk. But at times this fraction is much higher than at other times: between 1975 and 1985, the ratio of the regional cross-sectional consumption to income dispersion, a standard measure of risk sharing, decreased by fifty percent, while it doubled between 1987 and 1992. This stylized fact presents a new challenge to standard models, because it reveals that the departures from complete market allocations vary substantially over time.

Conditioning on a measure of housing collateral helps to understand this aspect of the consumption correlation puzzle, both over time and across different regions. In the data, our measure of housing collateral scarcity broadly tracks the variation in this regional consumption-to-income dispersion ratio. This ratio is twice as high relative to its lowest value when collateral scarcity is at its highest value in the sample. According to our estimates, the fraction of regional income risk that is traded away, more than doubles when we compare the lowest to the highest collateral scarcity period in postwar US data.

We find cross-sectional evidence for the housing collateral mechanism as well. Using regional measures of the housing collateral stock to sort regions into bins, we find that the income elasticity of consumption growth for regions in the lowest housing collateral quartile of US metropolitan areas is more than twice the size of the same elasticity for areas in the highest quartile, and their consumption growth is only half as correlated with aggregate consumption growth.

We propose an equilibrium model of household risk sharing that replicates these findings. In the model, households share risk only to the extent that borrowing is collateralized by housing wealth. This modest friction is a realistic one for an economy like the US. A key implication of the model is that the degree of risk sharing should vary over time and with the housing collateral ratio. Our emphasis on housing, rather than financial assets, reflects three features of the US economy: the participation rate in housing markets is very high $(2 / 3$ of households own their home), the value of the residential real estate makes up over seventy-five percent of total assets for the median household (Survey of Consumer Finances, 2001), and housing is a prime source of collateral. ${ }^{1}$

\footnotetext{
${ }^{1}$ To keep the model as simple as possible, we abstract from financial assets or other kinds of capital (such as cars) that households may use to collateralize loans. 75 percent of household borrowing in the
} 
Our model reproduces the quantity anomaly. The key is to impose borrowing constraints at the household level and then to aggregate household consumption to the regional level. First, the household constraints are much tighter than the constraints faced by a stand-in agent at the regional level. Second, because the idiosyncratic component of household income shocks are more negatively correlated within a region than the equilibrium household consumption changes that result from these shocks, aggregation produces cross-regional consumption growth dispersion that exceeds regional income growth dispersion. In addition, a reduction in the supply of housing collateral tightens the household collateral constraints, causing regional consumption growth to respond more to regional income shocks. As a result, when we run the same consumption insurance tests on the model's regional consumption data, we replicate the variation in the income elasticity of regional consumption growth that we document in the data.

Our model offers a single explanation for the apparent lack of consumption insurance at different levels of aggregation. ${ }^{2}$ Our approach differs from that in the literature on international risk sharing, which adopts the representative agent paradigm. That literature typically relies on frictions impeding the international flow of capital resulting from the government's ability to default on international debt or to tax capital flows (e.g. Kehoe and Perri (2002)), or resulting from transportation costs (e.g. Obstfeld and Rogoff (2003)). Such frictions cannot account for the lack of risk sharing between regions within a country or between households within a region. This paper shows that modest frictions at the household level in a model with heterogenous agents within a region or country can better our understanding of important macro puzzles.

This paper is not about a direct housing wealth effect on regional consumption: For an average unconstrained household that is not about to move, there is no reason to consume more when its housing value increases, simply because it has to live in a house and consume its services (see Sinai and Souleles (2005) for a clear discussion). We find no evidence in regional consumption data of a direct wealth effect: Regions consume more when total regional labor income increases and this effect is larger when housing wealth is smaller relative to human wealth in that region. We test for a separate housing wealth effect on regional consumption, and we did not find any. In UK data, Campbell and Cocco (2004) also find evidence in favor of a collateral effect on regional consumption, but only in aggregate measures of housing wealth. We find direct evidence that regional measures of housing wealth determine the sensitivity of regional consumption to regional income shocks, as predicted by the model.

Overview and Related Literature Section 2 describes a new data set of the largest US metropolitan statistical areas (MSA). Each MSA is a relatively homogenous region

data is collateralized by housing wealth (US Flow of Funds, 2003).

${ }^{2} \mathrm{~A}$ large literature documents that household-level consumption data are at odds with complete insurance as well; for early work see Cochrane (1991) and Mace (1991). 
in terms of rental price shocks. Since we do not have good data on the intra-regional time-variation in housing prices, metropolitan areas are a natural choice. ${ }^{3}$

Section 3 looks at the regional consumption data though the lens of a complete markets model, with a stand-in agent for each region. We back out regional 'consumption wedges' that measure the distance of the data from the complete market allocation. We then relate the time-series and cross-sectional variation in the amount of housing collateral to the distribution of regional consumption wedges.

This motivates section 4, which makes contact with the large empirical literature on risk sharing that tests the null hypothesis of perfect insurance by estimating linear consumption growth regressions (Cochrane (1991), Mace (1991), Nelson (1994), Attanasio and Davis (1996), Blundell, Pistaferri and Preston (2002), and ensuing work). ${ }^{4}$ In our consumption share growth regressions, the right-hand-side variable is regional income share growth interacted with the housing collateral ratio; income and consumption shares are income and consumption as a fraction of the aggregate, and the housing collateral ratio is the ratio of collateralizeable housing wealth to non-collateralizeable human wealth. The interaction term captures the collateral effect. Consistent with the regional risk-sharing literature that uses state level data (Wincoop (1996), Hess and Shin (1998), DelNegro (1998), Asdrubali, Sorensen and Yosha (1996), Athanasoulis and Wincoop (1998), and DelNegro (2002)), we reject full consumption insurance among US metropolitan regions. ${ }^{5}$

More importantly, and new to this literature, we find that collateral scarcity increases the correlation between income growth shocks and consumption growth. These collateral effects are economically significant. When the housing collateral ratio is at its fifth percentile level, only thirty-five percent of regional income share shocks are insured away. In contrast, when the housing collateral ratio is at its ninety-fifth percentile level, ninety-two percent of regional income share shocks are insured away. As a robustness check, we repeat the analysis for a panel of Canadian provinces, and we find similar variations in the income elasticity of regional consumption growth associated with fluctuations in housing collateral.

Section 5 adds a regional dimension to the model of Lustig and VanNieuwerburgh (2004) and investigates its risk-sharing implications. In the model, the effectiveness of the household risk sharing technology endogenously varies over time due to movements in the value of housing collateral. ${ }^{6}$ Instead, in Lustig and VanNieuwerburgh (2004), the focus is on time-variation in financial risk premia. Here, we study a different implication: In

\footnotetext{
${ }^{3}$ If housing prices are strongly correlated within a region, there are only small efficiency gains from looking at household instead of regional consumption data if the objective is to identify the collateral effect.

${ }^{4}$ Our paper also makes contact with the large literature on the excess sensitivity of consumption to predictable income changes, starting with Flavin (1981), who interpreted her findings as evidence for borrowing constraints, and followed by Hall and Mishkin (1982), Zeldes (1989), Attanasio and Weber (1995) and Attanasio and Davis (1996), all of which examine at micro consumption data.

${ }^{5}$ Asdrubali et al. (1996) find more evidence of risk sharing among regions and states than among countries.

${ }^{6}$ Ortalo-Magne and Rady (1998), Ortalo-Magne and Rady (1999) and Pavan (2005) have also developed models that deliver this feature.
} 
times in which collateral is scarce, the model predicts equilibrium consumption growth to be less strongly correlated across regions. It replicates key moments of the observed regional consumption and income distribution. First, the average ratio of the cross-sectional consumption dispersion to income dispersion is larger than one -the quantity anomaly-, and this ratio increases as collateral becomes scarcer, as in the data. Second, we run the same consumption growth regressions on model-simulated data, and replicate the results from the data.

\section{Data}

We construct a new data set of US metropolitan area level macroeconomic variables, as well as standard aggregate macroeconomic variables. All of the series are annual for the period 1951-2002.

\subsection{Aggregate Macroeconomic Data}

We use two distinct measures of the nominal housing collateral stock $H V$ : the market value of residential real estate wealth $\left(H V^{r w}\right)$ and the net stock current cost value of owneroccupied and tenant occupied residential fixed assets $\left(H V^{f a}\right)$. The first series is from the Flow of Funds (Federal Board of Governors) for 1945-2002 and from the Bureau of the Census (Historical Statistics for the US) prior to 1945. The last series is from the Fixed Asset Tables (Bureau of Economic Analysis) for 1925-2001. Appendix C provides detailed sources. $H V^{r w}$ is a measure of the value of residential housing owned by households, while $H V^{f a}$ which is a measure of the total value of residential housing. Real per household variables are denoted by lower case letters. The real, per household housing collateral series $h v^{r w}$ and $h v^{f a}$ are constructed using the all items consumer price index from the Bureau of Labor Statistics, $p^{a}$, and the total number of households from the Bureau of the Census. Aggregate nondurable and housing services consumption, and labor income plus transfers data are from the National Income and Product Accounts (NIPA). Real per household labor income plus transfers is denoted by $\eta^{a}$, real per capita aggregate consumption is $c^{a}$.

\subsection{Regional Macroeconomic Data}

We construct a new panel data set for the 30 largest metropolitan areas in the US. The regions combine for 47 percent of the US population. The metropolitan data are annual for 1951-2002. Thirteen of the regions are metropolitan statistical areas (MSA). The other seventeen are consolidated metropolitan statistical areas (CMSA), comprised of adjacent and integrated MSA's. Most CMSA's did not exist at the beginning of the sample. For consistency we keep track of all constituent MSA's and construct a population weighted 
average for the years prior to formation of the CMSA. The details concerning the consumption, income and price data we use are in the data appendix C. We use regional sales data to measure non-durable consumption. The appendix compares our new data to other data sources that partially overlap in terms of sample period and definition, and we find that they line up. The elimination of regions with incomplete data leaves us with annual data for 23 metropolitan regions from 1951 until 2002. We denote real per capita regional income and consumption by $\eta^{i}$ and $c^{i}$, and we define consumption and income shares as the ratio of regional to aggregate consumption and income: $\hat{c}_{t}^{i}=\frac{c_{t}^{i}}{c_{t}^{a}}$ and $\hat{\eta}_{t}^{i}=\frac{\eta_{t}^{i}}{\eta_{t}^{a}}$. For these regions we also construct a measure of regional housing collateral, combining information on regional repeat sale price indices with Census estimates on the housing stock (see appendix C.4 for details).

\subsection{Measuring the Housing Collateral Ratio}

In the model the housing collateral ratio $m y$ is defined as the ratio of collateralizable housing wealth to non-collateralizable human wealth. ${ }^{7}$ In Lustig and VanNieuwerburgh (2005a), we show that the log of real per household real estate wealth $(\log h v)$ and labor income plus transfers $(\log \eta)$ are non-stationary in the data. This is true for both $h v^{r w}$ and $h v^{f a}$. We compute the housing collateral ratio as $m y h v=\log h v-\log \eta$ and remove a constant and a trend. The resulting time series myrw and myfa are mean zero and stationary, according to an ADF test. Formal justification for this approach comes from a likelihood-ratio test for co-integration between $\log h v$ and $\log \eta$ (Johansen and Juselius (1990)). We refer the reader to Lustig and VanNieuwerburgh (2005a) for details of the estimation. For the longest available period 1925-2002, the correlation between myrw and $m y f a$ is 0.86 . The housing collateral ratios display large and persistent swings between 1925 and 2002.

In order to compare model and data more easily in the rest of the paper, we define a re-normalized collateral ratio that it is always positive: $\widetilde{m y}{ }_{t+1}=\frac{m y^{m a x}-m y_{t+1}}{m y^{m a x}-m y^{m i n}}$. The re-normalized housing collateral ratio $\widetilde{m y}_{t+1}$ is a measure of collateral scarcity; when the collateral ratio is at its highest point in the sample $\widetilde{m y}=0$, whereas a reading of 1 means that collateral is at its lowest level. The regional housing collateral ratios for each metropolitan area are constructed in the same way from regional housing wealth and regional income measures.

\footnotetext{
${ }^{7}$ Human wealth is an unobservable. We assume that the non-stationary component of human wealth $H$ is well approximated by the non-stationary component of labor income $Y$. In particular, $\log \left(H_{t}\right)=\log \left(Y_{t}\right)+\epsilon_{t}$, where $\epsilon_{t}$ is a stationary random process. This is the case if the expected return on human capital is stationary (see Jagannathan and Wang (1996) and Campbell (1996)). The housing collateral ratio then is measured as the deviation from the co-integration relationship between the value of the aggregate housing collateral measure and aggregate labor income.
} 


\section{Regional Consumption Wedges}

In this section and the next section, we establish the main stylized fact of the paper, that risk sharing across regions is better when housing collateral is more abundant. This section takes a first look at the data through the lens of the benchmark complete markets model with a single stand-in agent for each region. We back out the deviations from complete market allocations, and we label those deviations regional 'consumption wedges' ${ }^{8}$ The time-variation in the distribution of these wedges will guide us towards the right theory.

Environment We let $s^{t}$ denote the history of regional and aggregate income shocks. The stand-in household in a region ranks non-housing and housing consumption streams $\left\{c_{t}\left(s^{t}\right)\right\}$ and $\left\{h_{t}\left(s^{t}\right)\right\}$ according to

$$
U(c, h)=\sum_{s^{t} \mid s^{0}} \sum_{t=0}^{\infty} \beta^{t} \pi\left(s^{t} \mid s^{0}\right) u\left(c_{t}\left(s^{t}\right), h_{t}\left(s^{t}\right)\right),
$$

where $\beta$ is the time discount factor, common to all regions. The households have power utility over a CES-composite consumption good:

$$
u\left(c_{t}, h_{t}\right)=\frac{1}{1-\gamma}\left[c_{t}^{\frac{\varepsilon-1}{\varepsilon}}+\psi h_{t}^{\frac{\varepsilon-1}{\varepsilon}}\right]^{\frac{(1-\gamma) \varepsilon}{\varepsilon-1}},
$$

The preference parameter $\psi>0$ converts the housing stock into a service flow, $\gamma$ is the coefficient of relative risk aversion, and $\varepsilon$ is the intra-temporal elasticity of substitution between non-durable and housing services consumption. ${ }^{9}$

Complete Risk Sharing In a complete markets environment, we expect the stand-in households in any two different regions $i$ and $i^{\prime}$ to equalize their weighted marginal utility from non-durable consumption in all states of the world $\left(s^{t}, s^{\prime}\right)$ :

$$
\mu^{i} u_{c}\left(c_{t+1}^{i}\left(s^{t}, s^{\prime}\right), h_{t+1}^{i}\left(s^{t}, s^{\prime}\right)\right)=\mu^{i^{\prime}} u_{c}\left(c_{t+1}^{i^{\prime}}\left(s^{t}, s^{\prime}\right), h_{t+1}^{i^{\prime}}\left(s^{t}, s^{\prime}\right)\right)
$$

where $\mu^{i}$ is the inverse of the Lagrange multiplier on the time zero budget constraint. This condition is violated in the data, but, more importantly, we show that the distance from the actual allocations in the data to these complete market allocations varies dramatically over time.

\footnotetext{
${ }^{8}$ The stand-in agent is merely used as a convenient way to describe some moments of the data, because it is the reference model in this literature (e.g. Lewis (1995)). In our model, we will start at the household level and explicitly aggregate up to the regional level.

${ }^{9}$ These preferences belong to the class of homothetic power utility functions of Eichenbaum and Hansen (1990). Here we will focus on the special case of separability: $\gamma \varepsilon=1$. A separately available appendix extends the analysis to non-separable utility.
} 


\subsection{Consumption Wedges and the Aggregate Housing Collateral Ratio}

The regional consumption wedges $\kappa$ are defined to satisfy the standard complete markets restriction on the level of marginal utility across different regions:

$$
\frac{\mu^{i}}{\kappa_{t+1}^{i}} u_{c}\left(c_{t+1}^{i}\left(s^{t}, s^{\prime}\right), h_{t+1}^{i}\left(s^{t}, s^{\prime}\right)\right)=\frac{\mu^{i^{\prime}}}{\kappa_{t+1}^{i^{\prime}}} u_{c}\left(c_{t+1}^{i^{\prime}}\left(s^{t}, s^{\prime}\right), h_{t+1}^{i^{\prime}}\left(s^{t}, s^{\prime}\right)\right) \text {. }
$$

They measure the implicit regional consumption tax $\tau_{t+1}^{i}$ necessary to explain observed consumption $\frac{\kappa_{t+1}^{i}}{\mu^{i}}=\left(1+\tau_{t+1}^{i}\right)$. The consumption wedges trace the deviations from the complete market allocations.

Computing the Wedges We focus on the case of separability $\varepsilon=1 / \gamma$ and set $\gamma=2$ for all regions. To keep it simple, we normalize all initial regional weights $\mu^{i}$ to one. In this environment, complete markets implies constant and equal consumption shares. Now we simply feed in observed regional consumption share data $\left\{\hat{c}_{t}^{i}\right\}_{i=1, N}^{t=1, T}$, and compute the implied consumption wedges $\kappa_{t+1}^{i}=\left(\hat{c}_{t+1}^{i}\right)^{-\gamma}$.

The Distribution of Regional Consumption Wedges in Data In our 1951-2002 metropolitan data set, income growth is more strongly correlated across regions than consumption growth. The time average of the cross-sectional correlation of consumption growth is 0.27 , about half of the cross-correlation of labor income growth of 0.48 . This is the well known quantity anomaly.

More surprising is the strong time variation in the size of the regional consumption wedges. The upper panels of figure 1 plot the cross-sectional standard deviation (left box) and cross-sectional average (right box) of the regional wedges (dashed line) against our measure of housing collateral scarcity (full line, measured against the left axis). The average consumption tax varies between zero and four percent and the standard deviation varies between 14 and 22 percent. While there is quite some variation at business cycle frequencies, the low frequency variation dominates and seems to track the housing collateral ratio. The turning points in the housing market $(1960,1974,1991)$ all coincide with turning points in the cross-sectional distribution of these consumption wedges. Comparing the year with the lowest collateral scarcity measure (2002), and the year with the highest collateral scarcity measure (1974) is even more informative: The mean consumption tax increases from one percent (2002) to four percent (1974), while the standard deviation increases from 16 to 22 percent.

[Figure 1 about here.]

Normalizing Consumption Wedges Next, we normalize the moments of the regional consumption wedges by the same moments of the wedges that would arise in an autarchic economy (no risk sharing). These autarchic wedges are computed by feeding observed 
regional income share data $\left\{\widehat{\eta}_{t}^{i}\right\}_{i=1, N}^{t=1, T}$ into the definition of the wedges: $\kappa_{t+1}^{i, a u t}=\left(\widehat{\eta}_{t+1}^{i}\right)^{-\gamma}$. This normalization filters out the effects of changes in the distribution of regional income shocks at business cycle frequencies; the cross-sectional dispersion of regional income shocks increases in recessions. In the lower panels of figure 1, we plot the normalized moments of the consumption wedges. The average consumption wedge (right box, dashed line) tends to increase relative to the autarchic one when collateral is scarce. In addition, there is a lot more cross-sectional variation in the consumption wedges relative to the autarchic wedges (left box). In sum, the average US region experiences much higher marginal utility than predicted by the complete markets model when the housing collateral ratio is low. At the same time there is much more cross-sectional variation in marginal utility levels as well.

Underlying Changes in Consumption Distribution In figure 2, we plot the changes in the consumption distribution that underly these changes in the distribution of consumption wedges. The dashed line in the left panel plots the cross-sectional consumption share dispersion (measured against the right axis); the solid line plots our empirical measure of collateral scarcity (measured against the left axis). The turning points in the cross-sectional dispersion of regional consumption coincide with the turning points in our collateral scarcity measure, especially in the second part of the sample. In the right panel of the figure, we control for changes in income dispersion. The ratio of consumption dispersion to income dispersion is twice as high when is at its lowest value in the sample as when my is at its highest value in the sample (1.79 in 1974 versus .83 in 2002 , right panel). ${ }^{10}$

[Figure 2 about here.]

Changes in Regional Consumption Wedges We also looked at the growth rate of these consumption wedges $\frac{\kappa_{t+1}^{i}}{\kappa_{t}^{i}}$. These rates can be backed out of the growth rate of consumption shares in the data:

$$
\frac{\kappa_{t}^{i}}{\kappa_{t+1}^{i}} \frac{u_{c}\left(\hat{c}_{t+1}^{i}\left(s^{t}, s^{\prime}\right)\right)}{u_{c}\left(\hat{c}_{t}^{i}\left(s^{t}\right)\right)}=\frac{\kappa_{t}^{i^{\prime}}}{\kappa_{t+1}^{i^{\prime}}} \frac{u_{c}\left(\hat{c}_{t+1}^{i^{\prime}}\left(s^{t}, s^{\prime}\right)\right)}{u_{c}\left(\hat{c}_{t}^{i^{\prime}}\left(s^{t}\right)\right)}
$$

The standard deviation of the changes in the consumption wedges decreases from 12 percent in 1974 to 7 percent in 2002. This reflects the underlying decrease in the standard deviation of consumption share growth across US regions from 6 percent in 1974 to 3.5 percent in 2002. This is remarkable given that the standard deviation of income share growth rates increased from 1.8 percent to 3.7 percent.

In section 5, we produce a model with heterogenous households within a region that delivers the same pattern in these regional consumption wedges. The next section shows

\footnotetext{
${ }^{10}$ Clearly, there were other important advances in financial markets that may have contributed to these changes, in particular the increase in non-secured household debt and the deepening and regional integration of mortgage markets starting in the seventies. We return to the latter in the conclusion.
} 
that there is a lot of cross-sectional variation in housing collateral ratios as well and it supports our mechanism.

\subsection{Regional Collateral Scarcity and Consumption Wedges}

To explore the cross-sectional variation, we sort the 23 MSA's by their collateral ratio in each year and we look at average population-weighted consumption growth and income growth for the 6 regions with the lowest and the 6 regions with the highest regional collateral ratio. The regional housing collateral ratio is measured in the same way as the aggregate housing collateral ratio (see appendix C.4 for details).

Table 1 shows the results. Regions in the first quartile (highest collateral scarcity, $\widetilde{m y}^{i}$ is 0.84 on average, reported in column 1) experience more volatile consumption growth (column 2) that is only half as correlated with US aggregate consumption growth (column 3 ) than for the group with the most abundant collateral ( $\widetilde{m y}{ }^{i}$ is 0.26 on average). The last three columns report the result of a time-series regression of group-averaged consumption share growth on group-averaged income share growth. The income elasticity of consumption share growth is 0.66 (with t-stat 1.9) for the group with the most scarce collateral, whereas it is only 0.31 (with t-stat 1.3) for the group with the most abundant collateral. For the first group full insurance can be rejected, whereas for the last group it cannot.

[Table 1 about here.]

\section{Linear Model for Regional Consumption Growth Wedges}

The housing collateral ratio seems to be an important driving force behind the size of the consumption wedges. In this section we explore this possibility in the data. We assume the growth rate of the regional consumption wedge is linear in the product of the housing collateral ratio and the regional income share shock: $\Delta \log \hat{\kappa}_{t+1}^{i}=-\gamma \widetilde{m y_{t+1}} \Delta \log \hat{\eta}_{t+1}^{i}$, where $\hat{\kappa}^{i}$ is region $i$ 's consumption wedge, in deviation from the cross-sectional average. All growth rates of hatted variables denote the growth rates in the region in deviation from the cross-regional average, and the averages are population-weighted. When we impose separability on the utility function, this assumption delivers a linear consumption growth equation:

$$
\Delta \log \hat{c}_{t+1}^{i}=\widetilde{m y}{ }_{t+1} \Delta \log \hat{\eta}_{t+1}^{i}
$$

The consumption growth equation simply involves regional income share growth interacted with the collateral ratio. The interpretation is simple. If $\widetilde{m y}{ }_{t+1}$ is zero, there is no consumption wedge and this region's consumption growth equals aggregate consumption growth. On the other hand, if $\widetilde{m y}_{t+1}$ is one, this region's consumption wedge is at its largest, and the region is in autarchy: its non-housing consumption $c_{t}^{i}$ (growth) equals its labor income $\eta_{t}^{i}$ (growth). So, the model-implied correlation between the consumption share and the income share depends on the collateral ratio. 
The consumption growth equation links our model to the traditional risk-sharing tests based on linear consumption growth regressions, the workhorse of the consumption insurance literature. The next section delivers a formal theory of consumption wedges that ties the distribution of wedges to the housing collateral ratio. We show there that this linear specification of the consumption wedges actually works well inside the model.

\subsection{Estimation of the Linear Model}

We consider two different specifications of the consumption growth regressions. In all regressions, we include regional fixed effects to pick up unobserved heterogeneity across regions, and we take into account measurement error in non-durable consumption. We express observed consumption shares with a tilde and assume that income shares are measured without error. The linear model collapses to the following equation for observed consumption shares $\tilde{c}$ :

$$
\Delta \log \left(\tilde{c}_{t+1}^{i}\right)=a_{0}^{i}+a_{1} \widetilde{m y}_{t+1} \Delta \log \left(\hat{\eta}_{t+1}^{i}\right)+\nu_{t+1}^{i},
$$

where the left hand side variable is observed consumption share growth and $a_{0}^{i}$ are regionspecific fixed effects. All measurement error terms are absorbed in $\nu_{t+1}^{i}$. This equation resembles the standard consumption growth equation in the consumption literature, except for the collateral interaction term. We refer to this equation as 'Specification I'.

Estimation Specifics We assume that the measurement error in regional consumption share growth, $\nu_{t}^{i}$, is orthogonal to lagged values housing collateral ratio: $E\left[\nu_{t}^{i} \widetilde{m y}{ }_{t-k}\right]=$ $0, \forall k \geq 0$. Since only aggregate variables affect the aggregate housing collateral ratio $m y$ and only region-specific measurement error enters in $\nu^{i}$, this assumption follows naturally from the theory.

The benchmark estimation method is generalized least squares (GLS), which takes into account cross-sectional correlation in the residuals $\nu^{i}$ and heteroscedasticity. If the residuals and regressors are correlated, the GLS estimators of the parameters in the consumption growth regressions are inconsistent. To address this possibility, we report instrumental variables estimation results (by three-stage least squares) in addition to the GLS results. Because of the autoregressive nature of $\widetilde{m y}$, we use two, three and four-period leads of the dependent and independent variables as instruments (Arellano and Bond (1991)). In the empirical work, we construct $\widetilde{m y}$ by setting $m y^{\max }$ and $m y^{\min }$ equal to the 1925-2002 sample maximum and minimum.

Results The GLS and IV estimates of this specification are reported table 2, in the panel labeled 'Specification I'. The first two lines report the results for the entire sample 19522002 and two different collateral measures. Lines 3-4 report the results for the 1970-2002 
sub-sample; lines 5-6 use labor income plus transfers, only available for 1970-2000, instead of disposable income. Finally, lines 7-8 report the IV estimates.

[Table 2 about here.]

Full Insurance Rejected The null hypothesis of full insurance among US regions, $H_{0}$ : $a_{1}=0$ in panel A, is strongly rejected. The $p$-value for a Wald test is 0.00 for all rows in table 2. This is consistent with the findings of the regional risk-sharing literature for US states (see e.g. Hess and Shin (1998)). Across the board, in all the specifications (see rows of panel A), $a_{1}$ is positive and measured precisely. The point estimate for $a_{1}$ has a simple interpretation when the support of $\widetilde{m y}$ is symmetric around 0.5 and the current period $\widetilde{m y}_{t+1}=0.5: \frac{a_{1}}{2}$ measures the fraction of income growth shocks that the regions cannot insure away in an average period. Over the entire sample, between 33 percent (row 1) and 37 percent of disposable income growth shocks end up in consumption growth, while two-thirds of shocks are insured away on average.

Collateral Channel More importantly, the correlation of region-specific consumption growth and region-specific income growth is higher when housing collateral is scarce. The empirical distribution of the housing collateral ratio allows us to gauge the extent of time variation in the degree of risk sharing. The fifth percentile value for myrw and the coefficient on $a_{1}$ in row 1 imply a degree of risk-sharing of 34.6 percent. The 95th percentile implies a degree of risk-sharing of 91.5 percent. Likewise, for my fa the risk-sharing interval is $[35.9,92.4]$ percent. The coefficient estimates for the period 1970-2000 are only slightly higher (rows 3-4, panel A). The point estimates for $a_{1}$ are higher when we use labor income growth instead of disposable income growth (rows 5-6). The risk-sharing intervals are $[5,88]$ percent for row 5 and $[8,89]$ percent for row 6 . All of these point estimates imply large shocks to the regional risk sharing technology in the US induced by changes in the housing collateral ratio.

Instrumental Variable Estimates Rows 7-8 of table 2 report instrumental variable estimates where income changes are instrumented by 2 and 3-period leads of independent and dependent variables. The instrumental variables estimates reject full insurance, and the coefficient estimates are close to the ones obtained by GLS. Again, these lend support to the collateral channel.

Separate Income Term The second specification we consider guards against the possibility that we are only picking up the effects of income changes, not the collateral effect itself. We re-estimate the consumption growth equation with a separate regional income growth term:

$$
\Delta \log \left(\tilde{c}_{t+1}^{i}\right)=b_{0}^{i}+b_{1} \Delta \log \left(\hat{y}_{t+1}^{i}\right)+b_{2} m y_{t+1} \Delta \log \left(\hat{y}_{t}^{i}\right)+\nu_{t+1}^{i} .
$$


This in fact the same equation, because it contains the actual collateral ratio $m y_{t+1}$, not the re-scaled collateral scarcity measure $\widetilde{m y}_{t+1}$. The parameter $b_{1}$ in the second specification corresponds to $a_{1} \frac{m y^{\max }}{m y^{\max }-m y^{\min }}$ in the first specification and the coefficient $b_{2}$ corresponds to $-a_{1} \frac{1}{m y^{m a x}-m y^{m i n}}$. These results are in panel B of table 2, under the heading 'Specification II'. Essentially these results confirm the previous findings. The null hypothesis of full insurance is $H_{0}: b_{1}=b_{2}=0$ in panel $\mathrm{B}$. It is strongly rejected. These estimates confirm that the correlation of region-specific consumption growth and region-specific income growth is lower when housing collateral is abundant: $b_{2}<0$ is negative in all rows. The coefficient $b_{2}$ is estimated precisely. The coefficients $b_{1}$ and $b_{2}$ imply that two-thirds of income shocks are insured away on average, but that there is substantial time variation in the degree of risk sharing depending on the level of the collateral ratio. These estimates imply that in the sample the slope coefficients vary between .45 , when $m y=m y^{m i n}$, and .28 , when $m y=m y^{m i n}$, using myrw as the collateral measure.

Non-separable Utility Our previous results are robust to the inclusion of expenditure share growth terms which arise from the non-separability of the utility function. The point estimates for the slope coefficients on income growth interacted with the collateral ratio are very similar, but the expenditure share growth terms are not significant. The results are reported in a separate appendix, downloadable from the authors' web sites. In what follows, we abstract from non-separabilities.

\subsection{Estimation of the Linear Model using Regional Collateral Measures}

Sofar we have used the aggregate housing collateral measure only. This section briefly discusses the empirical relationship between the regional consumption wedges and two regional measures of collateral. Table 3 presents results for the case of separable preferences:

$$
\Delta \log \left(\hat{c}_{t+1}^{i}\right)=b_{0}^{i}+b_{1} \Delta \log \left(\hat{\eta}_{t+1}^{i}\right)+b_{2} X_{t+1}^{i} \Delta \log \left(\hat{\eta}_{t+1}^{i}\right)+\nu_{t+1}^{i},
$$

where $X^{i}$ is the home-ownership rate in region $i$ in the first row and the regional housing collateral ratio $m y^{i}$ in the second row. For both variables, we find that the correlation between consumption and income share growth is lower when the region-specific collateral measure is higher. The effects are large and the coefficients are precisely measured. For example, a one standard deviation increase in the region-specific housing collateral ratio $\left(X^{i}=m y^{i}\right)$ in row 2 increases the degree of risk-sharing by ten percent (from 60 to $66 \%$ ). The region-specific collateral measures vary between -.25 and .25 . The implied difference in the degree of risk sharing (the width of the risk-sharing interval) is $28.5 \%$.

In the third row of the table, we add the regional collateral measure as a separate regressor, to check for a regional housing wealth effect on consumption. The coefficient, $b_{3}$, is significant, but it has the wrong sign. After controlling for the risk-sharing role of housing, we find no separate increase in regional consumption growth when regional 
housing collateral becomes more abundant. Rather, the wealth effect goes the wrong way.

Finally, we also used bankruptcy indicators as a regional collateral measure and found that they were insignificant. US states have different levels of homestead exemptions that households can invoke upon declaring bankruptcy under Chapter 7 . We used both the amount of the exemption and a dummy for MSA's in a state with an exemption level above $\$ 20,000$. In neither regression did we find a significant coefficient.

[Table 3 about here.]

\subsection{Canadian Data}

As a robustness check, we repeat the analysis with data from Canadian provinces. While we only have data available for ten provinces from 1981-2003, the consumption data are arguably more standard: Non-durable consumption (personal expenditures on goods and services less expenditures on durable goods) instead of retail sales. The income measure is personal disposable income. We construct real per capita consumption and income shares, using the provincial CPI series. The housing wealth series measure the market value of the net stock of fixed residential capital, a measure corresponding to $h v^{f a}$. These housing wealth series are available for Canada, as well as for the ten provinces. The housing collateral ratio is constructed in the same way as for the U.S. data. Appendix C.5 describes these data in more detail.

[Table 4 about here.]

Table 4 confirms our finding for the U.S. that the degree of risk-sharing varies substantially with the housing collateral ratio. In the first two rows, we use the aggregate collateral ratio. Since $\widetilde{m y f a}$ is .5 on average and $m y f a$ is zero on average, they show that Canadian provinces share $85 \%$ of income risk on average. This is higher than in the U.S., presumably because there is more government redistribution. More importantly, the degree of risk sharing varies over time. When housing collateral is at its lowest point in the sample (in 1985), only $63 \%$ of income risk is shared, whereas in 2003, the degree of risk-sharing is $95 \%$. In rows 3 and 4 we use the same collateral measure, but now measured at the regional level. Again we find a precisely estimated slope coefficient with the right sign. Lastly, we confirm our finding for the U.S. data, that these results are not driven by a wealth effect. In row 4 , the coefficient on the housing collateral ratio $b_{3}$ shows up with the wrong sign. In the rest of the paper, we build a model to understand these fluctuations in risk-sharing. The empirical results for the U.S. will be our target.

\section{A Theory of Time-Varying Consumption Wedges}

The empirical distribution of consumption wedges discussed in section 3 and the linear consumption wedge regressions of section 4 confirm that the degree of risk sharing varies 
over time in unison with the housing collateral ratio. In this section we provide a model that can replicate this feature of the data.

A version of this model was first developed in Lustig and VanNieuwerburgh (2004). It is a dynamic general equilibrium model that approximates the modest frictions inhibiting perfect risk-sharing in advanced economies like the US. The model is based on two ideas: that debts can only be enforced to the extent that they can be collateralized, and that the primary source of collateral is housing. First, we relax the assumption in the Lucas endowment economy that contracts are perfectly enforceable, following Alvarez and Jermann (2000). As in Lustig (2003), we allow households to file for bankruptcy. Second, each household owns part of the housing stock. Housing provides both utility services and collateral services. When a household chooses not to honor its debt repayments, it loses all housing collateral but its labor income is protected from creditors. Defaulting households regain immediate access to credit markets. The lack of commitment gives rise to collateral constraints whose tightness depends on the relative abundance of housing collateral.

The key friction, collateralized borrowing, operates at the household level. The model here differs from Lustig and VanNieuwerburgh (2004) in that it adds a regional dimension. Regions differ in their housing services endowment and housing services cannot be transported across regions. Our main purpose is to show how the regional aggregates in the model, constructed by aggregating household data, behave like those in the data. A calibrated version of the model replicates the time-series and cross-regional variation in the degree or risk sharing observed in the data.

The section starts with a description of the environment in 5.1 and market structure in 5.2. We then provide a characterization of equilibrium allocations using consumption shares in section 5.3. The model gives rise to a simple, non-linear risk-sharing rule. We show that the household collateral constraints give rise to tighter constraints at the regional level in 5.4. Sections 5.5 and 5.6 calibrate and simulate the model, first without and then with aggregate uncertainty. We estimate the linear consumption growth regressions of section 4 on model-generated data.

\subsection{Uncertainty, Preferences and Endowments}

We consider an economy with a continuum of regions. There are two types of infinitely lived households in each of these regions, and households cannot move between regions.

Uncertainty There are three layers of uncertainty: an event $s$ consists of $x, y$, and $z$. We use $s^{t}$ to denote the history of events $s^{t}=\left(x^{t}, y^{t}, z^{t}\right)$, where $x^{t} \in X^{t}$ denotes the history of household events, $y^{t} \in Y^{t}$ denotes the history of regional events and $z^{t} \in Z^{t}$ denotes the history of aggregate events. $\pi\left(s^{t} \mid s_{0}\right)$ denotes the probability of history $s^{t}$, conditional on observing $s_{0}$.

The household-level event $x$ is first-order Markov, and the $x$ shocks are independently 
and identically (henceforth i.i.d.) distributed across regions. In our calibration below, $x$ takes on one of two values, high $(h i)$ or low $(l o)$. When $x=h i$, the first household in that region is in the high state, and, the second household is in the low state. When $x=l o$, the first household is in the low state. The region-level event $y$ is also first-order Markov and it is i.i.d. across regions. We will appeal to a law of large numbers (LLN) when integrating across households in different regions. ${ }^{11}$

Preferences The households $j$ in each region $i$ rank consumption plans consisting of (non-durable) non-housing consumption $\left\{c_{t}^{i j}\left(s^{t}\right)\right\}$ and housing services $\left\{h_{t}^{i j}\left(s^{t}\right)\right\}$ according to the objective function in equation (1).

Endowments Each of the households, indexed by $j$, in a region, indexed by $i$, is endowed with a claim to a labor income stream $\left\{\eta_{t}^{i j}\left(x_{t}, y_{t}, z^{t}\right)\right\}$. The aggregate non-housing endowment $\left\{\eta_{t}^{a}\left(z^{t}\right)\right\}$ is the sum of the household endowments in all regions:

$$
\eta_{t}^{a}\left(z^{t}\right)=\sum_{y_{t}} \pi_{z}\left(y_{t}\right) \eta_{t}^{i}\left(y_{t}, z^{t}\right)
$$

where $\pi_{z}\left(y_{t}\right)$ denotes the fraction of regions that draws aggregate state $z$. Likewise, the regional non-housing endowment $\left\{\eta_{t}^{i}\left(y_{t}, z^{t}\right)\right\}$ is the sum of the individual endowments of the households in that region:

$$
\eta_{t}^{i}\left(y_{t}, z^{t}\right)=\sum_{j=1,2} \eta_{t}^{i j}\left(x_{t}, y_{t}, z^{t}\right)
$$

The left hand side does not depend on $x_{t}$, because the two household endowments always sum to the regional endowment, regardless of whether the first household is in the high or the low state.

Each region $i$ receives a share of the aggregate non-housing endowment denoted by $\hat{\eta}_{t}^{i}\left(y_{t}, z_{t}\right) \gg 0$. Thus, regional income shares are defined as in the empirical section: $\hat{\eta}_{t}^{i}\left(y_{t}, z_{t}\right)=\frac{\eta_{t}^{i}\left(y_{t}, z^{t}\right)}{\eta_{t}^{a}\left(z^{t}\right)}$. Household $j$ 's labor endowment share in region $i$, measured as a fraction of the regional endowment share, is denoted $\hat{\hat{\eta}}_{t}^{j}\left(x_{t}\right) \gg 0$. The shares add up to one within each region: $\hat{\hat{\eta}}_{t}^{1}\left(x_{t}\right)+\hat{\hat{\eta}}_{t}^{2}\left(x_{t}\right)=1$. The level of the labor endowment of household $j$ in region $i$ can be written as:

$$
\eta_{t}^{i j}\left(x_{t}, y_{t}, z^{t}\right)=\hat{\hat{\eta}}_{t}^{j}\left(x_{t}\right) \hat{\eta}_{t}^{i}\left(y_{t}, z_{t}\right) \eta_{t}^{a}\left(z^{t}\right)
$$

In addition, each region is endowed with a stochastic stream of non-negative housing services $\chi_{t}^{i}\left(y^{t}, z^{t}\right) \gg 0$. In contrast to non-housing consumption, the housing services cannot be transported across regions. We will come back to the assumptions we make on

\footnotetext{
${ }^{11}$ The usual caveat applies when applying the LLN; we implicitly assume the technical conditions outlined by Uhlig (1996) are satisfied.
} 
$\chi^{i}$ at the end of section 5.3. So far, we have made the following assumptions about the endowment processes:

Assumption 1. The household-specific labor endowment share $\hat{\hat{\eta}}^{j}$ only depends on $x_{t}$. The regional income share $\hat{\eta}_{t}^{i}$ only depends on $\left(y_{t}, z_{t}\right)$. The events $(x, y, z)$ follow a first-order Markov process.

\section{$5.2 \quad$ Trading}

We set up an Arrow-Debreu economy where all trade takes place at time zero, after observing the initial state $s_{0} .{ }^{12}$ We denote the present discounted value of any endowment stream $\{d\}$ after a history $s^{t}$ as $\Pi_{s^{t}}\left[\left\{d_{\tau}\left(s^{\tau}\right)\right\}\right]$, defined by $\sum_{s^{\tau} \mid s^{t}} \sum_{\tau=t}^{\infty}\left[p_{\tau}\left(s^{\tau} \mid s^{t}\right) d_{\tau}\left(s^{\tau} \mid s^{t}\right)\right]$, where $p_{t}\left(s^{t}\right)$ denotes the Arrow-Debreu price of a unit of non-housing consumption in history $s^{t}$.

Households in each region purchase a complete, state-contingent consumption plan

$$
\left\{c_{t}^{i j}\left(\theta_{0}^{i j}, s^{t}\right), h_{t}^{i j}\left(\theta_{0}^{i j}, s^{t}\right)\right\}_{t=0}^{\infty}
$$

where $\theta_{0}^{i j}$ denotes initial non-labor wealth. ${ }^{13}$ They are subject to a single time zero budget constraint which states that the present discounted value of non-housing and housing consumption must not exceed the present discounted value of the labor income stream and the initial non-labor wealth:

$$
\Pi_{s_{0}}\left[\left\{c_{t}^{i j}\left(\theta_{0}^{i j}, s^{t}\right)+\rho^{i}\left(s^{t}\right) h_{t}^{i j}\left(\theta_{0}^{i j}, s^{t}\right)\right\}\right] \leqslant \theta_{0}^{i j}+\Pi_{s_{0}}\left[\left\{\eta_{0}^{i j}\left(s^{t}\right)\right\}\right],
$$

Collateral Constraints In this time-zero-trading economy, collateral constraints restrict the value of a household's consumption claim net of its labor income claim to be non-negative:

$$
\Pi_{s^{t}}\left[\left\{c_{\tau}^{i j}\left(\theta_{0}^{i j}, s^{\tau}\right)+\rho_{\tau}^{i}\left(s^{\tau}\right) h_{\tau}^{i j}\left(\theta_{0}^{i j}, s^{\tau}\right)\right\}\right] \geq \Pi_{s^{\tau}}\left[\left\{\eta_{\tau}^{i j}\left(x_{\tau}, y_{\tau}, z^{\tau}\right)\right\}\right]
$$

The left hand side denotes the value of adhering to the contract following node $s^{t}$; the right hand side the value of default. Default implies the loss of all housing collateral wealth, and a fresh start with the present value of future labor income. The households in each region are subject to a sequence of collateral constraints, one for each state $s^{t}$. These constraints are not too tight, in the sense of Alvarez and Jermann (2000), in an environment where agents cannot be excluded from trading, e.g. because they can hide (see Lustig (2003) for a formal proof).

\footnotetext{
${ }^{12}$ Lustig and VanNieuwerburgh (2004) describes an equivalent decentralization where all trade takes place sequentially.

${ }^{13} \theta_{0}^{i j}$ denotes the value of household $j$ 's initial claim to housing wealth, as well as any other financial wealth that is in zero net aggregate supply. We refer to this as non-labor wealth. The initial distribution of non-labor wealth is denoted $\Theta_{0}$.
} 
These constraints differ from the typical solvency constraints that decentralize constrained efficient allocations in environments with exclusion from trading upon default. ${ }^{14}$ If we imposed exclusion from trading instead, the solvency constraints would be looser on average, but the same mechanism would operate. The reason is that in autarchy the household would still have to buy housing services with its endowment of non-housing goods. An increase in the relative price of housing services would worsen the outside option and loosen the solvency constraints, as it does in our model.

Kehoe-Levine Equilibrium The definition of an equilibrium is straightforward. We simply check that the allocations solve the household problem and that the markets clear in all states of the world.

Definition 2. A Kehoe-Levine equilibrium is a list of allocations $\left\{c_{t}^{i j}\left(\theta_{0}^{i j}, s^{t}\right)\right\},\left\{h_{t}^{i j}\left(\theta_{0}^{i j}, s^{t}\right)\right\}$ and prices $\left\{\rho_{t}^{i}\left(s^{t}\right)\right\},\left\{p_{t}\left(s^{t}\right)\right\}$ such that, for a given initial distribution $\Theta_{0}$ over non-labor wealth holdings and initial states $\left(\theta_{0}, s_{0}\right)$, (i) the allocations solve the household problem, (ii) the markets for non-housing and housing consumption clear:

Consumption markets clear for all $t, z^{t}$ :

$$
\sum_{j=1,2} \sum_{x^{t}, y^{t}} \int c_{t}^{i j}\left(\theta_{0}^{i j}, x^{t}, y^{t}, z^{t}\right) \frac{\pi\left(x^{t}, y^{t}, z^{t} \mid x_{0}, y_{0}, z_{0}\right)}{\pi\left(z^{t} \mid z_{0}\right)} d \Theta_{0}=\eta_{t}^{a}\left(z^{t}\right)
$$

Housing markets in each region $i$ clear for all $t, x^{t}, y^{t}, z^{t}$ :

$$
\sum_{j=1,2} h_{t}^{i j}\left(\theta_{0}^{i j}, x^{t}, y^{t}, z^{t}\right)=\chi_{t}^{i}\left(y^{t}, z^{t}\right)
$$

\subsection{Equilibrium Allocations}

To characterize the equilibrium consumption dynamics we use stochastic consumption weights that describe the consumption of each household as a fraction of the aggregate endowment (see appendix A for a complete derivation). Instead of solving a social planner problem, we characterize equilibrium allocations and prices directly off the household's necessary and sufficient first order conditions. The household problem is a standard convex problem: the objective function is concave and the constraint set is convex. In equilibrium, for any two households $j$ and $j^{\prime}$ in any two regions $i$ and $i^{\prime}$, the level of marginal utilities satisfies:

$$
\xi_{t+1}^{i j} u_{c}\left(c_{t+1}^{i j}\left(\theta_{0}^{i j}, s^{t}, s^{\prime}\right), h_{t+1}^{i j}\left(\theta_{0}^{i j}, s^{t}, s^{\prime}\right)\right)=\xi_{t+1}^{i^{\prime} j^{\prime}} u_{c}\left(c_{t+1}^{i^{\prime} j^{\prime}}\left(\theta_{0}^{i^{\prime} j^{\prime}}, s^{t}, s^{\prime}\right), h_{t+1}^{i^{\prime} j^{\prime}}\left(\theta_{0}^{i^{\prime} j^{\prime}}, s^{t}, s^{\prime}\right)\right),
$$

\footnotetext{
${ }^{14}$ Most other authors in this literature take the outside option upon default to be exclusion from future participation in financial markets (e.g. Kehoe and Levine (1993), Krueger (2000), Krueger and Perri (2003), and Kehoe and Perri (2002)).
} 
at any node $\left(s^{t}, s^{\prime}\right)$, where $\xi^{i j}$ is the consumption weight of household $j$ in region $i$. These consumption weights are the household level counterpart of the regional consumption wedges we defined in section 3. Our model provides an equilibrium theory of these consumption wedges.

Cutoff Rule The equilibrium dynamics of the consumption weights or wedges are nonlinear; in particular they follow a simple cutoff rule. This cutoff characterization follows from the first order conditions of the constrained optimization problem in the time-zerotrading setup described above. We focus here on equilibrium allocations in the model where preferences over non-durable consumption and housing services are separable $(\gamma \varepsilon=1)$.

The weights start off at $\xi_{0}^{i j}=\nu^{i j}$ at time zero; this initial weight is the multiplier on the initial promised utility constraints (see appendix A). The new weight $\xi_{t}^{i j}$ of a generic household $i j$ that enters period $t$ with weight $\xi_{t-1}^{i j}$ equals the old weight as long as the household does not switch to a state with a binding collateral constraint. When a household enters a state with a binding constraint, its new weight $\xi_{t}^{i j}$ is re-set to a cutoff weight $\underline{\xi}_{t}\left(x_{t}, y_{t}, z^{t}\right)$.

$$
\tilde{\xi}_{t}^{i j}\left(\nu^{i j}, s^{t}\right)=\left\{\begin{array}{lr}
\xi_{t-1}^{i j} & \text { if } \xi_{t-1}^{i j}>\underline{\xi}_{t}\left(x_{t}, y_{t}, z^{t}\right) \\
\underline{\xi}_{t}\left(x_{t}, y_{t}, z^{t}\right) & \text { if } \xi_{t-1}^{i j} \leq \underline{\xi}_{t}\left(x_{t}, y_{t}, z^{t}\right)
\end{array}\right.
$$

$\underline{\xi}_{t}\left(x_{t}, y_{t}, z^{t}\right)$ is the consumption weight at which the collateral constraint (3) holds with equality. It does not depend on the entire history of household-specific and region-specific shocks $\left(x^{t}, y^{t}\right)$, only the current shock $\left(x_{t}, y_{t}\right)$. This amnesia property crucially depends on assumption 1. The reason is simple: the right hand side of the collateral constraint in (3) only depends on the current shock $\left(x_{t}, y_{t}\right)$ when the constraint binds. This immediately implies that household ij consumption shares cannot depend on the region's history of shocks (see proposition 6 in appendix A for a formal proof).

The consumption in node $s^{t}$ of household $i j$ is fully pinned down by this cutoff rule:

$$
c_{t}^{i j}\left(s^{t}\right)=\frac{\left(\xi_{t}^{i j}\left(\nu^{i j}, s^{t}\right)\right)^{\frac{1}{\gamma}}}{\xi_{t}^{a}\left(z^{t}\right)} c_{t}^{a}\left(z^{t}\right)
$$

Its consumption as a fraction of aggregate consumption equals the ratio of its individual stochastic consumption weight $\xi_{t}^{i j}$ raised to the power $\frac{1}{\gamma}$ to the aggregate consumption weight $\xi_{t}^{a}$. This aggregate consumption weight is computed by integrating over the new household weights across all households, at aggregate node $z^{t}$ :

$$
\xi_{t}^{a}\left(z^{t}\right)=\sum_{j=1,2} \sum_{x^{t}, y^{t}} \int\left(\xi_{t}^{i j}\left(\nu^{i, j}, s^{t}\right)\right)^{\frac{1}{\gamma}} \frac{\pi\left(x^{t}, y^{t}, z^{t} \mid x_{0}, y_{0}, z_{0}\right)}{\pi\left(z^{t} \mid z_{0}\right)} d \Phi_{0}^{j},
$$

where $\Phi_{0}^{j}$ is the cross-sectional joint distribution over initial household consumption weights 
$\nu$ and the initial shocks $\left(x_{0}, y_{0}\right)$ for households of type $j=1,2$. By the law of large numbers, the aggregate weight process only depends on the aggregate history $z^{t}$.

The risk sharing rule for non-housing consumption in (5) clears the market for nondurable consumption by construction, because the re-normalization of consumption weights by the aggregate consumption weight $\xi_{t}^{a}$ guarantees that the consumption shares integrate to one across regions. It follows immediately from (4), (5), and (6) that in a stationary equilibrium, each household's consumption share is drifting downwards as long as it does not switch to a state with a binding constraint, while the consumption share of the constrained households jump up. The rate of decline of the consumption share for all unconstrained households is the same, and equal to the aggregate weight shock $g_{t+1} \equiv \xi_{t+1}^{a} / \xi_{t}^{a}$. When none of the households is constrained between nodes $z^{t}$ and $z^{t+1}$, the aggregate weight shock $g_{t+1}$ equals one. In all other nodes, the aggregate weight shock is strictly greater than one. The risk-sharing rule for housing services is linear as well:

$$
h_{t}^{i j}\left(s^{t}\right)=\frac{\left(\xi_{t}^{i j}\left(\nu^{i j}, s^{t}\right)\right)^{\frac{1}{\gamma}}}{\xi_{t}^{i}\left(x^{t}, y^{t}, z^{t}\right)} \chi_{t}^{i}\left(y_{t}, z^{t}\right),
$$

where the denominator is now the regional weight shock, defined as

$$
\xi_{t}^{i}\left(x^{t}, y^{t}, z^{t}\right)=\sum_{j=1,2}\left(\xi_{t}^{i j}\left(\nu^{i j}, s^{t}\right)\right)^{\frac{1}{\gamma}}
$$

The appendix verifies that this rule clears the housing market in each region.

In the case of non-separable preferences between non-housing and housing consumption $(\gamma \varepsilon \neq 1)$, the equilibrium consumption allocations also follow a cutoff rule, similar to the one in equations (4), (5), and (7). In this case, the consumption weight changes when the non-housing expenditure share changes, even if the region does not enter a state with a binding constraint. The derivation is in a separate appendix, available on our web sites.

Equilibrium State Prices In each date and state, random payoffs are priced by the unconstrained household, who have the highest intertemporal marginal rate of substitution (see Alvarez and Jermann (2000)). The price of a unit of a consumption in state $s^{t+1}$ in units of $s^{t}$ consumption is their intertemporal marginal rate of substitution, which can be read off directly from the risk sharing rule in (5):

$$
\frac{p_{t+1}\left(s^{t+1}\right)}{p_{t}\left(s^{t}\right) \pi\left(s_{t+1} \mid s_{t}\right)}=\beta\left(\frac{c_{t+1}^{a}}{c_{t}^{a}}\right)^{-\gamma} g_{t+1}^{\gamma}
$$

This derivation relies only on the invariance of the unconstrained household's weight between $t$ and $t+1$. The first part is the representative agent pricing kernel under separability. The collateral constraints contribute a second factor to the stochastic discount factor, the aggregate weight shock raised to the power $\gamma$. 
Regional Rental Prices The equilibrium relative price of housing services in region $i$, $\rho^{i}$, equals the marginal rate of substitution between consumption and housing services of the households in that region:

$$
\rho_{t}^{i}\left(y^{t}, z^{t}\right)=\frac{u_{h}\left(c_{t}^{i j}\left(\theta_{0}^{i j}, s^{t}\right), h_{t}^{i j}\left(\theta_{0}^{i j}, s^{t}\right)\right)}{u_{c}\left(c_{t}^{i j}\left(\theta_{0}^{i j}, s^{t}\right), h_{t}^{i j}\left(\theta_{0}^{i j}, s^{t}\right)\right)}=\psi\left(\frac{h_{t}^{i j}}{c_{t}^{i j}}\right)^{\frac{-1}{\varepsilon}}=\psi\left(\frac{\xi_{t}^{a}}{\xi_{t}^{i}} \frac{\chi_{t}^{i}}{c_{t}^{a}}\right)^{\frac{-1}{\varepsilon}} .
$$

The second equality follows from the CES utility kernel; the last equality substitutes in the equilibrium risk sharing rules (5) and (7). Because each region consumes its own housing services endowment, the rental price is in principle region-specific and depends on the region-specific shocks $y^{t}$.

Non-Housing Expenditure Shares Using the risk sharing rule under separable utility, it is easy to show that the non-housing expenditure share is the same for all households $j$ in region $i$ (see appendix $\mathrm{A}$ ):

$$
\frac{c_{t}^{i j}}{c_{t}^{i j}+\rho_{t}^{i} h_{t}^{i j}} \equiv \alpha_{t}^{i j}=\alpha_{t}^{i}
$$

In the calibration, we focus on the case of a perfectly elastic supply of housing services at the regional level. To do so, we impose an additional restriction on the regional housing endowments.

Assumption 3. The regional housing endowments $\chi_{t}^{i}$ are chosen such that $\frac{\xi_{t}^{i}}{\xi_{t}^{a}} c_{t}^{a}\left(z^{t}\right)=$ $\kappa \chi_{t}^{i}\left(y^{t}, z^{t}\right)$, for some constant $\kappa$ and for all $y^{t}, z^{t}$.

The equilibrium expenditure shares $\alpha^{i}$ are a function of the aggregate history $z^{t}$ only: $\alpha_{t}^{i}=\alpha_{t}\left(z^{t}\right)$. Likewise, rental prices only depend on $z^{t}$.

Tightness of the Collateral Constraints Because of the collateral constraints, labor income shocks cannot be fully insured in spite of the full set of consumption claims that can be traded. How much risk sharing the economy can accomplish depends on the ratio of aggregate housing collateral wealth to non-collateralizeable human wealth. Integrating housing wealth and human across all households in all regions, that ratio can be written as:

$$
\frac{\Pi_{z^{t}}\left[\left\{c_{t}^{a}\left(z^{t}\right)\left(\frac{1}{\alpha_{t}\left(z^{t}\right)}-1\right)\right\}\right]}{\Pi_{z^{t}}\left[\left\{c_{t}^{a}\left(z^{t}\right)\right\}\right]},
$$

where in the numerator we used the assumption that the housing expenditure shares are identical across regions. In the model, we define the collateral ratio $m y_{t}\left(z^{t}\right)$ as the ratio of housing wealth to total wealth:

$$
m y_{t}\left(z^{t}\right)=\frac{\Pi_{z^{t}}\left[\left\{c_{t}^{a}\left(z^{t}\right)\left(\frac{1}{\alpha_{t}\left(z^{t}\right)}-1\right)\right\}\right]}{\Pi_{z^{t}}\left[\left\{c_{t}^{a}\left(z^{t}\right) \frac{1}{\alpha_{t}\left(z^{t}\right)}\right\}\right]} .
$$


If the aggregate non-housing expenditure share is constant, the collateral ratio is constant at $1-\alpha$. Suppose the aggregate endowment $\eta^{a}=c^{a}$ is constant as well. Then $m y$ or $\alpha$ index the risk-sharing capacity of the economy. When $\alpha=1, m y=0$ is zero and there is no collateral in the economy. All the collateral constraints necessarily bind at all nodes and households are in autarchy. ${ }^{15}$ On the other hand, as $\alpha$ becomes sufficiently small, $m y$ becomes sufficiently large, and perfect risk sharing becomes feasible, because the solvency constraints no longer bind in any of the nodes $s^{t}$.

In section 5.5 we investigate equilibria where the aggregate endowment is constant; each equilibrium is indexed by a different housing collateral ratio $m y$, or equivalently an expenditure ratio $\alpha$ : $m y=1-\alpha$. In section 5.6, we generalize the analysis and let the expenditure share be a function of the aggregate state $z^{t}$.

\subsection{Tighter Constraints}

In our model, a region is just a unit of aggregation. We define regional consumption as the sum of household consumption:

$$
c_{t}^{i}\left(\theta_{0}^{i 1}, \theta_{0}^{i 2}, y^{t}, z^{t}\right)=\sum_{j=1,2} c_{t}^{i j}\left(\theta_{0}^{i j}, x^{t}, y^{t}, z^{t}\right)
$$

The regional consumption share is defined as a fraction of total non-durable consumption, as in the empirical analysis: $\hat{c}_{t}^{i}=\frac{c_{t}^{i}}{c_{t}^{a}}$.

The constraints faced by these households are tighter than those faced by a stand-in agent, who consumes regional consumption and earns regional labor income, in each region: By the linearity of the pricing functional $\Pi(\cdot)$, the aggregated regional collateral constraint for region $i$ is just the sum of the household collateral constraints over households $j$ in region $i$ :

$$
\begin{array}{r}
\left.\sum_{j=1,2} \Pi_{s^{t}}\left[\left\{c_{t}^{i j}\left(\theta_{0}^{i j}, s^{t}\right)+\rho_{t}^{i}\left(y^{t}, z^{t}\right) h_{t}^{i j}\left(\theta_{0}^{i j}, s^{t}\right)\right\}\right]=\Pi_{s^{t}}\left[\left\{c_{t}^{i}\left(\theta_{0}^{i 1}, \theta_{0}^{i 2}, y^{t}, z^{t}\right)+\rho_{t}^{i}\left(y^{t}, z^{t}\right) \chi_{t}^{i}\left(y_{t}, z^{t}\right)\right)\right\}\right] \\
\geq \sum_{j} \Pi_{s^{t}}\left[\left\{\eta_{t}^{i j}\left(x_{t}, y_{t}, z^{t}\right)\right\}\right]=\Pi_{s^{t}}\left[\left\{\eta_{t}^{i}\left(y_{t}, z^{t}\right)\right\}\right] \text { for all } s^{t}
\end{array}
$$

This condition is necessary, but not sufficient: If household net wealth is non-negative in all states of the world for both households, then regional net wealth is too, but not viceversa. In particular, it is the household in the $x=h i$ state whose constraint is crucial, not the average household's. If we simply calibrated the model to regional income shocks, the constraints would hardly bind.

\footnotetext{
${ }^{15}$ Proof: If a set of households with non-zero mass had a non-binding solvency constraint at some node $\left(x^{t}, y^{t}, z^{t}\right)$, there would have to be another set of households with non-zero mass at node $\left(x^{t^{\prime}}, y^{t^{\prime}}, z^{t}\right)$ that violate their solvency constraint.
} 


\subsection{Model-generated Data Without Aggregate Uncertainty}

In this section and the next, we show that a calibrated version of the model replicates the moments of interest in the data. In a first step, we abstract from aggregate uncertainty. We compute various stationary equilibria, each one corresponding to a different value for the housing collateral ratio. We vary the collateral ratio $m y$ by varying the non-housing expenditure share $\alpha .{ }^{16}$ Since $\alpha$ is persistent in the data, comparing different stationary equilibrium allocations corresponding to different housing collateral ratios is a reasonable first step. In the next section, we compute the model with aggregate uncertainty.

\subsubsection{Computation of Stationary Equilibrium}

The aggregate endowment of non-housing consumption grows at a constant rate $\lambda$, as does the housing endowment in each region, while the aggregate non-housing expenditure share $\alpha$ is constant.

In a stationary equilibrium, the aggregate consumption weight $\xi_{t}^{a}$ grows at a constant rate $g$. Section A in the appendix discussed the details. We assign each household a label $\hat{c}$, which is this household's consumption share at the end of the last period. Let $\mathcal{C}$ denote the domain of the normalized consumption weights. Consider a household of type 1. Its new consumption weight at the start of the next period follows the cutoff rule $\varpi^{1}(\hat{c}, x, y): \mathcal{C} \times X \times Y \longrightarrow \mathcal{C}:$

$$
\begin{aligned}
\varpi^{1}(\hat{c}, x, y) & =\hat{c} \text { if } \hat{c}>\underline{\varpi}^{1}(x, y) \\
& =\underline{\varpi}^{1}(x, y) \text { elsewhere }
\end{aligned}
$$

where $\underline{\varpi}^{1}(x, y)$ is the cutoff consumption share. At the cutoff, the household's net wealth is exactly zero: $\left.C^{1}\left(\underline{\varpi}^{1}(x, y), x, y\right)\right)=0$, where $C^{1}(\hat{c}, x, y)$ is the net wealth function: $C^{1}(\hat{c}, x, y): \mathcal{C} \times X \times Y \longrightarrow R^{+}$, and it solves the following functional equation:

$$
C^{1}(\hat{c}, x, y)=\frac{\hat{c}}{\alpha}-\eta^{1}(x, y)+\beta(\lambda)^{-\gamma} g^{\gamma} \sum_{x^{\prime}, y^{\prime}} \pi\left(x^{\prime}, y^{\prime} \mid x, y\right) C^{1}\left(\hat{c}^{\prime}, x^{\prime}, y^{\prime}\right),
$$

Recall that the price today of a unit of non-durable consumption to be delivered next period is $\beta(\lambda)^{-\gamma} g^{\gamma}$, where $\lambda$ is the growth rate of the aggregate non-housing endowment $c^{a}$. The policy functions for a household of type 2 are defined analogously. The new consumption shares $\hat{c}^{\prime}$ follow immediately from the cutoff rule: $\hat{c}^{\prime}=\frac{\varpi^{1}(\hat{c}, x, y)}{g}$. Housing consumption is simply $h^{\prime}=\frac{\varpi^{1}(\hat{c}, x, y)}{g}\left(\frac{1}{\alpha}-1\right)$, because the expenditure shares do not vary across regions.

Definition 4. A stationary equilibrium consists of a scalar $g^{*}$, an invariant measure $\Phi^{j}(\hat{c}, x, y)$ for each type $j$ and a policy function $\left\{\varpi^{j}(\hat{c}, x, y)\right\}_{j=1,2}$ for the consumption

\footnotetext{
${ }^{16}$ This is equivalent to re-scaling the amount of non-durable consumption while keeping the expenditure share constant in the case of separable utility.
} 
shares that implements the cutoff rule $\left\{\underline{\varpi}^{j}(x, y)\right\}_{j=1,2}$ such that:

$$
\sum_{j=1,2} \int_{\mathcal{C} \times X \times Y} \varpi^{j}(\hat{c}, x, y) d \Phi^{j}(\hat{c}, x, y)=g^{*}
$$

In a stationary equilibrium, the consumption shares of all the unconstrained households drift down at a constant rate and the joint measure $\Phi^{j}$ over consumption shares $\hat{c}$ for type $j$ households and shocks $(x, y)$ is constant. Lustig (2003) proves the existence of a stationary equilibrium, based on Krueger (2000); section A in the appendix states the necessary conditions.

We approximate the net wealth function $C(\cdot)$ as a function of the consumption weight $\varpi$ using Tchebychev polynomials of degree 7 with 30 grid points (see Judd (1998)). The algorithm starts out by conjecturing an initial aggregate weight shock $g_{0}$. We then solve for the optimal cutoff rule, simulate the model and compute the new implied aggregate weight shock $g_{1}$. Iterations continue until $\{g\}$ converges to $g^{*}$.

\subsubsection{Calibration}

Preference Parameters We consider the case of separable utility by setting $\gamma$ at 2 and $\epsilon$ at .5, the estimate of the intratemporal elasticity of substitution by Yogo (2006). In the benchmark calibration, the discount factor $\beta$ is set equal to .95. We also explore lower values for $\beta$.

Non-Housing Endowment The aggregate housing and non-durable consumption endowment grow at a constant rate of $\lambda=1.83$ percent. We use a 5 -state first-order Markov process to approximate the regional labor income share dynamics (see Tauchen and Hussey (1991)): $\log \hat{\eta}_{t}^{i}=.94 \log \hat{\eta}_{t-1}^{i}+e_{t}^{i}$ with the standard deviation of the shocks $\sigma_{e}$ set to 1 percent. The estimation details are in appendix B. We do not model permanent income differences between regions. Finally, as is standard in this literature, we use a 2-state Markov process to match the level of household labor income share $\hat{\hat{\eta}}_{t}^{j}$ (as a fraction of regional labor income) dynamics. The persistence is .9 and the standard deviation is .4 (see Heaton and Lucas (1996)).

Average Housing Collateral Ratio We use two approaches to calibrate the average US ratio of housing wealth to housing plus human wealth: a factor payments and an asset values approach. First, we examine the factor payments. Between 1946 and 2002, the average ratio of total US rental income to labor income (compensation of employees) plus rental income $\frac{\rho h}{\rho h+y}$ was 3.8 percent (see table 5 , row 1 ). This measure of rental income includes imputed rents for owner-occupied housing. Second, we look at asset values. Over the same period, the average ratio of US residential wealth to labor income (plus transfers) is about 1.4 (row 3). In our model, we match this number with $m y=.025$ (see bottom 
panel of figure 4). Both approaches suggest a ratio smaller than five percent.

The above calculation ignores non-housing sources of collateral. If we include dividends and interest payments, and we treat proprietary income as non-collateralizable, then the factor payment ratio increases to 13.2 percent (row 2). In terms of asset values, row 4 shows that the average ratio of the market value of US non-farm,non-financial corporations to non-farm, non-financial labor income is 3.56 (see Lustig and VanNieuwerburgh (2005b) for data construction). Thus, the total ratio of collateralizable wealth to labor income is 4.96 (row 5). In our model, we match this number with $m y=.07$. Using a broad measure of collateral, we end up with a ratio close to 10 percent.

[Table 5 about here.]

All regions have the same non-housing expenditure share $\alpha\left(z^{t}\right)$ (see assumption 3). In this section, $\alpha$ is constant. We compute stationary equilibria for 25 points on a grid for the housing collateral ratio $m y=1-\alpha \in[.005, .165]$.

\subsubsection{History of Household Shocks}

The changes in the regional consumption shares $\hat{c}_{t}^{i}\left(x^{t}, y^{t}\right)=\frac{\xi^{i}\left(x^{t}, y^{t}\right)}{\xi_{t}^{a}}$ are governed by the growth rate of the regional weight relative to that of the aggregate weights $g$. This is a measure of how constrained the households in this region are relative to the rest of the economy. These regional consumption shares depend on the history of household-specific shocks $x^{t}$, but only in a limited sense. When one of the households switches from the low to the high state, her weight increases, causing regional consumption to increase even when the regional income share stays constant $\left(\hat{\eta}_{t}^{j}\right.$ increases but $\hat{\eta}^{i}$ is constant $) .{ }^{17}$ However, these household shocks are i.i.d across regions, so that their effects disappear when we integrate over all household-specific histories:

$$
\int_{x^{t} \in X^{t}} \hat{c}_{t}^{i}\left(x^{t}, y^{t}\right) d \Pi\left(x^{t}\right)=\int_{x^{t} \in X^{t}} \frac{\xi^{i}\left(x^{t}, y^{t}\right)}{\xi_{t}^{a}} d \Pi\left(x^{t}\right) \simeq \hat{c}_{t}^{i}\left(y^{t}\right)
$$

by the LLN. Even though the collateral constraints pertain to households and households within a region are heterogeneous, on average, the regional consumption share $\hat{c}_{t}^{i}\left(y^{t}\right)$ behaves as if it is the consumption share of a representative household in the region facing a single, but tighter, collateral constraint (see section 5.4).

To an econometrician with only regional data generated by the model, it looks as if the stand-in agent's consumption share is subject to preference shocks or measurement error. These preference shocks follow from switches in the identity of the constrained household within the region. To illustrate this point, figure 3 plots the simulated equilibrium household and regional consumption shares against income shares. The first panel shows the

\footnotetext{
${ }^{17}$ This is why it is possible that the cross-sectional dispersion of regional consumption shares may exceed the cross-sectional dispersion of regional income shares. This occurs often in the data, see right panel of figure 2 .
} 
two households' income (dashed lines) and consumption shares (full lines) in one particular region. The second panel just adds up across the two households to show the regional income (dashed line) and consumption shares (full line) for the same history of shocks $x^{t}, y^{t}$ and the same region. Finally, the third panel shows the regional consumption and income shares for the same sequence of regional shocks $y^{t}$, but integrates out the effect of $x^{t}$ by averaging across 1000 regions as in equation (12). When one of the households switches to the high household-specific state and is constrained, its consumption share increases. This increases the regional consumption share, even though the regional income share may not have changed. Because such household-specific shocks are i.i.d. across regions, they are averaged out in the bottom panel. On average, regional consumption shares only respond to regional income shares.

[Figure 3 about here.]

\subsubsection{Joint Distribution of Regional Consumption, Income and Housing Col- lateral}

As we did for the data in sections 3 and 4, we now examine the properties of the cross-section distribution of regional consumption and the income elasticity of regional consumption growth in the model. For each of 25 values of $m y$ between $.5 \%$ and $16.5 \%$, we simulate the model for 600 periods and 1000 regions to obtain a panel of consumption and income shares.

The Cross-Sectional Consumption Distribution in the Model The top panel in figure 4 plots the ratio of the cross-sectional dispersion of regional consumption shares to income shares for the 25 equilibria. The regional consumption-to-income dispersion ratio declines from 2 , when the collateral ratio is .5\%, to .5 when the collateral ratio is $16.5 \%$. For the 23 US MSA's, the mean consumption-to-income dispersion ratio over the 1952-2002 sample is 1.28. The model matches this number for our benchmark collateral ratio of $5 \%$. When collateral is scarce, the cross-sectional standard deviation of regional consumption exceeds the standard deviation of regional income. It looks as if there are regional gains from risk sharing that are left unexploited, while, in fact, there are none.

Income Elasticity of Regional Consumption The second panel of figure 4 plots the elasticity $a_{1}$ of regional consumption share growth with respect to regional income share growth against the housing collateral ratio. The slope coefficient $a_{1}$ is obtained by running the risk-sharing regression

$$
\Delta \log \left(\hat{c}_{t+1}^{i}\right)=a_{0}^{i}+a_{1} \Delta \log \left(\hat{\eta}_{t+1}^{i}\right)+\nu_{t+1}^{i},
$$

on model-generated data, where $a_{0}^{i}$ is a regional fixed effect. 
To understand the regression results, recall that in equilibrium, the growth rate of the regional consumption shares is determined by the difference between the growth rates of the regional weight and the growth rate of the aggregate weight: $\Delta \log \left(\hat{c}_{t+1}^{i}\right)=\Delta \log \xi_{t+1}^{i}-g$. As argued in the previous section, $\Delta \log \xi_{t+1}^{i}$ only responds to regional income shocks on average $\left(\Delta \log \hat{\eta}_{t+1}^{i}\right)$. The effect of household-specific shocks $x$ is absorbed in the error term $\nu_{t+1}^{i}$. Thus, our model provides a theory of the measurement error term $\nu_{t+1}^{i}$.

In the benchmark case of $\beta=.95$, the elasticity decreases from 0.4 to 0.1 as the housing collateral ratio increases from .005 to .165. At our benchmark collateral value of five percent, the slope is 0.28 . These slope coefficients are similar to what we found in the data (section 4). As we lower the discount factor, the slope coefficients increase in absolute value. For $\beta=.90$ (not shown in the graph), the constraints are tighter on average, and the slope coefficients vary between 0.5 and 0.1 .

[Figure 4 about here.]

These slope coefficients reflect two forces. First, in case of a positive shock to household/regional income, the cutoff shares are much higher in low collateral economies (see upper panel of figure 5). Second, in case of a negative shock, the household consumption shares drift down at a higher rate $g$ in the low collateral economy (see lower panel of figure 5). The same logic applies to the regional consumption shares. From equation (11) for fixed $g$, an increase in $\alpha$, or equivalently, a decrease in the housing collateral ratio increases the cutoff level $\underline{\varpi}^{1}(x, y)$ at which the net wealth function hits zero for any state $(x, y)$ (see proposition 8 in the appendix ). On average, the percentage increase in the household consumption share $\log \underline{\varpi}^{1}(x, y)-\log g-\log \hat{c}$, will be larger when a household switches to a higher $x$ or $y$. Likewise, the decrease in consumption share is larger after a bad shock because $\log g$ is larger. The same logic applies to the regional consumption share, because it is the sum of the shares for the two types of households. These effects are further pronounced for lower discount rates; the open circles are for $\beta=.90$ and the plus signs are for $\beta=.85$.

[Figure 5 about here.]

The Quantity Anomaly Regional consumption is very sensitive to regional income shocks, in spite of the fact that most of the risk faced by households has been traded away in equilibrium, even at low collateral ratios. This is apparent in figure 6 . The upper panel plots the standard deviation of regional consumption growth (full circles correspond to $\beta=.95$ ), while the lower panel plot the standard deviation of household consumption growth. In the data, the average standard deviation of consumption growth for US metropolitan areas is 4.15 percent. The model generates slightly too much regional risk sharing when $\beta=.95$, but for $\beta=.9(\beta=.85)$, the model matches the 4.15 percent dispersion when $m y$ is $4 \%$ $(6 \%)$. 
The full lines in each panel represent the standard deviation of regional and household income growth, respectively. As is apparent from the bottom panel of 6 , more than $75 \%$ of total household risk has been insured. Yet, in the top panel, the standard deviation of regional income growth risk is lower than that of regional consumption growth risk for low levels of housing collateral! What explains this quantity anomaly?

First, at the household level: The standard deviation of the household consumption share growth rate equals the standard deviation of the growth rate of the household weight shocks, and we find that $\operatorname{std}\left(\frac{1}{\gamma} \Delta \log \xi_{t+1}^{i j}\right)<\operatorname{std}\left(\Delta \log \eta_{t+1}^{i j}\right)$. Second, at the regional level: The standard deviation of regional consumption share growth rate equals the standard deviation of the growth rate of the regional weight shock, and we find that $\operatorname{std}\left(\Delta \log \xi_{t+1}^{i}\right)>$ $\operatorname{std}\left(\Delta \log \widehat{\eta}_{t+1}^{i}\right)$. This reversal comes about because (1) the household income share shocks $\Delta \log \hat{\hat{\eta}}_{t+1}^{i j}$ are perfectly negatively correlated across the households within region, while (2) the individual household weight shocks that result from these shocks are not. At the household level, income growth is more negatively correlated within a region than consumption growth because of intra-regional risk-sharing -not in spite of risk sharing! Therefore, when we aggregate from the household to the regional level, household risk sharing gives rise to regional consumption growth volatility that exceeds regional income growth volatility.

[Figure 6 about here.]

\subsection{Model-generated Data with Aggregate Uncertainty}

Rather than comparing equilibria with different collateral ratios, we now compute an equilibrium with aggregate uncertainty, in which the housing collateral ratio varies over time.

Calibration of the expenditure ratio We modify the calibration to let the housing collateral ratio, or equivalently the non-housing expenditure share, be a function of the aggregate state: $\alpha\left(z^{t}\right)$. In particular, we assume that the log of the aggregate non-housing expenditure ratio $\ell=\log \left(\frac{\alpha}{1-\alpha}\right)$ follows an autoregressive process:

$$
\ell_{t}=\mu_{\ell}+.96 \log \ell_{t-1}+\epsilon_{t},
$$

with $\sigma_{\epsilon}=.03$ and $\mu_{\ell}$ was chosen to match the average US post-war non-housing expenditure ratio of 4.41, taken from Piazzesi, Schneider and Tuzel (2004). Denote by $\mathcal{L}$ the domain of $\ell$. We scale up the quantity of labor income in the model to match an average collateral ratio of 10 percent. In other words, we stack the deck against ourselves by allowing for a broad measure of collateral (see rows 2 or 5 of table 5 ). The rest of the calibration remains the same. 


\subsubsection{Computation of Markov Stationary Equilibrium}

When the aggregate shocks move the non-housing expenditure share $\alpha$ and the collateral ratio around, the joint measure over consumption shares and states changes over time. Instead of keeping track the entire measure or the entire history of aggregate shocks in the state space, we have policy functions depend on a vector with the $k$ last aggregate weight shocks: $\vec{g}_{k}=\left[g_{-1}, g_{-2}, \ldots, g_{-k}\right] \in \mathcal{G} .{ }^{18}$ Consider a household of type 1 . A household's new consumption weight at the start of the next period follows a simple cutoff rule $\varpi^{1}\left(\hat{c}, x, y, \ell, \vec{g}_{k}\right): \mathcal{C} \times X \times Y \times \mathcal{L} \times \mathcal{G} \longrightarrow \mathcal{C}:$

$$
\begin{aligned}
\varpi^{1}\left(\hat{c}, x, y, \ell, \vec{g}_{k}\right) & =\hat{c} \text { if } \hat{c}>\underline{\varpi}^{1}\left(x, y, \ell, \vec{g}_{k}\right) \\
& =\underline{\varpi}^{1}\left(x, y, \ell, \vec{g}_{k}\right) \text { elsewhere, }
\end{aligned}
$$

where $\underline{\varpi}^{1}\left(x, y, \ell, \vec{g}_{k}\right)$ is the cutoff consumption share for which the collateral constraints hold with equality. The cutoff consumption share satisfies $\left.C^{1}\left(\underline{\varpi}^{1}\left(x, y, \ell, \vec{g}_{k}\right), x, y, \ell, \vec{g}_{k}\right)\right)=$ 0 , where $C^{1}\left(\hat{c}, x, y, \ell, \vec{g}_{k}\right): \mathcal{C} \times X \times Y \times \mathcal{L} \times \mathcal{G} \longrightarrow R^{+}$is the net wealth function. The policy functions for a household of type 2 are defined analogously. Next period's consumption shares are:

$$
\hat{c}^{\prime}=\frac{\varpi^{1}\left(\hat{c}, x, y, \ell, \vec{g}_{k}\right)}{g},
$$

where $g=\sum_{j=1,2} \int_{\mathcal{C} \times X \times Y \times \mathcal{L} \times \mathcal{G}} \varpi^{j}\left(\hat{c}, x, y ; \ell, \vec{g}_{k}\right) d \Phi^{j}\left(\hat{c}, x, y ; \ell, \vec{g}_{\infty}\right)$ is the actual aggregate weight shock. Let $\Phi^{j}\left(\hat{c}, x, y ; \ell, \vec{g}_{\infty}\right)$ denote the joint measure over $\hat{c}$ and $(x, y)$ which depends on the infinite history of shocks, and let $\Xi\left(\ell, \vec{g}_{\infty}\right)$ denote the joint measure over $\ell$ and $g$.

Definition 5. An approximate $k^{\text {th }}$-order Markov stationary equilibrium consists of a forecasting function $g\left(\ell, \vec{g}_{k}\right)$, a measure $\Phi^{j}\left(\hat{c}, x, y ; \ell, \vec{g}_{\infty}\right)$ for each type $j$ and a policy function $\left\{\varpi^{j}\left(\hat{c}, x, y ; \ell, \vec{g}_{k}\right)\right\}_{j=1,2}$ that implements the cutoff rule $\left\{\underline{\varpi}^{j}\left(x, y, \ell, \vec{g}_{k}\right)\right\}_{j=1,2}$, where the forecasting function has zero average prediction errors:

$$
g\left(\ell, \vec{g}_{k}\right)=\sum_{j=1,2} \int_{\vec{g}_{\infty} \mid \vec{g}_{k}} \int_{C \times X \times Y \times \mathcal{L} \times \mathcal{G}} \varpi^{j}\left(\hat{c}, x, y ; \ell, \vec{g}_{k}\right) d \Phi^{j}\left(\hat{c}, x, y ; \ell, \vec{g}_{\infty}\right) d \Xi\left(\ell, \vec{g}_{\infty}\right)
$$

To approximate the household's net wealth function $C(\cdot)$, we use 5th-degree Tchebychev polynomials in the two continuous state variables, the consumption weights $\varpi$ and the $\log$ expenditure ratio $\ell$. We compute a first-order Markov equilibrium. The prediction errors are percentage deviations of actual from spent aggregate consumption. These approximation errors are small. Table 6 shows that they never exceed $1.9 \%$ in absolute value, they are $.3 \%$ on average and their standard deviation is about $.4 \%$. The computation is accurate.

\footnotetext{
${ }^{18}$ The model tells us which moment of the distribution in the last period to keep track of: if many agents were severely constrained last period and $g_{-1}$ was large, very few are constrained this period and $g$ is small.
} 
[Table 6 about here.]

\subsubsection{The Joint Distribution of Regional Consumption, Income and Housing Collateral}

The model with aggregate shocks generates an equilibrium distribution of regional consumption, income and housing collateral that closely resembles that in the data. We simulate a panel of $T=15000$ periods and $N=100$ regions. On average, the ratio of housing wealth to total wealth, $m y$, is $10 \%$ and the average collateral scarcity is $\widetilde{m y}=.71$. We start by computing the regional consumption wedges.

The Distribution of Regional Consumption Wedges in Model The wedges are defined as before, but now computed from model-generated regional consumption shares: $\kappa_{t+1}^{i}=\left(\hat{c}_{t}^{i}\right)^{-\gamma}=\left(\frac{\xi_{t+1}^{i}}{\xi_{t+1}^{a}}\right)^{-\gamma}$. Figure 7 reveals a close correlation between the cross-sectional standard deviation (left box) and the cross-sectional mean (right box) of the regional wedges (dashed line), and the collateral scarcity measure (full line, measured against the right axis). The mean regional consumption tax varies between five and zero percent, while the standard deviation varies between 19 and 26 percent, and both track the collateral scarcity measure closely. These model-generated wedges line up closely with the wedges we found for the 23 MSA's reported in figure 1. These changes in the moments of the wedges reflect changes in the underlying distribution of regional consumption shares.

[Figure 7 about here.]

Underlying Changes in Consumption Distribution Figure 8 shows the cross-sectional dispersion of consumption in the model. When housing collateral is scarce, the crosssectional dispersion increases (left box). The turning points in the cross-sectional dispersion of consumption coincide with the turning points in the housing collateral ratio. For example, between periods 325 and 375 it increases by 40 percent, from .15 to .23 as the collateral scarcity increases from .5 to .9. The right panel controls for changes in the income dispersion. The ratio of consumption dispersion to income dispersion is almost twice as high when collateral scarcity is at its highest value in the simulation. We found the same variation in the data (see figure 2). Again, the model generates the quantity anomaly. When collateral is scarce, the cross-sectional consumption dispersion exceeds the cross-sectional income dispersion.

[Figure 8 about here.]

Figure 9 confirms the positive correlation between the consumption share dispersion and the collateral scarcity measure in a scatter plot of 15000 model-generated data points. The thick cloud in the upper right corner shows that the same level of consumption dispersion 
corresponds to various collateral ratios. ${ }^{19}$ We find a similar pattern in the data, especially after 1972 (right panel of figure 10).

[Figure 9 about here.]

One shortcoming is that the model produces too little dispersion in regional consumption shares relative to the data. When comparing the scale on figures 9 and 10, keep in mind that the mean consumption share in the data is $1 / 23$, while in the model the mean consumption share is 1 . This is not surprising, because part of the higher dispersion in the data reflects permanent differences between the metropolitan areas. Our calibration abstracts from these permanent differences. The level differences disappear in growth rates. And indeed, our model does match the average regional standard deviation of consumption share growth over time and the ratio of consumption share to income share dispersion in the data (see figure 6).

[Figure 10 about here.]

Income Elasticity of Consumption Share Growth Finally, we use the same simulation to re-estimate the consumption share growth regressions that we ran on the regional consumption share data in section 4 . The results are reported in table 7. As in the data, we run two different specifications of the linear consumption growth regressions. In the first specification (panel A), we only include an interaction term between regional income growth and the collateral ratio. The slope coefficient in the first specification varies between .32 , for $\beta=.95$, and .58 , for $\beta=.75$. Because $\widetilde{m y}$ is .71 on average in the simulation, the average fraction of income shocks that ends up in consumption is $23 \%$ for $\beta=.95$. That implies that $77 \%$ of income risk is insured on average. For $\beta=.75$, the average fraction of risk that is shared among regions is $58 \%$. The $66 \%$ estimate for the average fraction of income risk shared in the data (see section 4 , table 2 , panel B) corresponds to a value for $\beta$ between .95 and .90 . More importantly, the slope coefficients imply a lot of time-variation in the degree of risk sharing. In the model, the $5^{\text {th }}$ and $95^{t h}$ percentile of $\widetilde{m y}$ are .55 and .95. That distribution implies a $90 \%$ confidence interval for the degree of risk-sharing of $[69.3,82.2]$ percent for $\beta=.95$ and $[44.5,67.9]$ percent for $\beta=.75$.

The second specification allows for a separate income growth term. Panel B reveals that the slope coefficient varies in the sample between -.04 when $m y=m y^{\max }$ and .34 when $m y=m y^{m i n}$, in the case of $\beta=.95$. In the case of $\beta=.75$, the coefficient varies between .09 and .54. In the data, the slope coefficients varied between .28 and .45 (see section 4 , table 2, panel B). Also, the regression $R^{2}$ are very close to those in the data, around $7 \%$. They are low simply because regional risk is small compared to household risk.

[Table 7 about here.]

\footnotetext{
${ }^{19}$ This reflects the dependence of equilibrium allocations on the history of aggregate shocks, in addition to their dependence on the collateral ratio.
} 


\section{Concluding Remarks}

Two aspects of financial markets are often studied separately. One is their role in allocating consumption risk, the other is asset returns. A model with limited commitment and default resulting in the loss of housing collateral is successful in explaining both features. In Lustig and VanNieuwerburgh (2004), we focus on the asset pricing implications ${ }^{20}$, and in a related paper (Lustig and VanNieuwerburgh (2005a)), we test the model's asset pricing predictions on US stock returns. We find that US investors demand higher risk premia on stocks whose returns are more correlated with aggregate consumption growth when the housing collateral ratio is low. The focus of this paper was on the risk-sharing dynamics of the model. We presented evidence from a new data set of US metropolitan areas consumption that supports the collateral mechanism: the conditional correlation of regional consumption growth with income growth increases substantially when collateral is scarce. More recent work by Campbell and Cocco (2004) shows direct evidence from UK data that housing prices are an important factor in consumption decisions at the household level. Iacoviello (2004) considers the implications of housing collateral constraints for aggregate consumption.

Household level frictions, such as the collateral constraints we study, may help us understand aggregate consumption dynamics across different regions and countries. Most existing work in this literature focusses on frictions at the aggregate level, such as sovereign debt constraints. These models have a hard time explaining imperfect risk-sharing at different levels of aggregation. The aggregation arguments we develop here open up new avenues to explain macro risk-sharing patterns by modeling micro-frictions. Hortacsu, Lustig and Moskowitz (2005) provide more evidence by explicitly tracing some variation in US regional risk sharing back to financial market participation differences.

Finally, the collateral mechanism explored here may also help explain low-frequency household risk-sharing patterns. In recent work, Krueger and Perri (2003) document that the dramatic increase in labor income inequality in the US between 1970 and 2002 was not accompanied by a similar increase in household consumption inequality. ${ }^{21}$ Our housing collateral effect seems consistent with these trends in household consumption and income inequality as well. As shown in figure 11, in the US, the ratio of residential wealth to labor income increased from 1.4 to 1.9 and the ratio of mortgages to income increased from .45 to .8. This indicates an increase of between 30 and 45 percent in the US collateral ratio over this period! A persistent increase in housing collateral of that magnitude would give a substantial boost to risk sharing and a reduction in the cross-sectional dispersion of income

\footnotetext{
${ }^{20}$ We solve a calibrated version of this model and find that the collateral mechanism is important to quantitatively match unconditional and conditional asset pricing moments, as well as to generate enough variation in returns across assets.

${ }^{21}$ They explain this fact in the limited commitment model of Kehoe and Levine (1993); in this model, the increase in income risk worsens the household's outside option and this renders the risk sharing technology more effective, because the constraints bind less often. In our model constraints bind less often when the value of housing collateral increases.
} 
relative to consumption.

[Figure 11 about here.]

\section{References}

Alvarez, Fernando and Urban Jermann, "Efficiency, Equilibrium, and Asset Pricing with Risk of Default.," Econometrica, 2000, 68 (4), 775-798.

Arellano, Manuel and Stephen Bond, "Some Tests of Specification for Panel Data: Monte Carlo Evidence and an Application to Employment Equations," Review of Economic Studies, 1991, 58, 277-297.

Asdrubali, Pierfederico, Bent Sorensen, and Oved Yosha, "Channels of Interstate Risk Sharing: United States 1963-1990," Quaterly Journal of Economics, 1996, 111, 1081-1110.

Athanasoulis, Stefano and Eric Van Wincoop, "Risk Sharing Within the United States: What Have Financial Markets and Fiscal Federalism Accomplished?," Working Paper Federal Reserve Bank of New York, 1998, 9808.

Atkeson, Andy and Tamim Bayoumi, "Do Private Capital Markets Insure Regional Risk? Evidence from the United States and Europe.," Open Economies Review, 1993, 4, 303-324.

Attanasio, Orazio P. and Guglielmo Weber, "Is Consumption Growth Consistent with Intertemporal Optimization? Evidence from the Consumer Expenditure Survey," The Journal of Political Economy, December 1995, 103 (6), 1121-1157.

and Steven J. Davis, "Relative Wage Movements and the Distribution of Consumption," The Journal of Political Economy, December 1996, 104 (6), 1127-1262.

Backus, David, Patrick Kehoe, and Finn Kydland, "International Real Business Cycles," Journal of Political Economy, 1992, 100 (4), 745-75.

Blundell, Richard, Luigi Pistaferri, and Ian Preston, "Partial Insurance, Information and Consumption Dynamics," July 2002. Mimeo.

Campbell, John and Joao Cocco, "Do House Prices Affect Consumption? Evidence From Micro Data," August 2004. Working Paper, Harvard University.

Campbell, John Y., "Understanding Risk and Return," The Journal of Political Economy, April 1996, 104 (2), 298-345.

Case, Karl E. and Robert J. Shiller, "Prices of Single-Family Homes Since 1970: New Indexes for Four Cities," New England Economic Review, September/October 1987, pp. 46-56.

_ _ John M. Quigley, and Robert J. Shiller, "Comparing Wealth Effects: The Stock Market versus The Housing Market," October 2001. UC Berkeley Working Papers.

Cochrane, John H., "A Simple Test of Consumption Insurance," The Journal of Political Economy, October 1991, 99 (5), 957-976.

Crucini, Mario J., "On International and National Dimensions of Risk Sharing," Review of Economics and Statistics, 1999, 81, 73-84. 
DelNegro, Marco, "Aggregate Risk Sharing Across US States and Across European Countries," January 1998. Yale University mimeo.

"Asymmetric Shocks Among U.S. States," Journal of International Economics, 2002, 56, $273-297$.

Eichenbaum, Martin and Lars Peter Hansen, "Estimating Models with Intertemporal Substitution Using Aggregate Time Series Data," Journal of Business and Economic Statistics, 1990, 8 (1), 53-69.

Flavin, Marjorie, "The Adjustment of Consumption to Changing Expectations About Future Income," Journal of Political Economy, 1981, 89, 974-10091.

Hall, Robert E. and Frederic S. Mishkin, "The Sensitivity of Consumption to Transitory Income: Estimates from Panel Data on Households," Econometrica, 1982, 50, 461-481.

Heaton, John and Deborah Lucas, "Evaluating the Effects of Incomplete Markets on Risk Sharing and Asset Pricing," Journal of Political Economy, 1996, 104, 668-712.

Hess, Gregory D. and Kwanho Shin, "Intranational Business Cycles in the United States," Journal of International Economics, April 1998, 44 (2), 289-313.

__ and __ , "Risk Sharing by Households Within and Across Regions and Industries," Journal of Monetary Economics, 2000, 45, 533-560.

Hortacsu, Ali, Hanno Lustig, and Tobias Moskowitz, "The Volatility of Regional Capital Flows in the US," Working Paper University of Chicago, 2005.

Iacoviello, Matteo, "Consumption, House Prices and Collateral Constraints: a Structural Econometric Analysis.," January 2004.

Jagannathan, Ravi and Zhenyu Wang, "The Conditional CAPM and the Cross-Section of Expected Returns," The Journal of Finance, March 1996, 51 (1), 3-53.

Johansen, Soren and Katarina Juselius, "Maximum Likelihood Estimation and Inference on Cointegration with Applications to the Demand for Money," Oxford Bulletin of Economics and Statistics, May 1990, 52, 169-210.

Judd, K., Numerical Methods in Economics, Cambridge, Mass.: MIT Press, 1998.

Kehoe, Patrick J. and Fabrizio Perri, "International Business Cycles with Endogenous Incomplete Markets," Econometrica, May 2002, 70 (3), 907-928.

Kehoe, Timothy and David Levine, "Debt-Constrained Asset Markets.," Review of Economic Studies, 1993, 60, 865-888.

Krueger, Dirk, "Risk Sharing in Economies with Incomplete Markets," June 2000. mimeo.

and Fabrizio Perri, "Does Income Inequality Lead to Consumption Inequality? Evidence and Theory.," November 2003. Mimeo.

Lewis, Karen, "Puzzles in International Financial Markets," in Gene Grossman and Kenneth Rogoff, eds., Handbook of International Economics, North-Holland: Elsevier, 1995, chapter 37, pp. 1913-1949. 
"What Can Explain The Apparent Lack of International Consumption Risk-Sharing?," Journal of Political Economy, 1996, 104, 267-297.

Lustig, Hanno, "The Wealth Distribution and the Market Price of Aggregate Risk," 2003. Mimeo University of Chicago.

- and Stijn VanNieuwerburgh, "A Theory of Housing Collateral, Consumption Insurance and Risk Premia," April 2004. Working Paper NYU Stern and University of Chicago.

_ and _ _ "Housing Collateral, Consumption Insurance and Risk Premia: An Empirical Perspective," Journal of Finance, 2005, 60(3), 1167-1219.

_ and _ _ "The Returns on Human Capital: Good News on Wall Street is Bad News on Main Street," July 2005. Working Paper NYU Stern and University of Chicago.

Mace, Barbara J., "Full Insurance in the Presence of Aggregate Uncertainty," The Journal of Political Economy, October 1991, 99 (5), 928-956.

Marcet, Albert and Ramon Marimon, "Recursive Contracts," 1999. working paper Universitat Pompeu Fabra.

Nelson, Julie A., "On Testing for Full Insurance using Consumer Expenditure Survey Data," The Journal of Political Economy, April 1994, 102 (2), 384-394.

Obstfeld, Maurice and Kenneth Rogoff, "The Six Major Puzzles in International Economics: Is There a Common Cause?," Working Paper Harvard and UC Berkeley, 2003.

Ortalo-Magne, Francois and Sven Rady, "Housing Market Fluctuations in a Life-Cycle Economy with Credit Constraints.," 1998. Working Paper London School of Economics.

— and _ , "Why Are Housing Prices so Volatile? Income Shocks in a Stochastic Heterogeneous-Agents Model.," 1999. Working Paper London School of Economics.

Pavan, Marina, "Consumer Durables and Risky Borrowing: The Effects of Bankruptcy Protection," Working Paper Boston College, 2005.

Piazzesi, Monika, Martin Schneider, and Selale Tuzel, "Housing, Consumption and Asset Pricing," January 2004. working paper UCLA.

Pollakowski, Henry O., "Data Sources for Measuring House Price Changes," Journal of Housing Research, 1995, 6 (3), 377-389.

Sinai, Todd and Nick Souleles, "Owner-Occupied Housing as a Hedge Against Rent Risk," forthcoming Quarterly Journal of Economics, 2005.

Stokey, Nancy, Robert E. Lucas, and E. C. Precott, Recursive Methods in Economic Dynamics, Cambridge, Mass.: Harvard University Press., 1989.

Tauchen, G. and R. Hussey, "Quadrature-Based Methods for Obtaining Approximate Solutions to Nonlinear Asset Pricing Models," Econometrica, 1991, 59, 371-396.

Uhlig, Harald, "A Law of Large Numbers for Large Economies," Economic Theory, 1996, 8, $41-50$.

Wincoop, Eric Van, "Regional Risk Sharing," European Economic Review, 1996, 40, 219-254. 
Yogo, Motohiro, "A Consumption-Based Explanation of the Cross-Section of Expected Stock Returns," April 2006. Journal of Finance (forthcoming).

Zeldes, Stephen, "Consumption and Liquidity Constraints: An Empirical Investigation," Journal of Political Economy, 1989, 97, 305-346.

\section{A Technical Appendix}

This appendix spells out the household problem in an economy where all trade takes place at time zero. Most of the following results are based on Lustig (2003) and Lustig and VanNieuwerburgh (2004).

Household Problem A household of type $\left(\theta_{0}^{i j}, s_{0}\right)$ purchases a complete contingent consumption plan $\left\{c_{0}^{i j}\left(\theta_{0}^{i j}, s_{0}\right), h^{i j}\left(\theta_{0}^{i}, s_{0}\right)\right\}$ at time-zero market state prices $\left\{p, p \rho^{i}\right\}$. The household solves:

$$
\sup _{\left\{c^{i j}, h^{i j}\right\}} U\left(c^{i j}\left(\theta_{0}^{i j}, s_{0}\right), h^{i j}\left(\theta_{0}^{i j}, s_{0}\right)\right)
$$

subject to the time-zero budget constraint

$$
\Pi_{s_{0}}\left[\left\{c_{0}^{i j}\left(\theta_{0}^{i j}, s_{0}\right)+\rho^{i}\left(s_{0}\right) h^{i j}\left(\theta_{0}^{i j}, s_{0}\right)\right\}\right] \leqslant \theta_{0}^{i j}+\Pi_{s_{0}}\left[\left\{\eta_{0}^{i j}\right\}\right]
$$

and an infinite sequence of collateral constraints for each $t$ and $s^{t}$

$$
\Pi_{s^{t}}\left[\left\{c_{t}^{i j}\left(\theta_{0}^{i j}, s^{t}\right)+\rho^{i}\left(s^{t}\right) h_{t}^{i j}\left(\theta_{0}^{i j}, s^{t}\right)\right\}\right] \geq \Pi_{s^{t}}\left[\left\{\eta_{t}^{i j}\left(s^{t}\right)\right\}\right], \forall s^{t} .
$$

Dual Problem Given Arrow-Debreu prices $\left\{p, p \rho^{i}\right\}$ the household with label $\left(\theta_{0}^{i j}, s_{0}\right)$ minimizes the $\operatorname{cost} C(\cdot)$ of delivering initial utility $w_{0}^{i j}$ to itself:

$$
\begin{aligned}
C\left(w_{0}^{i j}, s_{0}\right)= & \min _{\{c, h\}}\left(c_{0}^{i j}\left(w_{0}^{i j}, s_{0}\right)+h_{0}^{i j}\left(w_{0}^{i j}, s_{0}\right) \rho_{0}^{i}\left(s_{0}\right)\right) \\
& +\sum_{s^{t}} p\left(s^{t} \mid s_{0}\right)\left(c_{t}^{i j}\left(w_{0}^{i j}, s^{t} \mid s_{0}\right)+h_{t}^{i j}\left(w_{0}^{i j}, s^{t} \mid s_{0}\right) \rho_{t}^{i}\left(s^{t} \mid s_{0}\right)\right)
\end{aligned}
$$

subject to the promise-keeping constraint

$$
U_{0}\left(\left\{c^{i j}\right\},\left\{h^{i j}\right\} ; w_{0}^{i j}, s_{0}^{i}\right) \geq w_{0}^{i j}
$$

and the collateral constraints

$$
\Pi_{s^{t}}\left[\left\{c_{t}^{i j}\left(w_{0}^{i j}, s^{t}\right)+\rho_{t}^{i}\left(s^{t}\right) h_{t}^{i j}\left(w_{0}^{i j}, s^{t}\right)\right\}\right] \geq \Pi_{s^{t}}\left[\left\{\eta_{t}^{i j}\left(s^{t}\right)\right\}\right], \forall s^{t} .
$$

The initial promised value $w_{0}^{i j}$ is determined such that the household spends its entire initial wealth:

$$
C\left(w_{0}^{i j}, s_{0}\right)=\theta_{0}^{i j}+\Pi_{s_{0}}\left[\left\{\eta^{i j}\left(s^{t}\right)\right\}\right] .
$$

There is a monotone relationship between $\theta_{0}^{i j}$ and $w_{0}^{i j}$. The above problem is a standard, convex programming problem. We set up the saddle point problem and then make it recursive by defining cumulative multipliers (Marcet and Marimon (1999)). Let $\nu^{i j}$ be the Lagrange multiplier on the 
promise keeping constraint and $\gamma_{t}^{i j}\left(w_{0}^{i j}, s^{t}\right)$ be the Lagrange multiplier on the collateral constraint in history $s^{t}$. Define a cumulative multiplier at each node: $\zeta_{t}^{i j}\left(w_{0}, s^{t}\right)=1-\sum_{s^{t}} \gamma_{t}^{i j}\left(w_{0}^{i j}, s^{t}\right)$. Finally, we rescale the market state price

$$
\hat{p}_{t}\left(s^{t}\right)=p_{t}\left(z^{t}\right) / \beta^{t} \pi_{t}\left(s^{t} \mid s_{0}\right) .
$$

By using Abel's partial summation formula and the law of iterated expectations to the Lagrangian, we obtain an objective function that is a function of the cumulative multiplier process $\zeta^{i}$ :

$D\left(c, h, \zeta^{i j} ; w_{0}^{i j}, s_{0}\right)=\sum_{t \geq 0} \sum_{s^{t}}\left\{\beta^{t} \pi\left(s^{t} \mid s_{0}\right)\left[\begin{array}{c}\zeta_{t}^{i j}\left(w_{0}^{i j}, s^{t} \mid s_{0}\right) \hat{p}_{t}\left(s^{t}\right)\left(c_{t}^{i j}\left(w_{0}^{i j}, s^{t}\right)+\rho_{t}^{i}\left(s^{t}\right) h_{t}\left(w_{0}^{i j}, s^{t}\right)\right) \\ +\gamma_{t}^{i j}\left(w_{0}^{i j}, s^{t}\right) \Pi_{s^{t}}\left[\left\{\eta^{i}\right\}\right]\end{array}\right]\right\}$

such that

$$
\zeta_{t}^{i j}\left(w_{0}^{i j}, s^{t}\right)=\zeta_{t-1}^{i j}\left(w_{0}^{i j}, s^{t-1}\right)-\gamma_{t}^{i j}\left(w_{0}^{i j}, s^{t}\right), \zeta_{0}^{i j}\left(w_{0}^{i j}, s_{0}\right)=1
$$

Then the recursive dual saddle point problem is given by:

$$
\inf _{\left\{c^{i j}, h^{i j}\right\}} \sup _{\left\{\zeta^{i j}\right\}} D\left(c^{i j}, h^{i j}, \zeta^{i j} ; w_{0}^{i j}, s_{0}\right)
$$

such that

$$
\sum_{t \geq 0} \sum_{s^{t}} \beta^{t} \pi\left(s^{t} \mid s_{0}\right) u\left(c_{t}^{i j}\left(w_{0}^{i j}, s^{t}\right), h_{t}^{i j}\left(w_{0}^{i j}, s^{t}\right)\right) \geq w_{0}^{i j}
$$

To keep the mechanics of the model in line with standard practice, we re-scale the multipliers. Let

$$
\xi_{t}^{i j}\left(\nu, s^{t}\right)=\frac{\nu^{i j}}{\zeta_{t}^{i j}\left(w_{0}^{i j}, s^{t}\right)},
$$

The cumulative multiplier $\xi^{i j}\left(\nu, s^{t}\right)$ is a non-decreasing stochastic sequence, which is initialized at $\nu^{i j}$ at time zero. We can use $\nu^{i j}$ as the household label. If the constraint for household $\left(\nu^{i j}, s_{0}\right)$ binds, it goes up, else it stays put. This follows immediately from the complementary slackness condition for the solvency constraint.

Optimal Non-Housing Consumption The f.o.c. for $c\left(\nu^{i j}, s^{t}\right)$ is :

$$
\hat{p}_{t}\left(s^{t}\right)=\xi_{t}^{i j}\left(\nu^{i j}, s^{t}\right) u_{c}\left(c_{t}^{i j}\left(\nu^{i j}, s^{t}\right), h_{t}^{i j}\left(\nu^{i j}, s^{t}\right)\right) .
$$

Upon division of the first order conditions for any two households $i j$ and $k l$, the following restriction on the joint evolution of marginal utilities over time and across states must hold:

$$
\frac{u_{c}\left(c_{t}^{i j}\left(\nu^{i j}, s^{t}\right), h_{t}^{i j}\left(\nu^{i j}, s^{t}\right)\right)}{u_{c}\left(c_{t}^{k l}\left(\nu^{k l}, s^{t}\right), h_{t}^{k l}\left(\nu^{k l}, s^{t}\right)\right)}=\frac{\xi_{t}^{k l}\left(\nu^{k l}, s^{t}\right)}{\xi_{t}^{i j}\left(\nu^{i j}, s^{t}\right)} .
$$

Growth rates of marginal utility of non-durable consumption, weighted by the multipliers, are equalized across agents:

$$
\frac{\xi_{t+1}^{i}\left(\nu^{i j}, s^{t+1}\right)}{\xi_{t}^{i}\left(\nu^{i j}, s^{t}\right)} \frac{u_{c}\left(c_{t+1}^{i j}\left(\nu^{i j}, s^{t+1}\right), h_{t+1}^{i j}\left(\nu^{i j}, s^{t+1}\right)\right)}{u_{c}\left(c_{t}^{i j}\left(\nu^{i j}, s^{t}\right), h_{t}^{i j}\left(\nu^{i j}, s^{t}\right)\right)}=\frac{\hat{p}_{t+1}\left(s^{t+1}\right)}{\hat{p}_{t}\left(s^{t}\right)}=\frac{\xi_{t+1}^{k l}\left(\nu^{k l}, s^{t+1}\right)}{\xi_{t}^{k l}\left(\nu^{k l}, s^{t}\right)} \frac{u_{c}\left(c_{t+1}^{k l}\left(\nu^{k l}, s^{t+1}\right), h_{t+1}^{k l}\left(\nu^{k l}, s^{t+1}\right)\right)}{u_{c}\left(c_{t}^{k l}\left(\nu^{k l}, s^{t}\right), h_{t}^{k l}\left(\nu^{k l}, s^{t}\right)\right)} .
$$


In the case of separable preferences between non-housing and housing consumption, there is a simple mapping from the multipliers $\xi$ at $s^{t}$ to the equilibrium allocations of both commodities. We refer to this mapping as the risk-sharing rule:

$$
c_{t}^{i j}\left(\nu^{i j}, s^{t}\right)=\frac{\xi_{t}^{i j}\left(\nu^{i j}, s^{t}\right)^{\frac{1}{\gamma}}}{\xi_{t}^{a}\left(z^{t}\right)} c_{t}^{a}\left(z^{t}\right)
$$

where

$$
\xi_{t}^{a}\left(z^{t}\right)=\sum_{j=1,2} \sum_{x^{t}, y^{t}} \int\left(\xi_{t}^{i j}\left(\nu^{i j}, s^{t}\right)\right)^{\frac{1}{\gamma}} \frac{\pi\left(x^{t}, y^{t}, z^{t} \mid x_{0}, y_{0}, z_{0}\right)}{\pi\left(z^{t} \mid z_{0}\right)} d \Phi_{0}^{j},
$$

where $\Phi_{0}^{j}$ is the cross-sectional joint distribution over initial consumption weights and initial endowments for a household of type $j$. By the law of large numbers, the aggregate weight process only depends on the aggregate history $z^{t}$. It is easy to verify that this rule satisfies the optimality condition and the market clearing conditions.

The time zero ratio of marginal utilities is pinned down by the ratio of multipliers on the promise-keeping constraints. For $t>0$, it tracks the stochastic weights $\xi$. From the first order condition w.r.t. $\xi_{t}^{i j}\left(\nu^{i j}, s^{t}\right)$ and the complementary slackness conditions, we obtain a reservation weight policy:

$$
\begin{aligned}
& \xi_{t}^{i j}=\xi_{t-1}^{i j} \text { if } \xi_{t-1}^{i j}>\underline{\xi}_{t}\left(x_{t}, y_{t}, z^{t}\right) \\
& \xi_{t}^{i j}=\underline{\xi}_{t}\left(x_{t}, y_{t}, z^{t}\right) \text { otherwise. }
\end{aligned}
$$

where the cutoff $\underline{\xi}_{t}$ is defined such that the collateral constraints hold with equality:

$$
\Pi_{s^{t}}\left[\left\{c_{t}^{i j}\left(\nu^{i j}, s^{t} ; \underline{\xi}_{t}\left(\nu^{i j}, s^{t}\right)\right)+\rho^{i}\left(s^{t}\right) h^{i}\left(\nu^{i j}, s^{t} ; \underline{\xi}_{t}\left(\nu^{i j}, s^{t}\right)\right)\right\}\right]=\Pi_{s^{t}}\left[\left\{\eta_{t}^{i j}\left(s^{t}\right)\right\}\right] .
$$

The history-independence of the cutoff is established in proposition 6 .

Optimal Housing Consumption The risk-sharing rule for housing services also follows a cutoff rule:

$$
h_{t}^{i j}\left(s^{t}\right)=\frac{\left(\xi_{t}^{i j}\left(s^{t}\right)\right)^{\frac{1}{\gamma}}}{\xi_{t}^{i}\left(x^{t}, y^{t}, z^{t}\right)} \chi_{t}^{i}\left(y^{t}, z^{t}\right),
$$

where the denominator is now the regional weight shock, defined as

$$
\xi_{t}^{i}\left(x^{t}, y^{t}, z^{t}\right)=\sum_{j=1,2}\left(\xi_{t}^{i j}\left(s^{t}\right)\right)^{\frac{1}{\gamma}}
$$

To minimize notation, we dropped the $\nu$ in the $\xi$ functions. Given this risk sharing rule and the form of the utility function, the regional rental price for any region $i$ is given by:

$$
\rho_{t}^{i}=\psi\left(\frac{h_{t}^{i j}}{c_{t}^{i j}}\right)^{\frac{-1}{\varepsilon}}=\psi\left(\frac{\xi_{t}^{a}}{\xi_{t}^{i}} \frac{\chi_{t}^{i}}{c_{t}^{a}}\right)^{\frac{-1}{\varepsilon}}
$$

We now verify that this risk-sharing rule clears the housing market in each region and satisfies the first order condition for housing services consumption. 
Proof. First, note that these risk sharing rules clear the housing market in each region because $\left(\xi_{t}^{i 1}\left(s^{t}\right)\right)^{\frac{1}{\gamma}}+\left(\xi_{t}^{i 2}\left(s^{t}\right)\right)^{\frac{1}{\gamma}}=\xi_{t}^{i}$ by definition. Second, let's check whether it satisfies the first order condition for non-durable and durable consumption:

$$
\begin{gathered}
\xi_{t}^{i j} u_{c}\left(c_{t}^{i j}\left(s^{t}\right), h_{t}^{i j}\left(s^{t}\right)\right)=\hat{p}_{t}\left(s^{t} \mid s_{0}\right) \\
\xi_{t}^{i j} u_{h}\left(c_{t}^{i j}\left(s^{t}\right), h_{t}^{i j}\left(s^{t}\right)\right)=\rho_{t}^{i}\left(y^{t}, z^{t}\right) \hat{p}_{t}\left(s^{t} \mid s_{0}\right)
\end{gathered}
$$

Recall that the marginal utility of non-housing consumption and housing consumption are:

$$
\begin{aligned}
& u_{c}\left(c_{t}^{i j}\left(s^{t}\right), h_{t}^{i j}\left(s^{t}\right)\right)=\left(c_{t}^{i j}\right)^{\frac{-1}{\varepsilon}}\left[\left(c_{t}^{i j}\right)^{\frac{\varepsilon-1}{\varepsilon}}+\psi\left(h_{t}^{i j}\right)^{\frac{\varepsilon-1}{\varepsilon}}\right]^{\frac{1-\varepsilon \gamma}{\varepsilon-1}} \\
& u_{h}\left(c_{t}^{i j}\left(s^{t}\right), h_{t}^{i j}\left(s^{t}\right)\right)=\psi\left(h_{t}^{i j}\right)^{\frac{-1}{\varepsilon}}\left[\left(c_{t}^{i j}\right)^{\frac{\varepsilon-1}{\varepsilon}}+\psi\left(h_{t}^{i j}\right)^{\frac{\varepsilon-1}{\varepsilon}}\right]^{\frac{1-\varepsilon \gamma}{\varepsilon-1}}
\end{aligned}
$$

In the case of separability, $\varepsilon=\frac{1}{\gamma}$, and the marginal utility of housing services becomes: $u_{h}\left(c_{t}^{i j}\left(s^{t}\right), h_{t}^{i j}\left(s^{t}\right)\right)=$ $\psi\left(h_{t}^{i j}\right)^{\frac{-1}{\varepsilon}}$. Substituting this into the optimality condition for housing produces the following expression:

$$
\xi_{t}^{i j} \psi\left(h_{t}^{i j}\right)^{\frac{-1}{\varepsilon}}=\xi_{t}^{i j} \psi\left[\frac{\left(\xi_{t}^{i, j}\right)^{\frac{1}{\gamma}}}{\xi_{t}^{i}} \chi_{i, t}\right]^{\frac{-1}{\varepsilon}}=\psi\left[\frac{\chi_{i, t}}{\xi_{t}^{i}}\right]^{-1 / \varepsilon}=\rho_{t}^{i}\left(y^{t}, z^{t}\right) \hat{p}_{t}\left(s^{t} \mid s_{0}\right)
$$

where the second equality follows from inserting the risk sharing rule for housing services, and the last equality follows from separability, $\gamma=\frac{1}{\varepsilon}$. Likewise, inserting the risk sharing rule for non-durable consumption into the optimality condition gives:

$$
\xi_{t}^{i j} \psi\left[\frac{\left(\xi_{t}^{i, j}\right)^{\frac{1}{\gamma}}}{\xi_{t}^{a}} c_{t}^{a}\right]^{\frac{-1}{\varepsilon}}=\left[\frac{c_{t}^{a}}{\xi_{t}^{a}}\right]^{\frac{-1}{\varepsilon}}=\hat{p}_{t}\left(s^{t} \mid s_{0}\right)
$$

Dividing through by the last line of the preceding equation, we obtain the following result: $\rho_{t}^{i}=$ $\psi\left(\frac{\xi_{t}^{a}}{\xi_{t}^{2}} \frac{\chi_{t}^{i}}{c_{t}^{t}}\right)^{\frac{-1}{\varepsilon}}$ for any household $j$ in region $i$. This is exactly the rental price we conjectured at the start, together with the risk sharing rule, which confirms that the risk sharing rule satisfies the first order condition for optimality. The risk sharing rule also clears the housing market in every region and it clears the market for non-durable consumption.

Non-separability With non-separable preferences between non-housing and housing consumption $(\gamma \varepsilon \neq 1)$, a similar risk sharing rule holds (derivation available on authors' web sites).

The Non-Housing Expenditure Share The non-housing expenditure share is the same for all households $j$ in region $i$ :

$$
\frac{c_{t}^{i j}}{c_{t}^{i j}+\rho_{t}^{i} h_{t}^{i j}} \equiv \alpha_{t}^{i j} \equiv \alpha_{t}^{i}
$$

Proof. To show this, we use the equilibrium risk-sharing rule for non-housing and housing con- 
sumption, as well as the expression for $\rho_{t}^{i}$ to obtain:

$$
\begin{aligned}
\alpha_{t}^{i j} & =\frac{\frac{\xi_{t}^{i j}\left(\nu^{i j}, s^{t}\right) \frac{1}{\gamma}}{\xi_{t}^{a}\left(z^{t}\right)} c_{t}^{a}\left(z^{t}\right)}{\frac{\xi_{t}^{i j}\left(\nu^{i j}, s^{t}\right) \frac{1}{\gamma}}{\xi_{t}^{a}\left(z^{t}\right)} c_{t}^{a}\left(z^{t}\right)+\psi\left[\frac{\xi_{t}^{a}}{\xi_{t}^{i}\left(y^{t}, z^{t}\right)} \frac{\chi_{t}^{i}\left(y_{t}, z^{t}\right)}{c_{t}^{a}\left(z^{t}\right)}\right]^{\frac{-1}{\varepsilon}} \frac{\left(\xi_{t}^{i j}\left(s^{t}\right)\right)^{\frac{1}{\gamma}}}{\xi_{t}^{i}\left(y^{t}, z^{t}\right)} \chi_{t}^{i}\left(y_{t}, z^{t}\right)} \\
& =\frac{1}{1+\psi\left[\frac{\xi_{t}^{a}}{\xi_{t}^{i}\left(y^{t}, z^{t}\right)} \frac{\left.\chi_{t}^{i}\left(y_{t}, z^{t}\right)\right]^{\frac{\varepsilon-1}{\varepsilon}}}{c_{t}^{a}\left(z^{t}\right)}\right]^{\frac{\varepsilon^{2}}{\varepsilon}}}
\end{aligned}
$$

Note that this expression is the same for all households $j$ in region $i$.

Assumption 3 imposes that the regional shares $\alpha^{i}$ only depend on the aggregate history $z^{t}$ : $\alpha_{t}^{i}=\alpha_{t}\left(z^{t}\right)$. Hence, we assume that the ratio $\frac{\xi_{t}^{i}}{\xi_{t}^{a}} c_{t}^{a}=\chi_{t}^{i}$ for all regions, and all aggregate histories. Note that all regions have the same rental price as well, as a result of this assumption.

\section{History Independence of the Cutoff Rule}

Proposition 6. In a state with a binding collateral constraint, the equilibrium consumption share, $\hat{c}_{t}^{i j}=\frac{c_{t}^{i j}}{c_{t}^{a}}$, only depends on $\left(x_{t}, y_{t}\right)$ and $z^{t}$.

Proof. When the collateral constraint binds for household $i j$,

$$
\begin{array}{r}
\Pi_{s^{t}}\left[\left\{c_{t}^{i j}\left(w_{0}^{i j}, s^{t}\right)\left[1+\frac{\rho_{t}^{i}\left(s^{t}\right) h_{t}^{i j}\left(w_{0}^{i j}, s^{t}\right)}{c_{t}^{i j}\left(w_{0}^{i j}, s^{t}\right)}\right]\right\}\right]=\Pi_{s^{t}}\left[\left\{\eta_{t}^{i j}\left(x_{t}, y_{t}, z^{t}\right)\right\}\right], \\
\Pi_{s^{t}}\left[\left\{\hat{c}_{t}^{i j} c_{t}^{a}\left(z^{t}\right) \frac{1}{\alpha_{t}\left(z^{t}\right)}\right\}\right]=\Pi_{s^{t}}\left[\left\{\hat{\hat{\eta}}_{t}^{i j}\left(x_{t}\right) \hat{\eta}^{i}\left(y_{t}, z_{t}\right) \eta_{t}^{a}\left(z^{t}\right)\right\}\right],
\end{array}
$$

where the second line follows from the definition of the non-housing expenditure share, and we use assumption 3 .

Obviously, the right hand side does not depend on $\left(x^{t-1}, y^{t-1}\right)$, only on $\left(x_{t}, y_{t}\right)$. Fix an arbitrary aggregate history $z^{t}$. We can take two households with histories $\left(x^{t-1}, x_{t}, y^{t-1}, y_{t}\right)$ and $\left(x^{t-1} / \prime, x_{t}, y^{t-1} \prime \prime, y_{t}\right)$. The right hand side is the same for both, because the labor endowment share process is first order Markov in $(x, y, z)$ (see assumption 1), and the pricing functional only depends on $z^{t}$. So, the left hand side has to be the same for both regions as well. Since the non-housing expenditure share only depends on the aggregate history $z^{t}$, this immediately implies that the household's consumption share $\hat{c}_{t}^{i j}$ can only depend on $\left(x_{t}, y_{t}, z^{t}\right)$ when the collateral constraint binds.

Stationary Equilibrium $S=(X \times Y)$ and $\mathcal{S}$ is the associated $\sigma$-algebra. $\mathcal{B}(C)$ is the Borel set of $C$.

Theorem 7. Let $(S, \mathcal{S})$ and $(C, \mathcal{B}(C))$ be measurable spaces. The policy function $\varpi^{j}(\hat{c}, x, y)$ : $C \times Y \times X \longrightarrow C$ implies a Markov transition function:

$$
\begin{aligned}
P[((\hat{c}, x, y), A \times B] & =\pi(B \mid x, y) \text { if } \varpi^{j}(\hat{c}, x, y) \in A \\
& =0 \text { if } \varpi^{j}(\hat{c}, x, y) \notin A
\end{aligned}
$$

for all $(\hat{c}) \in C,(x, y) \in S, A \in \mathcal{B}(\mathcal{C}), B \in \mathcal{S}$. 
defines a transition function on $(\mathcal{S}, \mathcal{B}(\mathcal{C}))$.

(see Stokey, Lucas and Precott (1989) p. 284, Theorem 9.13). Now, the invariant measure $\Phi^{j}, j=1,2$ satisfies:

$$
\begin{array}{r}
\int_{C \times X \times Y} P\left[((\hat{c}, x, y), A \times B] d \Phi^{j}(\hat{c}, x, y)=\Phi^{j}(A \times B) .\right. \\
A \in \mathcal{B}(\mathcal{C}), B \in \mathcal{S} .
\end{array}
$$

The transition function $P$ satisfies the mixing condition, necessary for the existence of a unique, stationary measure, (Condition M in Stokey et al. (1989), p. 348) if the transition probability matrix $\pi\left(x^{\prime}, y^{\prime} \mid x, y\right)$ has only non-zero elements and if perfect risk sharing cannot be sustained, $g>1$, because in that case there is zero mass of consumption shares above the highest cutoff level $\max _{x, y} \underline{\varpi}^{j}(x, y)$, and it is easy to verify that this cutoff level can be attained from anywhere in the state space in a finite number of steps. If the mixing condition is satisfied, this establishes the existence of a unique, stationary equilibrium. Lustig (2003) provides a detailed proof in a similar environment.

Proposition 8. Fix $a g \geq 1$ and $g \leq \frac{\eta_{\max }}{\eta_{\min }}$. Consider two non-housing expenditure shares $\alpha^{\prime \prime}>\alpha^{\prime}$. Then $\underline{\varpi}^{1, \prime \prime}(x, y)<\underline{\varpi}^{1, \prime}(x, y)$ for all $(x, y)$.

Proof. We know that the net wealth function solves the following functional equation:

$$
C^{1}(\hat{c}, x, y)=\frac{\hat{c}}{\alpha}-\eta^{1}(x, y)+\beta g^{\gamma}(\lambda)^{-\gamma} \sum_{x^{\prime}, y^{\prime}} \pi\left(x^{\prime}, y^{\prime} \mid x, y\right) C^{1}\left(\hat{c}^{\prime}, x^{\prime}, y^{\prime}\right)
$$

and the cutoff consumption share satisfies $\left.C^{1}\left(\underline{\varpi}^{1}(x, y), x, y\right)\right)=0$. Since $\alpha^{\prime \prime}>\alpha^{\prime}$, it has to be the case that $C^{1, \prime \prime}(\hat{c}, x, y)<C^{1, \prime}(\hat{c}, x, y)$ for any $\hat{c}, x, y$, which implies that the cutoff consumption share satisfies $\left.\left.\underline{\varpi}^{1, \prime \prime}(x, y), x, y\right)>\underline{\varpi}^{1, \prime}(x, y), x, y\right)$.

\section{B Calibration of Regional Labor Income Shocks}

We use the regional data set described in appendix $(\mathrm{C})$ to calibrate the persistence of the regional income share process, used in section 5.5. We estimate an AR(1) process for the log regional income share. We estimate an AR(1) process for 1952-2002 and use the log disposable income share:

$$
\begin{aligned}
\log \hat{\eta}_{t+1}^{i}= & .9434 \log \hat{\eta}_{t}^{i}+\nu_{t+1}^{i} \\
& (0.0092) \quad(0.0286)
\end{aligned}
$$

If we introduce fixed effects, to correct for permanent income differences, the slope coefficient drops to .85. Based on these estimates, we set the $\operatorname{AR}(1)$ coefficient equal to 0.94 and the standard deviation of the innovation equal to 0.01. We use the Tauchen and Hussey (1991) method to discretize the AR(1) process into a 5-state Markov chain. The grid points are

$$
[-0.0879,-0.0440,0,0.0440,0.0879]
$$


and the transition matrix is:

$$
\left[\begin{array}{ccccc}
0.9526 & 0.0474 & 0.0000 & 0 & 0 \\
0.0069 & 0.9666 & 0.0265 & 0.0000 & 0 \\
0.0000 & 0.0140 & 0.9721 & 0.0140 & 0.0000 \\
0.0000 & 0.0000 & 0.0265 & 0.9666 & 0.0069 \\
0.0000 & 0.0000 & 0.0000 & 0.0474 & 0.9526
\end{array}\right]
$$

Likewise, we calibrate the income share process within a region, $\hat{\hat{\eta}}$, as a two state Markov chain. The states are $[.6,1.4]$ and the transition matrix is $[.9, .1 ; .1, .9]$.

\section{Data Appendix}

This appendix describes the metropolitan data set in detail. First we define aggregate collateral measures (section C.1). Then, we define metropolitan areas and describe the sample (section C.2). Lastly, in section C.3, we describe consumption and income data and compare them to national aggregates.

\section{C.1 Aggregate Collateral Measures}

Residential Wealth 1890-1970: Historical Statistics of the United States, Colonial Times to 1970, series N197, "Non-farm Residential Wealth". Original source: Grebler, Blanck and Winnick, The Capital Formation in Residential Real Estate: Trends and Prospects, Princeton University press, 1956 (Tables 15 and A1). Excluded are clubs, motels, dormitories, hotels and the like. The series measures the current value of structures and land. Structures are reported in current dollars by transforming the value in constant dollars by the construction cost index (series N121 and 139). Structures in constant dollars are obtained from an initial value of residential wealth in 1890 (based on 1890 Census report 'Real Estate Mortgages') and estimates of net capital formation in constant dollars. Land values are based on an estimation of the share of land value to total value using federal Housing Administration data. These estimates are in Winnick, Wealth Estimates for Residential Real Estate, 1890-1950, doctoral dissertation, Columbia University, 1953.

1945-2001: Flow of Funds, Federal Reserve Board, Balance sheet of households and non-profit organizations (B.100, row 4). Line 4: Market value of (owner-occupied) household real estate (code FL155035015). The market value of real estate wealth includes land and structures, inclusive vacant land, vacant homes for sale, second homes and mobile homes.

Fixed Assets 1925-2001: Bureau of Economic Analysis, Fixed Asset Tables, Current cost of net stock of owner-occupied and tenant-occupied residential fixed assets for non-farm persons. This includes 1-4 units and 5+ units and is the sum of new units, additions and alterations, major replacements and mobile homes.

\section{C.2 Metropolitan Areas}

Definition The concept of a metropolitan areas is that of a core area containing a large population nucleus, together with adjacent communities having a high degree of economic and social integration with that core. They include metropolitan statistical areas (MSA's), consolidated 
metropolitan statistical areas (CMSA's), and primary metropolitan statistical areas (PMSA's). An area that qualifies as an MSA and has a population of one million or more may be recognized as a CMSA if separate component areas that demonstrate strong internal, social, and economic ties can be identified within the entire area and local opinion supports the component areas. Component areas, if recognized, are designated PMSA's. If no PMSA's are designated within the area, then the area remains an MSA.

The S\&MM survey uses the definitions of MSA throughout the survey and of CMSA when CMSA's are created. We use the 30 metropolitan areas described in table 8 . Before the creation of the CMSA's, we keep track of all separate MSA's that later form the CMSA in order to obtain a consistent time series. For example, the Dallas-Forth Worth CMSA consists of the populationweighted sum of the separate Dallas MSA and Forth Worth MSA until 1973 and of the combined area thereafter.

Households The total number of households in the 30 metropolitan areas is 47 percent of the US total in 2000 compared to 40 percent in 1951. The total number of households are from the Bureau of the Census. Most of the increase occurs before 1965. Likewise, the 30 metropolitan areas we consider contain exactly 47 percent of the population in 1999 (see tables 8 and 9, first column).

[Table 8 about here.]

\section{C.3 Metropolitan Consumption and Income Data}

Price Indices Data are for urban consumers from the Bureau of Labor Statistics. The Consumer Price all items Index $p_{t}^{i, a}$, its rent component $p_{t}^{i, h}$ and the food component $p_{t}^{i, c}$ are available at the metropolitan level (Bureau of Labor Statistics). The price of rent is a proxy for the price of shelter and the price of food is a proxy for the price of non-durables. We use the rent and food components because the shelter and non-durables components are only available from 1967 onwards. Two-thirds of consumer expenditures on shelter consists of owner-occupied housing. The Bureau of Labor Statistics uses a rental equivalence approach to impute the price of owner-occupied housing. Because $\rho_{t}^{i}$ is a relative rental price, our theory is conceptually consistent with the Bureau of Labor Statistics approach. All indices are normalized to 100 for the period 1982-84.

Consumption and Income Inter-regional risk-sharing studies use retail sales data as a proxy for non-durable consumption (DelNegro (1998) and references therein). Such data for metropolitan areas have not been used before. We collect retail sales data from the annual Survey of Buying Power published by Sales \& Marketing Management (S\&MM). Nominal non-durable consumption for region $i, C_{t}^{i}$, is total retail sales minus hardware and furniture sales and vehicle sales. From the same source we obtain the number of households in each region, $N_{t}^{i}$. Real per household consumption $c^{i}$ is nominal non-durable consumption deflated by $p_{t}^{i, c}$ and divided by the number of households $N_{t}^{i}$.

Disposable personal income $Y_{t}^{i}$ is also from S\&MM. Disposable personal income consists of labor income, financial market income and net transfers. The latter two contain a potentially important insurance component. Therefore we also use labor income plus net transfers from the Regional Economic Information System (REIS). The latter are only available for 1970-2000. Real per household disposable income $\eta^{i}$ is nominal disposable income deflated by $p_{t}^{i, a}$ and divided by the number of households $N_{t}^{i}$. 
Appendix C compares non-durable retail sales and disposable income data with aggregate consumption and income data, with metropolitan non-durable consumption data from the Consumption Expenditure Survey (1986-2000 from Bureau of Labor Statistics), and with metropolitan labor income data plus transfers (1969-2000 from REIS). The correlation between the growth rates of aggregate real non-durable consumption per household and the metropolitan average of real nondurable retail sales per household is 0.77 . Also, our metropolitan data are highly correlated with the metropolitan data from the Bureau of Labor Statistics and the REIS.

There are no complete consumer price index data for Baltimore, Buffalo, Phoenix, Tampa and Washington. There are no complete consumption and income data for Anchorage. Elimination of these regions leaves us with annual data for 23 metropolitan regions from 1951 until 2002. This is the regional data set we use in the empirical work.

Comparison We compares non-durable retail sales and disposable income with aggregate consumption and income data (Table 9), with metropolitan non-durable consumption data from the Consumption Expenditure Survey (Bureau of Labor Statistics, 1986-2000, Table 10) and with metropolitan labor income data plus transfers from the REIS for 1969-2000 (Table 11). The correlation between the growth rates of aggregate real non-durable consumption per household and the metropolitan average of real non-durable retail sales per household is 0.77. Also, our metropolitan data are highly correlated with the metropolitan data from the Bureau of Labor Statistics and the REIS.

Source and Definitions We collect data from the Survey of Buying Power (and Media Markets), a special September issue of the magazine Sales and Marketing Management. The data are proprietary and we thank S\&MM for permission to use them. We use five series and reproduce the S\&MM definitions below.

Total retail sales measures sales from five major store groups considered to be the primary channels of distribution for consumer goods in local markets. Store group sales represent the cumulative sales of all products and or services handled by a particular store type, not just the product lines associated with the name of the store group. The five store groups are: food stores, automotive dealers, eating and drinking places, furniture, home furnishings and appliance stores, and general merchandize stores. Total retail sales reflect net sales. Receipts from repairs and other services by retailers are also included, but retail sales by wholesalers and service establishments are not.

Automotive dealer sales are sales by retail establishments primarily engaged in selling new and used vehicles for personal use and in parts and accessories for these vehicles. This includes boat and aircraft dealers and excludes gasoline service stations.

Furniture, home furnishings and appliance store sales measures sales by retail stores selling goods used for the home, other than antiques. It includes dealers in electronics (radios, TV's, computers and software), musical instruments and sheet music, and recordings.

Households measures the number of households, defined by the Census which includes all persons occupying a housing unit. A single person living alone in a housing unit is also considered to be a household. The members of a household need not be related.

Effective Buying Income is an income measure of income developed by S\&MM. It is equivalent to disposable personal income, as produced by the Bureau of Economic Analysis in the NIPA tables. It is defined as the sum of labor market income, financial income and net transfers minus 
taxes. Labor income is wages and salaries, other labor income (such as employer contributions to private pension funds), and proprietor's income (net farm and non-farm self-employment income). Financial income is interests (from all sources), dividends (paid by corporations), rental income (including imputed rental income of owner-occupants of non-farm dwellings) and royalty income. Net transfers is Social Security and railroad retirement, other retirement and disability income, public assistance income, unemployment compensation, Veterans Administration payments, alimony payments, alimony and child support, military family allotments, net winnings from gambling, and other periodic income minus social security contributions. Taxes is personal tax (federal, state and local), non-tax payments (fines, fees, penalties, ...) and taxes on owner-occupied nonbusiness real estate. Not included is money received from the sale of property, the value of income in kind (food stamps, public housing subsidy, medical care, employer contributions for persons), withdrawal of bank deposits, money borrowed, tax refunds, exchange of money between family members living in the same household, gifts and inheritances, insurance payments and other types of lump-sum receipts. Income is benchmarked to the decennial Census data.

We create a durable retail sales series by adding automotive dealer sales and furniture, home furnishings and appliance store sales. Non-durable retail sales is total retail sales minus durable retail sales.

Comparison with Aggregate Data We construct aggregate non-durable retail sales per households and compare it to aggregate non-durable consumption per household. The aggregate consumption data are from the National Income and Product Accounts (NIPA). The two nominal time series are very similar. Non-durable metropolitan retail sales per household are on average 17 percent higher than national non-durable consumption per household. Their correlation between their growth rates is 0.75 . The one exception is 1999 when retail sales grow at a rate of 19.6 percent compared to 5.6 percent for non-durable consumption. We believe this is an anomaly in the data and deflate the 1999 retail sales so that the metropolitan average growth rate equals the national one. This correction is identical across areas. The volatility of NIPA consumption growth is 2.57 percent whereas the volatility of aggregated S\&MM non-durable retail sales is 2.89 percent. For comparison, the volatility of non-durable retail sales growth at the regional level varies between 3.8 percent (Washington-Baltimore CMSA) and 8.3 percent (Dallas-Forth Worth CMSA).

We compare the sum of motor vehicles and parts and furniture and household equipment for the US. to the metropolitan data on automotive dealer sales and furniture, home furnishings and appliance store sales. Nationwide, these two categories of consumption make up 84 percent of all durable purchases. Sales are higher by an average of 30 percent. The pattern of the two series mimic each other closely. The correlation between national durable consumption growth and the average metropolitan durable retail sale growth is 0.80. For 1999 the sales data show a much bigger increase than the durable consumption data (27 percent versus 8.6 percent). As for non-durables, we correct the 1999 metropolitan retail sales for this discrepancy. We refer to the two series as metropolitan non-durable and durable consumption per household.

Effective buying income (EBI) per household corresponds to the Bureau of Economic Analysis's disposable income (personal income minus personal tax and non-tax payments). The S\&MM income data are tracking disposable income closely. There are a two discrete jumps in the EBI time-series (1988 and 1995), but the concept remains disposable, personal income. The S\&MM is not precise as to which income categories were excluded between 1987 and 1988 and between 1994 and 1995 . From comparing the definition of EBI before and after the changes, it seems to us that the most 
important changes are the exclusion of other labor income (such as employer contributions to pension plans, ...) and income in kind (such as food stamps, housing subsidies, medial care,...). To obtain a consistent time-series, we correct the S\&MM income data by the ratio of average EBI to disposable income from the NIPA. This correction is identical across areas. We refer to this series as metropolitan disposable income per household. Table 9 summarizes.

\section{[Table 9 about here.]}

Comparison with CEX Data We compare the SM\&M data to the non-durable and durable consumption data from the Consumer Expenditure Survey (CEX). Based on household data, the Bureau of Labor Statistics (Bureau of Labor Statistics) provides metropolitan averages for 13 overlapping two-year periods (1986-87 until 1994-95 and 1996-97 until 1999-2000). The two data sources have 25 regions with full data in common. Buffalo is in the CEX sample until 1994-95 and is replaced by Tampa, Denver and Phoenix from 1996-97 onwards.

Consumption expenditures on non-durables are defined as in Attanasio and Weber (1995): It includes food at home, food away from home, alcohol, tobacco, utilities, fuels and public services (natural gas, heating fuel electricity, water, telephone and other personal services), transportation (gasoline and motor oil, public transportation), apparel and services (clothes, shoes, other apparel products and services), entertainment, personal care products and services, reading, and miscellaneous items. Durable consumption includes vehicle purchases and household furnishings and equipment. Consumption expenditures on housing services measure the cost of shelter. $p_{t}^{i h} h_{t}^{i}$ is comprised of owned dwellings, rented dwellings and other lodging. The CEX imputes the cost for owner-occupied dwellings by adding up mortgage interest rates, property taxes and maintenance, improvements, repairs, property insurance and other expenditures. The average expenditure share on housing was 31.5 percent in 2000 .

Non-durable and housing services consumption add up to 55-60 percent of total annual consumption expenditures. Excluded consumption items are consumer durables (furniture, household supplies), vehicle purchases, insurance (vehicle, life, social security), health care and education.

For each area, we construct bi-annual averages from the S\&MM consumption data. The correlation between all data cells is 0.77 for non-durables and 0.66 for durables. The average correlation across regions is 0.88 for non-durables and 0.73 for durables. We conclude that the metropolitan sales data give an accurate measure of consumption on non-durables and durables at the metropolitan level.

We also compare the bi-annual averages of before-tax income from the CEX with the metropolitan disposable income. The correlation is high for each region. The average correlation across regions is 0.94 and is 0.91 for all data cells jointly. Table 10 summarizes the correlations by region for the 25 areas with all 13 periods.

[Table 10 about here.]

Comparison with REIS Data Disposable income contains two important channels of insurance. It includes income from financial markets and the net income from government transfers and taxes. For consumption to fully capture income smoothing, the income concept should exclude smoothing that takes place through financial markets, credit markets and through the federal tax 
and transfer system. The Regional Economic Information System (REIS) of the Bureau of Economic Analysis allows us to construct separate series for labor market income, financial market income and net transfers for each metropolitan area.

For the overlapping period 1969-2000, we compute the correlation between the idiosyncratic component of log disposable income, $\log \left(\hat{y}_{t}^{i, d}\right)$, from the S\&MM and labor income plus transfers $\log \left(\hat{y}_{t}^{i, l t}\right)$ from the REIS. Table 11 shows that the correlation is generally high, but with a few exceptions (Miami, Cincinnati, Milwaukee). The average correlation is 0.64. This imperfect correlation is due to a combination of measurement error in income and insurance through financial markets. The discrepancy warrants use of both income measures in the empirical analysis.

[Table 11 about here.]

\section{C.4 Regional Housing Collateral}

Following Case, Quigley and Shiller (2001), we construct the market value of the housing stock in region $i$ as the product of four components:

$$
H V_{t}^{i}=N_{t}^{i} H O_{t}^{i} H P_{t}^{i} V_{0}^{i}
$$

$V_{0}^{i}$ is the median house price for detached single family housing from the US Bureau of the Census for 2000. For the CMSA's, it is constructed as a population weighted average of the median home value for the constituent MSA's. Population data are from the REIS.

Home Ownership Home ownership rates $H O_{t}^{i}$ are from the US Bureau of the Census. We combine home ownership rates for 1980, 1990 and 2000 from the Decennial Census with annual home ownership data for the largest 75 cities for 1986-2001, also from the Bureau of the Census. We project a home ownership rate for 1986 using the 1980 and 1990 number and the annual changes in the national home ownership rate. We use the changes in the major cities to infer MSA-level changes between 1986 and 1990. Between 1981 and 1986 and 1975 and 1979 we apply national changes to the MSA's. This procedure captures most of the regional and time series behavior of home-ownership rates. Table 12 illustrates the large regional differences in the median home value and home ownership rate in 1980 and 2000.

House Price Index $H P_{t}^{i}$ is the housing price index from the Office of Federal Housing Enterprize Oversight, based on the weighted repeat sales method of Case and Shiller (1987). It measures house price increases in detached single family homes between successive sales or mortgage refinancing of the identical housing unit. The index is available for 1975-2000 for all MSA's in our sample. We construct an index for the CMSA's as a population weighted average of the MSA's. The OFHEO database contains 17 million transactions over the last 27 years. There is a literature on quality-controlled house price indices. They broadly fall into two categories. Hedonic methods capture the contribution of narrowly defined dwelling unit and location characteristics to the price of a house in a certain region (number of bedrooms, garage, neighborhood safety, school district, etc.). Out of sample, houses are priced as a bundle of such characteristics. Repeat sales indices are based on houses that have been sold or appraised twice. Because they pertain to the same property, they control for a number of hedonic characteristics (bedrooms, neighborhood safety, etc.). See Pollakowski (1995) for a literature review and a description of data availability. 
Regional Housing Collateral Ratio The regional collateral ratio $m y^{i}$ is measured in the same way as the aggregate collateral ratio $m y$. We regress the difference between the log real per capita housing value $\log h v^{i}=\log \left(\frac{H V^{i}}{p^{a, i}}\right)$ and the $\log$ real per capita labor income on a constant and a time trend. The housing collateral ratio is the residual from that regression. The resulting measure is available for $1975-2000$.

[Table 12 about here.]

\section{C.5 Canadian Data}

All data for Canada are from Statistics Canada (CANSIM), obtained from the Provincial Economic Accounts. They span the period 1981-2003, and the cross-section contains 10 provinces: Alberta, British Columbia, Manitoba, New Brunswick, Newfoundland and Labrador, Nova Scotia, Ontario, Quebec, Saskatchewan, and Prince Edward Island. We also use aggregate data for Canada. Consumption at the aggregate and regional level is measured as personal expenditures on non-durables and services less personal expenditures on durable goods. income is defined as personal disposable income. For each region, there is also a consumer price index and a population series available. The corresponding tables are 384-002 and 384-002.

The housing wealth data measure the stock of fixed residential capital for single and multiple dwellings. The series measures the end-of-year net stock at current prices, and are available from 1941 onwards. This value represents the cost of replacing the depreciated residential stock and is constructed using the perpetual inventory method. These series are available for Canada, as well as the ten provinces. The table is $030-0002$.

As for the U.S. data, we calculate regional consumption shares are the ratio of real per capita regional consumption to real per capita aggregate consumption. We do the same for the income measure. We compute growth rates of the shares as log changes. The regional and aggregate housing collateral ratios my are computed as the residual from a regression of the log housing wealth-to-income ratio on a constant and a trend. The collateral scarcity measure is computed as $\widetilde{m y}=\frac{m y^{m a x}-m y_{t}}{m y^{m a x}-m y^{m i n}}$, where $m y^{\max }$ and $m y^{m i n}$ are the sample maximum and minimum. In our sample, the maximum value for $m y$ is reached in 2003 (0.0495), and the minimum in $1985(-.1102)$. 
Figure 1: Housing Collateral Scarcity and Moments of Wedges in Data.

The upper panel plots the cross-sectional standard deviation and mean of the raw wedges; the lower panel plots the cross-sectional standard deviation and the mean of the wedges divided by the same moments of the autarchic wedges. On the left axis is the collateral scarcity measure $\widetilde{m y}$ (solid blue line). On the right axis is the standard deviation (or mean) (across regions) of the wedges (dashed red line). $\gamma$ is 2. The sample is $1952-2002$ (annual data). The collateral measure is myrw (residential wealth).
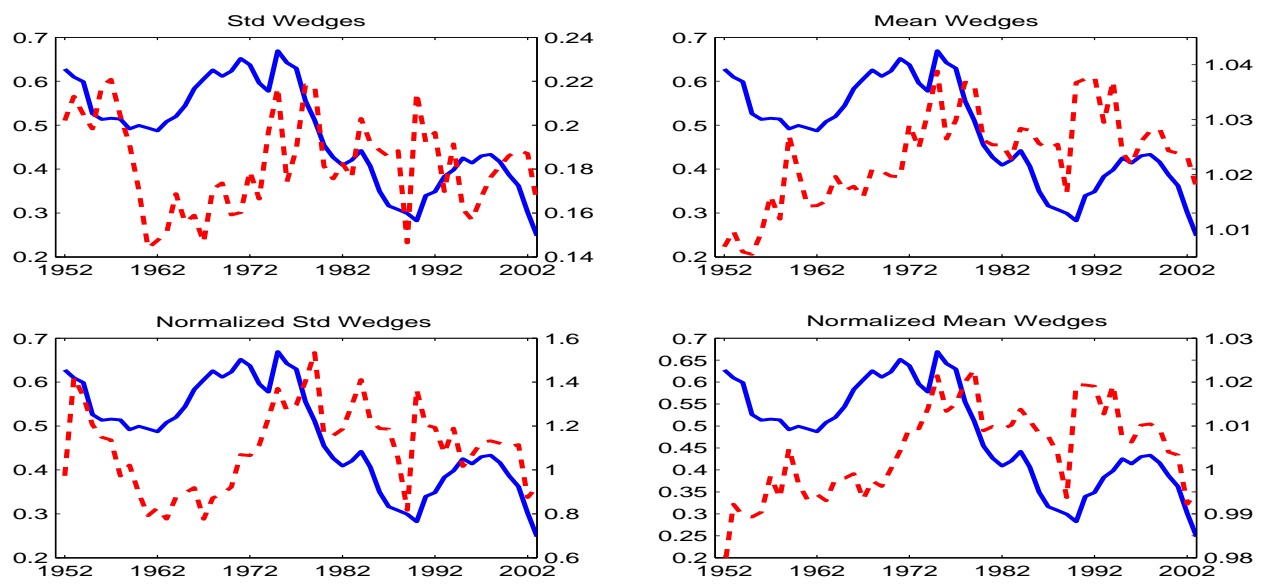

Figure 2: Housing Collateral Scarcity and Consumption/Income Dispersion in Data. The left panel plots the regional (non-durable) consumption share dispersion. The right panel plots the ratio of regional (non-durable) consumption share dispersion to regional income share dispersion. On the left axis is the collateral scarcity measure $\widetilde{m y}$ (solid blue line). On the right axis is the observed cross-sectional consumption share dispersion (dashed red line) and the ratio of observed cross-sectional consumption share dispersion to income share dispersion (dashed red line). The sample is 1952-2002 (annual data) for 23 MSA's. The collateral measure is myrw (residential wealth).
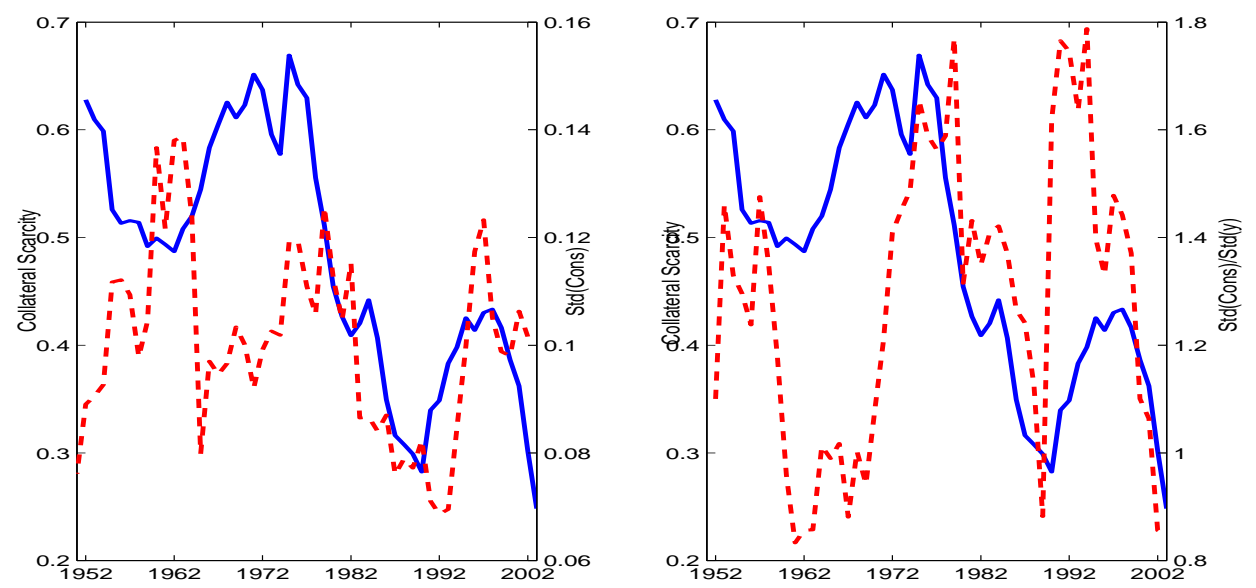
Figure 3: Aggregation to Regional Consumption and Income Shares.

The full lines are the consumption shares and the dashed lines are the income shares. The horizontal axis denotes time in years. The upper panel plots a simulated time path for two households in the same region. The income share for household $j$ in region $i$ that is plotted is $\hat{\hat{\eta}}_{t}^{i j} \hat{\eta}_{t}^{i}$. The second panel plots the regional consumption shares (full line) against the regional income share (dashed line). The shocks $x^{t}, y^{t}$ are the same for both plots. The bottom panel plots the consumption shares for the same regional shocks $y^{t}$, but averaged across $x^{t}$, by simulating 1000 regions. The preference parameters are $\gamma=2$ and $\varepsilon=0.5$
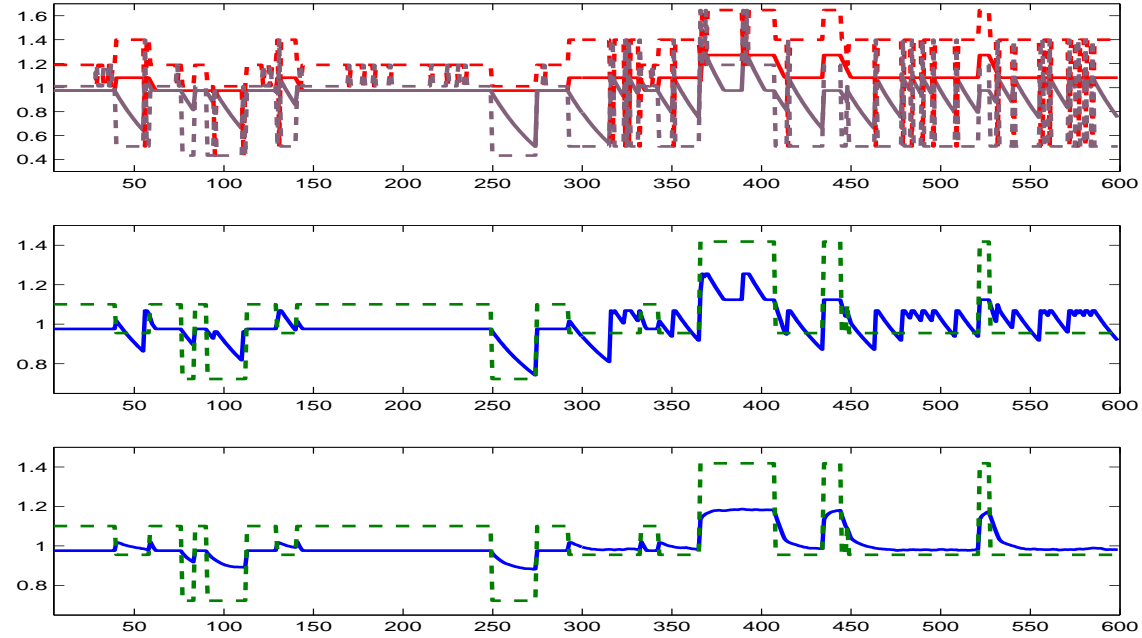

Figure 4: Income Elasticity of Consumption Share Growth and the Housing Collateral Ratio.

The filled dots denote different stationary equilibria for the benchmark case with $\beta=.95$, each for a different collateral ratio $m y$ (denoted on the horizontal axis). For each collateral value my on the grid, consumption and income shares are generated by simulating the model for 600 periods and 1000 regions. The upper panel plots the regional consumption-to-income dispersion ratio. The middle panel shows the income elasticity of regional consumption growth ('slope'). The bottom panel shows the ratio of housing wealth to labor income. The parameters are $\gamma=2, \epsilon=.5, \beta=.95$

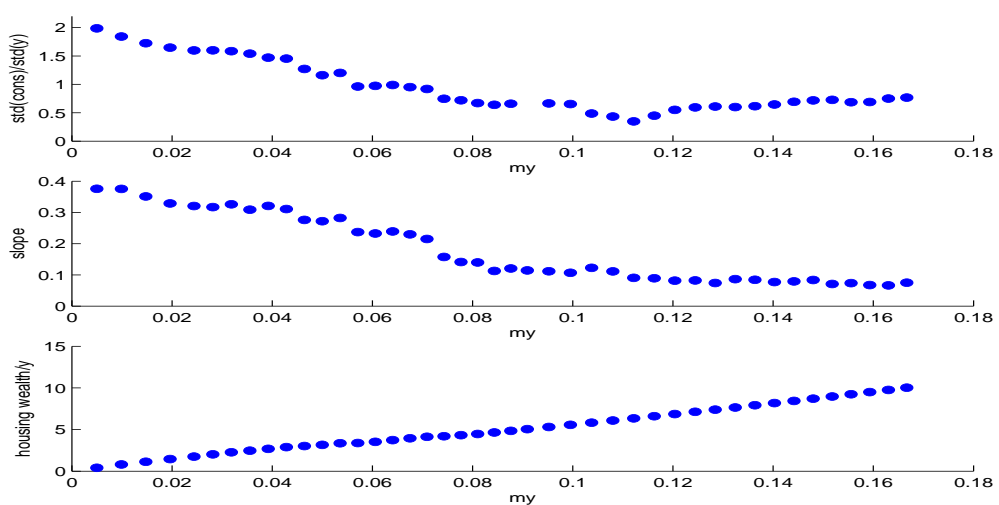


Figure 5: Cutoff Weights and Aggregate weight shock.

The filled dots denote different stationary equilibria for the benchmark case with $\beta=.95$, each with a different collateral ratio $m y$; the empty dots denote the case of $\beta=.9$, and the + denote the case of $\beta=.85$. The horizontal axis denotes the collateral ratio my. The upper panel plots the cutoff consumption weight $\varpi()$ in the highest state. The lowest panel plots $g$. The parameters are $\gamma=2, \epsilon=.5, \beta=.95$. The full line plots the standard deviation of household income growth. For each collateral value $m y$ on the grid, consumption and income shares are generated by simulating the model for 600 periods and 1000 regions.
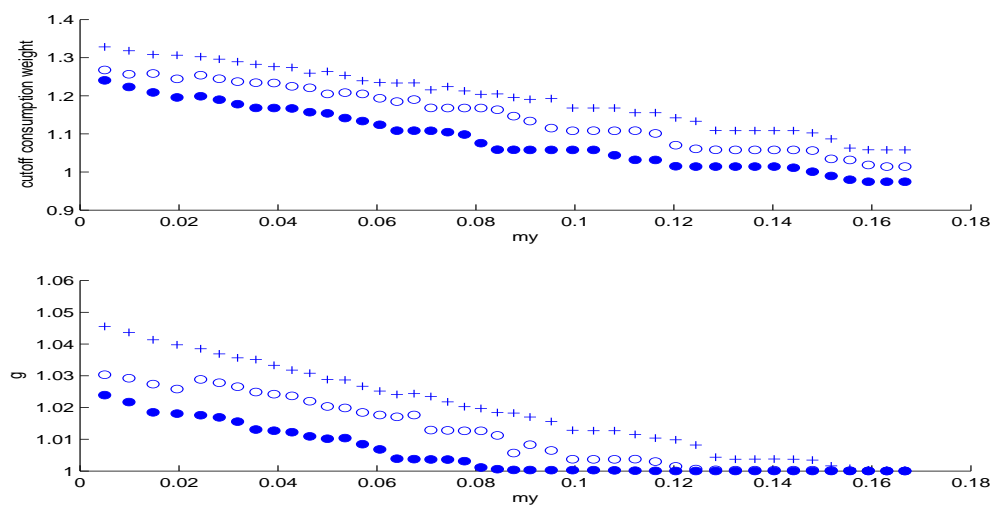

Figure 6: The Quantity Anomaly at the Regional Level.

The filled dots denote different stationary equilibria for the benchmark case with $\beta=.95$, each with a different collateral ratio $m y$; the empty dots denote the case of $\beta=.9$, and the + denote the case of $\beta=.85$. The horizontal axis denotes the collateral ratio my. The upper panel plots the standard deviation of regional consumption growth. The full line plots the standard deviation of regional income growth. The lowest panel plots the standard deviation of household consumption growth. The parameters are $\gamma=2, \epsilon=.5, \beta=.95$. The full line plots the standard deviation of household income growth. For each collateral value $m y$ on the grid, consumption and income shares are generated by simulating the model for 600 periods and 1000 regions.
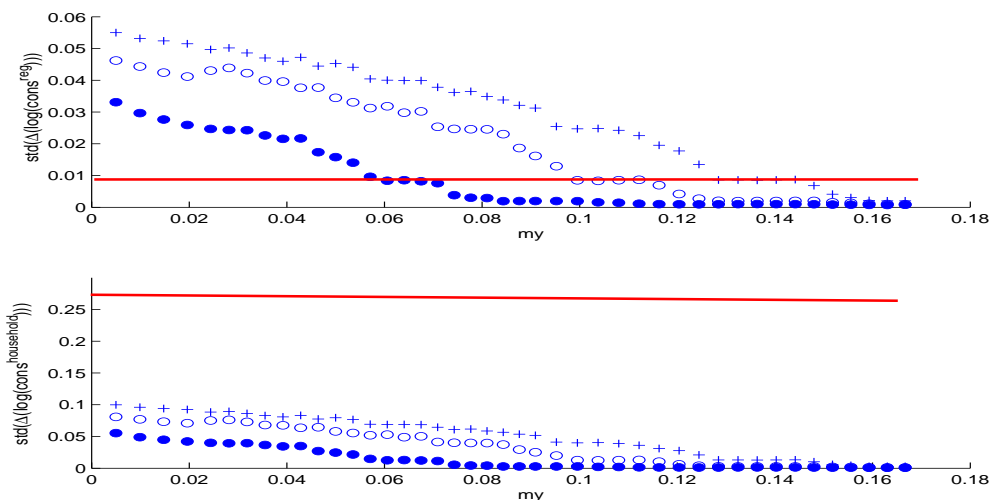
Figure 7: Housing Collateral Scarcity and Moments of Wedges in Model.

The left panel plots a simulated time path for $T=500$ of the collateral scarcity measure (solid line) against the standard deviation of regional consumption wedges (dashed line). The right panel plots a simulated time path for $T=500$ of the collateral scarcity measure (solid line) against the mean of consumption wedges (dashed line). The right axis shows the scale of the collateral scarcity measure $\widetilde{m y}$. The left axis shows the scale of the consumption wedge moments. The preference parameters are: $\beta=.95, \gamma=2$ and $\varepsilon=0.5$. The mean of $m y$ is 10 percent, the mean of $\widetilde{m y}$ is .71 in this simulation.
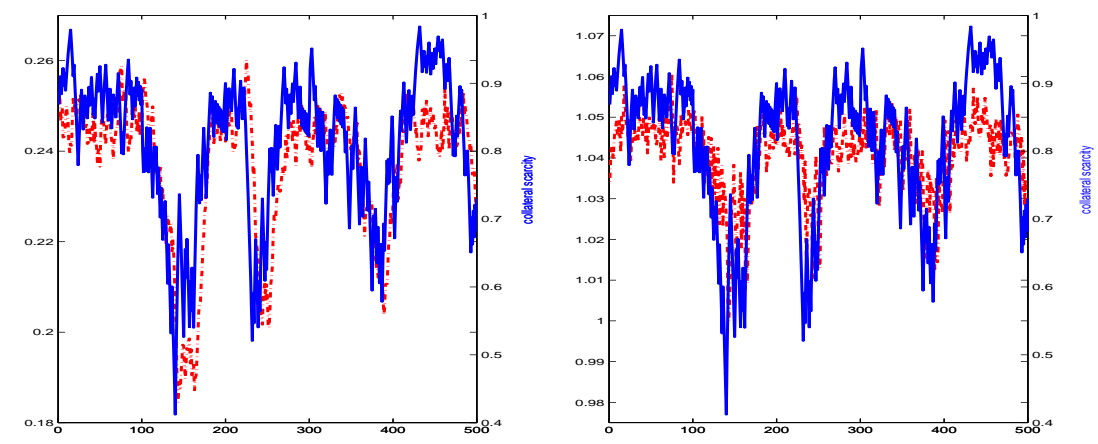

Figure 8: Housing Collateral Scarcity and Consumption/Income Dispersion in Model. The left panel plots a simulated time path for $T=500$ of the collateral scarcity measure (solid line) against the regional consumption dispersion (dashed line). The right panel plots a simulated time path for $T=500$ of the collateral scarcity measure (solid line) against the ratio of regional consumption dispersion to regional income dispersion (dashed line). The right axis shows the scale of the collateral scarcity measure $\widetilde{m y}$. The left axis shows the scale of the consumption dispersion measure. The preference parameters are: $\beta=.95, \gamma=2$ and $\varepsilon=0.5$. The mean of $m y$ is 10 percent, the mean of $\widetilde{m y}$ is .71 in this simulation.
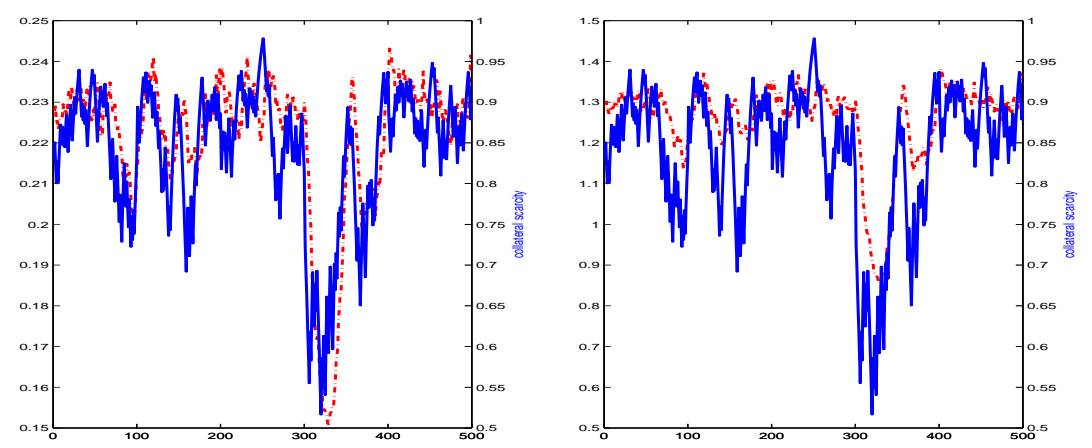
Figure 9: Consumption Dispersion and the Collateral Ratio in Model.

Scatter plot of the collateral scarcity measure $\widetilde{m y}$ (horizontal axis) against the regional consumption share dispersion (vertical axis) for $T=15000$. The mean consumption share is one. The preference parameters are: $\beta=.95, \gamma=2$ and $\varepsilon=0.5$. The mean of $m y$ is 10 percent and the mean $\widetilde{m y}$ is .71 .

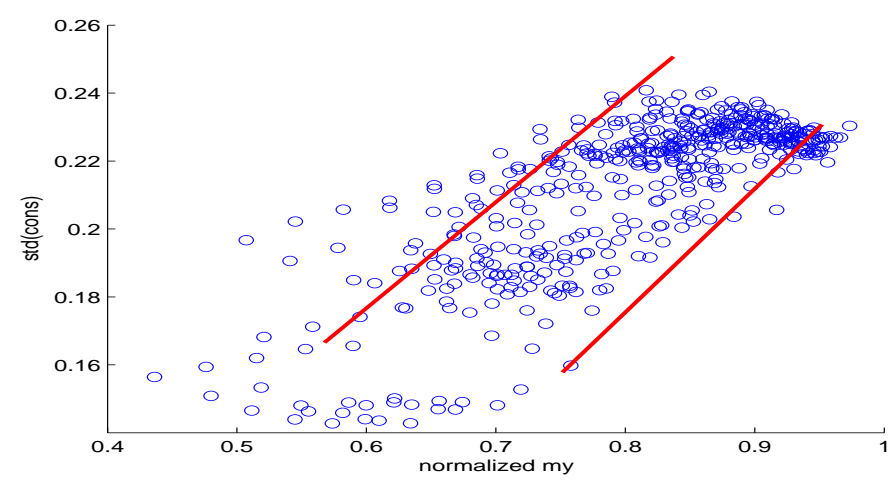

Figure 10: Consumption Dispersion and the Collateral Ratio in Data.

Scatter plot of the collateral scarcity measure $\widetilde{m y}$ (horizontal axis) against the regional consumption share dispersion (vertical axis). The mean consumption share is $1 / 23$. The sample is 1953-2002 (annual data) for 23 MSA's. The collateral measure is myrw (residential wealth). The mean $\widetilde{m y}$ is .48 in the data.
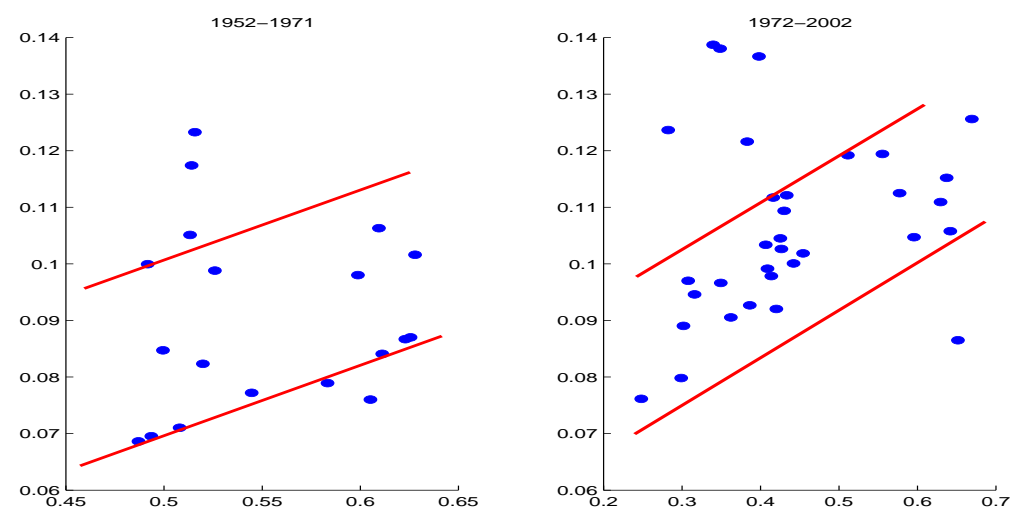
Figure 11: Collateralizable Wealth.

Plot of the ratio of the value of outstanding household mortgages divided by total labor income (full line) and the ratio of residential wealth to total labor income (dotted line). The sample is 1980-2002 (annual data).

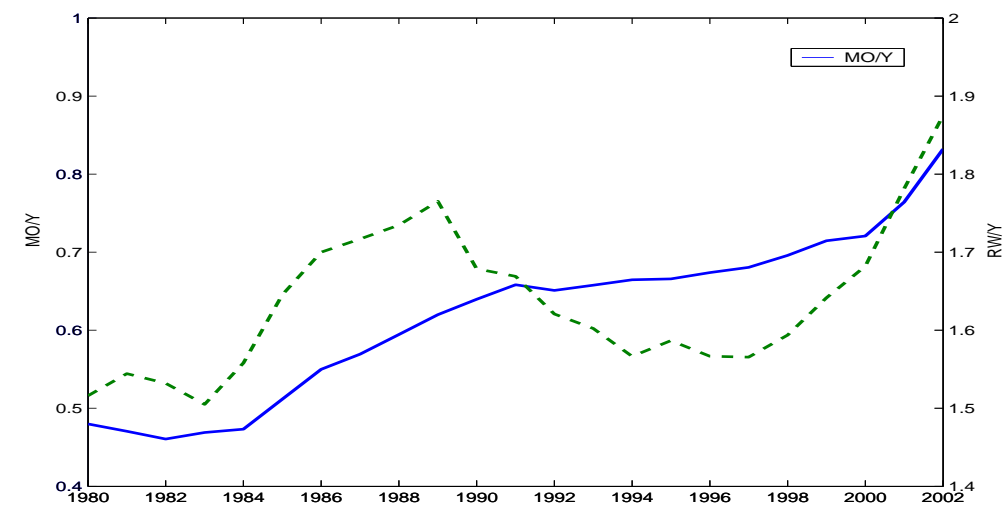


Table 1: Quartiles.

Quartiles ranked from high to low collateral scarcity. The sample is 1975-2000 (annual data). All results are for 23 US metropolitan areas sorted each year into quartiles based on that period/region's collateral scarcity measure $\widetilde{m y}_{t}^{i}$. The first column reports the average collateral scarcity overt the sample for each quartile. The second column reports the standard deviation of average population-weighted non-durable consumption growth in each quartile. The third column reports the correlation with real per capita US non-durable consumption growth (NIPA). The fourth column reports the slope coefficient in a time series regression of average population-weighted consumption share growth on average population-weighted income share growth for each quartile. The fifth and sixth columns reports the t-stat and regression $R^{2}$.

\begin{tabular}{c|c|cc|ccc}
\hline & $\widetilde{m y}^{i}$ & $\operatorname{std}\left(\Delta \log \left(c_{t}^{i}\right)\right)$ & $\operatorname{corr}\left(\Delta \log \left(c_{t}^{i}\right), \Delta \log \left(c_{t}^{a}\right)\right)$ & Slope & {$[t$-stat $]$} & $R^{2}$ \\
\hline 1 & 0.842 & 0.033 & 0.257 & 0.659 & {$[1.896]$} & .13 \\
2 & 0.577 & 0.032 & 0.233 & 0.354 & {$[0.987]$} & .04 \\
3 & 0.407 & 0.018 & 0.278 & 0.472 & {$[1.757]$} & .11 \\
4 & 0.226 & 0.028 & 0.502 & 0.319 & {$[1.283]$} & .06 \\
\hline
\end{tabular}

Table 2: Income Growth Elasticity of Consumption Shares in Data

In panel A we estimate: $\Delta \log \tilde{c}_{t+1}^{i}=a_{0}^{i}+a_{1} \widetilde{m y}_{t+1} \Delta \log \hat{\eta}_{t+1}^{i}+\nu_{t+1}^{i}$. In panel B we estimate: $\Delta \log \tilde{c}_{t+1}^{i}=$ $b_{0}^{i}+b_{1} \Delta \log \hat{\eta}_{t+1}^{i}+b_{2} m y_{t+1} \Delta \log \hat{\eta}_{t+1}^{i}+\nu_{t+1}^{i}$. Rows 1-2 are for the period 1952-2002 (1166 observations). The measure of idiosyncratic income is disposable personal income. Rows 3-4 are identical to rows 1-2 but are for the period 1970-2000 (713 observations) in panel A and 1970-2002 (759 observations) in panel B. Regressions 5-6 use labor income plus transfers, available only for 1970-2000. In each block, the rows use the variables myrw and myfa, estimated for the period 1925-2002. my $y^{\max }\left(\mathrm{my}^{\min }\right)$ is the sample maximum (minimum) in 1925-2002. The coefficients on the fixed effect, $a_{0}^{i}$, are not reported. Estimation is by feasible Generalized Least Squares, allowing for both cross-section heteroscedasticity and contemporaneous correlation. Rows 7-8 are the results for the instrumental variable estimation by 3 SLS. Instruments are a constant, $\log \left(\hat{\eta}_{t+2}^{i}\right), \log \left(\hat{\eta}_{t+3}^{i}\right), \log \left(\hat{\eta}_{t+4}^{i}\right), \Delta \hat{\rho}_{t+2}^{i}, \Delta \hat{\rho}_{t+3}^{i}, \Delta \hat{\rho}_{t+4}^{i}$, $\log \left(\tilde{c}_{t+2}^{i}\right), \log \left(\tilde{c}_{t+3}^{i}\right), \log \left(\tilde{c}_{t+4}^{i}\right)$, and $m y_{t+2}, m y_{t+3}, m y_{t+4}$. The sample is 1952-1998 (1051 observations). All results are for 23 US metropolitan areas.

\begin{tabular}{ll|ccc|ccccc}
\hline & & \multicolumn{3}{|c|}{ Panel A: Specification I } & \multicolumn{5}{c}{ Panel B: Specification II } \\
Coll. Measure & $a_{1}$ & $\sigma_{a_{1}}$ & $R^{2}$ & $b_{1}$ & $\sigma_{b_{1}}$ & $b_{2}$ & $\sigma_{b_{2}}$ & $R^{2}$ \\
\hline 1 & myrw & .70 & $(.05)$ & 6.4 & .35 & $(.03)$ & -.30 & $(.26)$ & 6.5 \\
2 & myfa & .75 & $(.06)$ & 6.9 & .36 & $(.03)$ & -1.74 & $(.50)$ & 6.8 \\
\hline 3 & myrw & .70 & $(.03)$ & 4.7 & .33 & $(.02)$ & -.64 & $(.17)$ & 4.7 \\
4 & myfa & .78 & $(.03)$ & 5.0 & .37 & $(.02)$ & -2.12 & $(.31)$ & 5.0 \\
\hline 5 & myrw & 1.02 & $(.05)$ & 10.5 & .48 & $(.02)$ & -1.03 & $(.23)$ & 10.5 \\
6 & myfa & 1.08 & $(.05)$ & 10.3 & .51 & $(.03)$ & -1.13 & $(.30)$ & 10.4 \\
\hline 7 & myrw & .63 & $(.07)$ & & .31 & $(.04)$ & -.32 & $(.38)$ & \\
8 & myfa & .69 & $(.08)$ & & .32 & $(.04)$ & -1.75 & $(.64)$ & \\
\hline
\end{tabular}


Table 3: Risk-Sharing Tests with Regional Collateral Measures.

Rows 1 and 2 of the table reports estimation results for $\Delta \log \hat{c}_{t+1}^{i}=b_{0}^{i}+b_{1} \Delta \log \hat{\eta}_{t+1}^{i}+b_{2} X_{t+1}^{i} \Delta \log \hat{\eta}_{t+1}^{i}+\nu_{t+1}^{i}$. Rows 3 of the table reports estimation results for $\Delta \log \hat{c}_{t+1}^{i}=b_{0}^{i}+b_{1} \Delta \log \hat{\eta}_{t+1}^{i}+b_{2} X_{t+1}^{i} \Delta \log \hat{\eta}_{t+1}^{i}+b_{3} X_{t+1}^{i}+$ $\nu_{t+1}^{i}$. In row $1, X^{i}$ is the region-specific home-ownership rate (575 observations). In row 2 and row $3, X^{i}=m y^{i}$ is the region-specific housing collateral ratio (569 observations). It is measured as the residual from a regression of the $\log$ ratio of real per capita regional housing wealth to real per capita labor income, $\log \left(h v_{t}^{i}\right)-\log \left(\eta_{t}^{i}\right)$, on a constant and a time trend. A higher $m y^{i}$ means more abundant collateral in region $i$. In all regressions $\eta$ is disposable income. The coefficients on the fixed effect $b_{0}^{i}$ is not reported. Estimation is by feasible Generalized Least Squares allowing for both cross-section heteroscedasticity and contemporaneous correlation. All regressions are for the period 1975-2000 for 23 US metropolitan areas, the longest period with metropolitan housing data.

\begin{tabular}{|c|c|c|c|c|c|c|c|c|}
\hline Coll & Measure & $b_{1}$ & $\sigma_{b_{1}}$ & $b_{2}$ & $\sigma_{b_{2}}$ & $b_{3}$ & $\sigma_{b_{3}}$ & $R^{2}$ \\
\hline 1 & $H O^{i}$ & .45 & $(.02)$ & -.11 & $(.03)$ & & & 6.1 \\
\hline 2 & $m y^{i}$ & .40 & $(.02)$ & -.57 & $(.12)$ & & & 6.2 \\
\hline 3 & $m y^{i}$ & .39 & $(.02)$ & -.45 & $(0.14)$ & -0.03 & $(0.003)$ & 6.6 \\
\hline
\end{tabular}

Table 4: Risk-Sharing Tests with Canadian Data.

In row 1 (panel A) we estimate: $\Delta \log \tilde{c}_{t+1}^{i}=a_{0}^{i}+a_{1} \widetilde{m y}{ }_{t+1} \Delta \log \hat{\eta}_{t+1}^{i}+\nu_{t+1}^{i}$. In row 2 (panel B) we estimate: $\Delta \log \tilde{c}_{t+1}^{i}=b_{0}^{i}+b_{1} \Delta \log \hat{\eta}_{t+1}^{i}+b_{2} m y_{t+1} \Delta \log \hat{\eta}_{t+1}^{i}+\nu_{t+1}^{i}$. Rows 1 and 2 use the aggregate collateral measure for Canada myfa. Row 3 (panel B) reports estimation results for $\Delta$ log $\hat{c}_{t+1}^{i}=$ $b_{0}^{i}+b_{1} \Delta \log \hat{\eta}_{t+1}^{i}+b_{2} X_{t+1}^{i} \Delta \log \hat{\eta}_{t+1}^{i}+\nu_{t+1}^{i}$. Finally, row 4 (panel C) reports estimation results for $\Delta \log \hat{c}_{t+1}^{i}=$ $b_{0}^{i}+b_{1} \Delta \log \hat{\eta}_{t+1}^{i}+b_{2} X_{t+1}^{i} \Delta \log \hat{\eta}_{t+1}^{i}+b_{3} X_{t+1}^{i}+\nu_{t+1}^{i}$. In rows 3 and $4, X^{i}$ is the regional collateral measure $m y^{i}$ in Canadian province $i$. Both the aggregate and regional housing collateral ratios are measured as the residual from a regression of the log ratio of real per capita regional housing wealth to real per capita labor income on a constant and a time trend. The coefficients on the fixed effect, $a_{0}^{i}$ or $b_{0}^{i}$ are not reported. Estimation is by feasible Generalized Least Squares allowing for both cross-section heteroscedasticity and contemporaneous correlation. All regressions are for the period 1981-2003 for 10 Canadian provinces. The panel contains 220 observations.

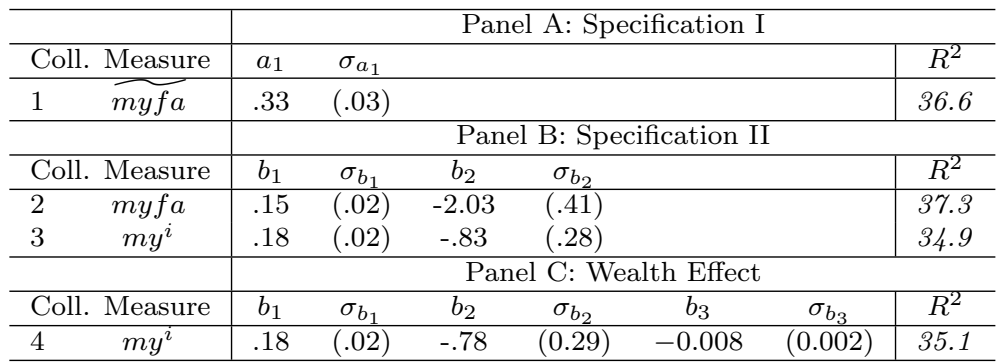

Table 5: Measuring the Average Collateral Ratio

The first line $\frac{\rho h}{\rho h+y}$ reports the average ratio of rental income $\rho h$ (rental income of persons with capital consumption adjustment) to labor income $y$ (compensation of employees) plus rental income. The second line reports $\frac{\rho h+d+r}{\rho h+y+d+r}$ the average ratio of rental income plus net dividends $(d)$ plus interest payments $(r)$ to labor income plus proprietor's income. All series are taken from Table 1.12. National Income by Type of Income (NIPA). The third line $\frac{r w}{y}$ reports the ratio of labor income to residential wealth. The residential wealth series is from the Flow of Funds Tables. The fourth line $\frac{k}{y}$ reports the ratio of the value of US non-farm, non-financial corporations to labor income (non-farm, non-financial). The value of non-farm, non-financial corporations is also computed using Flow of Funds Tables.

\begin{tabular}{cc|cc}
\hline & & 29-02 & 46-02 \\
\hline 1 & $\frac{\rho h}{\rho h+y}$ & 0.046 & 0.038 \\
2 & $\frac{\rho h+d+r}{\rho h+y+d+r}$ & 0.145 & 0.132 \\
\hline 3 & $\frac{r w}{y}$ & & 1.40 \\
4 & $\frac{k}{y}$ & & 3.56 \\
5 & $\frac{k+r w}{y}$ & & 4.96 \\
\hline
\end{tabular}


Table 6: Prediction errors

This table reports approximation errors in the calculation of first-order Markov stationary equilibria. The sample is a model-simulated panel for 5000 years (annual data) and 5000 regions with $\gamma=2, \epsilon=.5$ and the AR(1) process for the non-housing expenditure share in equation (5.6). The mean $\widetilde{m y}$ is .71 in this sample, the mean $m y$ is 10 percent.

\begin{tabular}{c|cccc}
\hline discount & mean & std & max & min \\
\hline .95 & .002718 & .004020 & .018938 & -.006343 \\
.90 & .000091 & .003863 & .017134 & -.011169 \\
.85 & .002676 & .004741 & .016611 & -.012598 \\
\hline
\end{tabular}

Table 7: Income Growth Elasticity of Consumption Shares in Model

The sample is a model-simulated panel for 1000 years (annual data) and 100 regions with $\gamma=2, \epsilon=.5$ and the $\mathrm{AR}(1)$ process for the non-housing expenditure share in equation (5.6). Each row corresponds to a different value of the time discount factor $\beta$. In panel A we estimate: $\Delta \log \tilde{c}_{t+1}^{i}=a_{0}^{i}+a_{1} \widetilde{m y}_{t+1} \Delta \log \hat{\eta}_{t+1}^{i}+\nu_{t+1}^{i}$. The first and second columns of panel A report the slope coefficient and the regression's $R^{2}$. In panel B we estimate: $\Delta \log \hat{c}_{t+1}^{i}=b_{0}^{i}+b_{1} \Delta \log \hat{\eta}_{t+1}^{i}+b_{2} m y_{t+1} \Delta \log \hat{\eta}_{t+1}^{i}+\nu_{t+1}^{i}$. The three last columns of the table report the min, max and mean of the collateral ratio $m y_{t}$ over the simulated sample. The mean of $m y$ is .10 and the mean of $\widetilde{m y}$ is .71 .

\begin{tabular}{c|cc|ccc|ccc}
\hline & \multicolumn{3}{|c}{ Panel A } & \multicolumn{3}{c}{ Panel B } & \multicolumn{3}{c}{ Collateral Ratio } \\
\hline discount & $a_{1}$ & $R^{2}$ & $b_{1}$ & $b_{2}$ & $R^{2}$ & mymin & mymax & mean $(\operatorname{my})$ \\
\hline .95 & 0.323 & 0.077 & 0.385 & -1.596 & 0.077 & 0.026 & 0.267 & .106 \\
.90 & 0.542 & 0.074 & 0.552 & -1.498 & 0.074 & 0.034 & 0.284 & .106 \\
.85 & 0.550 & 0.068 & 0.553 & -1.434 & 0.068 & 0.034 & 0.266 & .106 \\
.75 & 0.584 & 0.070 & 0.628 & -1.883 & 0.071 & 0.042 & 0.277 & .106 \\
\hline
\end{tabular}


Table 8: Population and Composition of Metropolitan Areas.

Total population numbers (in thousands) are displayed next to the metropolitan areas. For the Consolidated Metropolitan areas (CMSA), the constituent MSA's are listed and the fraction of their population in the total of the CMSA is shown next to their name. All numbers are from the Regional Economic Information System of the Bureau of Economic Analysis for the year 2000.

\begin{tabular}{|c|c|c|c|}
\hline Anchorage (AK), MSA & 261 & Miami CMSA & 3,897 \\
\hline Atlanta (GA), MSA & 4,145 & Miami, FL & $58.1 \%$ \\
\hline Baltimore (MD), MSA & 2,557 & Fort Lauderdale, FL & $41.9 \%$ \\
\hline Boston CMSA & 6,068 & Milwaukee CMSA & 1,691 \\
\hline Boston, MA-NH & $58.6 \%$ & Milwaukee-Waukesha, WI & $88.8 \%$ \\
\hline Worcester, MA-CT & $8.7 \%$ & Racine, WI & $11.2 \%$ \\
\hline Lawrence, MA-NH & $6.7 \%$ & Minneapolis (MN-WI) MSA & 2,797 \\
\hline Lowell, MA-NH & $5.1 \%$ & New York CMSA & 21,134 \\
\hline Brockton, MA & $4.3 \%$ & New York, NY & $45.5 \%$ \\
\hline Portsmouth-Rochester, NH-ME & $4.2 \%$ & Bergen-Passaic, NJ & $6.6 \%$ \\
\hline Manchester, NH & $3.4 \%$ & Bridgeport, CT & $0.5 \%$ \\
\hline Nashua, NH & $3.3 \%$ & Dutchess County, NY & $1.2 \%$ \\
\hline New Bedford, MA & $3.2 \%$ & Danbury, CT & $0.4 \%$ \\
\hline Fitchburg-Leominster, MA & $2.5 \%$ & Jersey City, NJ & $3.0 \%$ \\
\hline Buffalo (NY), MSA & 1,169 & Middlesex-Somerset-Hunterdon, NJ & $5.6 \%$ \\
\hline Chicago CMSA & 9,176 & Monmouth-Ocean, NJ & $5.4 \%$ \\
\hline Chicago, IL & $90.3 \%$ & Nassau-Suffolk, NY & $13.5 \%$ \\
\hline Gary, IN & $6.9 \%$ & Newburgh, NY-PA & $1.8 \%$ \\
\hline Kenosha, WI & $1.6 \%$ & Newark, NJ & $9.9 \%$ \\
\hline Kankakee, IL & $1.1 \%$ & New Haven-Meriden, CT & $6.2 \%$ \\
\hline Cincinnati CMSA & 1,983 & Stamford-Norwalk, CT & $0.6 \%$ \\
\hline Cincinnati, OH-KY-IN & $92.6 \%$ & Trenton, NJ & $1.7 \%$ \\
\hline Hamilton-Middletown, $\mathrm{OH}$ & $7.4 \%$ & Waterbury, CT & $0.5 \%$ \\
\hline Cleveland CMSA & 2,946 & Philadelphia CMSA & 6,194 \\
\hline Cleveland-Lorain-Elyria, $\mathrm{OH}$ & $76.4 \%$ & Philadelphia, PA-NJ & $82.4 \%$ \\
\hline Akron, $\mathrm{OH}$ & $23.6 \%$ & Wilmington, NC & $9.5 \%$ \\
\hline Dallas CMSA & 5,254 & Atlantic-Cape May, NJ & $5.7 \%$ \\
\hline Dallas, TX & $67.4 \%$ & Vineland-Millville-Bridgeton, NJ & $2.3 \%$ \\
\hline Fort Worth-Arlington, TX & $32.6 \%$ & Phoenix - Mesa MSA & 3,276 \\
\hline Denver CMSA & 2,597 & Pittsburgh (PA), MSA & 2,356 \\
\hline Denver, CO & $81.7 \%$ & Portland CMSA & 2,273 \\
\hline Boulder-Longmont, $\mathrm{CO}$ & $11.3 \%$ & Portland-Vancouver, OR-WA & $84.7 \%$ \\
\hline Greeley, CO & $7.0 \%$ & Salem, OR & $15.3 \%$ \\
\hline Detroit CMSA & 5,463 & Saint Louis (MO-IL), MSA & 2,606 \\
\hline Detroit, MI & $81.4 \%$ & San Diego (CA), MSA & 2,825 \\
\hline Ann Arbor, MI & $10.6 \%$ & San Francisco CMSA & 7,056 \\
\hline Flint, MI & $8.0 \%$ & San Francisco, CA & $24.6 \%$ \\
\hline Honolulu (HI), MSA & 876 & San Jose, CA & $23.9 \%$ \\
\hline Houston CMSA & 4,694 & Oakland, CA & $34.1 \%$ \\
\hline Houston, TX & $89.5 \%$ & Vallejo-Fairfield-Napa, CA & $7.4 \%$ \\
\hline Galveston-Texas City, TX & $5.3 \%$ & Santa Cruz-Watsonville, CA & $3.6 \%$ \\
\hline Brazoria, TX & $5.2 \%$ & Santa Rosa, CA & $6.5 \%$ \\
\hline Kansas City (MO-KS), MSA & 1,782 & Seattle CMSA & 3,562 \\
\hline Los Angeles CMSA & 16,440 & Seattle-Bellevue-Everett, WA & $67.9 \%$ \\
\hline Los Angeles-Long Beach, CA & $58.1 \%$ & Tacoma, WA & $19.8 \%$ \\
\hline Orange County, CA & $17.4 \%$ & Bremerton, WA & $6.5 \%$ \\
\hline Riverside-San Bernardino, CA & $20.0 \%$ & Olympia, WA & $5.8 \%$ \\
\hline \multirow[t]{2}{*}{ Ventura, CA } & $4.6 \%$ & Tampa (FL), MSA & 2,404 \\
\hline & & Washington,DC-MD-VA-WV, PMSA & 4,948 \\
\hline
\end{tabular}


Table 9: Comparison With Aggregate US data.

The first column gives the number of households in the metropolitan data set. The second column gives the fraction of US households that are in the metropolitan data set. The third column gives the nondurable retail sales per household (in \$) in the metropolitan data set (NDS). The fourth column gives the ratio of non-durable retail sales per household to non-durable consumption per household in the NIPA data (NDC). The fifth and sixth column do the same for durable sales and consumption (DS and DC). The seventh and eight column give the effective buying income per household in the metropolitan data set (EBI) and the ratio of the latter to disposable income per household from NIPA (DI).

\begin{tabular}{|c|cc|cc|cc|cc|}
\hline Year & $\begin{array}{c}\text { HH } \\
(000)\end{array}$ & $\begin{array}{c}\text { metr. HH } \\
(\%)\end{array}$ & $\begin{array}{c}\text { NDS } \\
(\$)\end{array}$ & $\begin{array}{c}\text { NDS to } \\
\text { NDC }\end{array}$ & $\begin{array}{c}\text { DS } \\
(\$)\end{array}$ & $\begin{array}{c}\text { DS to } \\
\text { DC }\end{array}$ & $\begin{array}{c}\text { EBI } \\
(\$)\end{array}$ & $\begin{array}{c}\text { EBI to } \\
\text { DI }\end{array}$ \\
\hline 1951 & 17,623 & 39.4 & 3,008 & 1.23 & 799 & 1.36 & 5,959 & 1.15 \\
1960 & 23,080 & 43.7 & 3,519 & 1.22 & 899 & 1.26 & 7,711 & 1.11 \\
1970 & 28,332 & 44.7 & 4,688 & 1.09 & 1,180 & 1.05 & 11,936 & 1.03 \\
1980 & 36,144 & 44.7 & 9,683 & 1.12 & 2,660 & 1.24 & 24,975 & 1.00 \\
1990 & 41,784 & 44.8 & 15,418 & 1.15 & 5,531 & 1.37 & 43,698 & 0.95 \\
2000 & 49,379 & 47.2 & 24,741 & 1.30 & 11,888 & 1.90 & 56,566 & 0.83 \\
\hline
\end{tabular}

Table 10: Comparison With Household Data.

Correlation of household non-durable consumption, durable consumption and income data, aggregated by the CEX for metropolitan areas and the metropolitan area non-durable and durable retail sales and disposable income data from S\&MM.

\begin{tabular}{|c|ccc|}
\hline MSA & Nond.Cons & Dur.Cons & Income \\
\hline Washington, DC (PMSA) & 0.926 & 0.660 & 0.973 \\
Baltimore, MD (PMSA) & 0.973 & 0.791 & 0.956 \\
Atlanta, GA (MSA) & 0.740 & 0.522 & 0.944 \\
Miami, FL (CMSA) & 0.533 & 0.399 & 0.922 \\
Dallas, TX (CMSA) & 0.939 & 0.839 & 0.917 \\
Houston, TX (CMSA) & 0.936 & 0.955 & 0.932 \\
\hline Los Angeles, CA (CMSA) & 0.836 & 0.845 & 0.944 \\
San Francisco, CA (CMSA) & 0.921 & 0.797 & 0.981 \\
San Diego, CA (MSA) & 0.838 & 0.511 & 0.961 \\
Portland, OR (CMSA) & 0.989 & 0.932 & 0.973 \\
Seattle, WA (CMSA) & 0.928 & 0.841 & 0.935 \\
Honolulu, HI (MSA) & 0.858 & 0.409 & 0.956 \\
Anchorage, AK (MSA) & 0.931 & 0.601 & 0.847 \\
\hline New York, NY (CMSA) & 0.952 & 0.727 & 0.957 \\
Philadelphia, PA (CMSA) & 0.812 & 0.698 & 0.932 \\
Boston, MA (CMSA) & 0.876 & 0.515 & 0.799 \\
Pittsburgh, PA (MSA) & 0.921 & 0.759 & 0.846 \\
\hline Chicago, IL (CMSA) & 0.803 & 0.601 & 0.953 \\
Detroit, MI (CMSA) & 0.960 & 0.534 & 0.956 \\
Milwaukee, WI (CMSA) & 0.792 & 0.636 & 0.949 \\
Minneapolis-St, Paul, MN (MSA) & 0.940 & 0.863 & 0.972 \\
Cleveland, OH (CMSA) & 0.881 & 0.878 & 0.956 \\
Cincinnati, OH (CMSA) & 0.898 & 0.864 & 0.974 \\
St. Louis, MO (MSA) & 0.881 & 0.815 & 0.945 \\
Kansas City, MO-KS (MSA) & 0.958 & 0.708 & 0.961 \\
\hline Average & 0.881 & 0.708 & 0.938 \\
\hline
\end{tabular}


Table 11: Comparison With Regional Income Data

Correlation of regional disposable income from S\&MM and labor income plus Transfers from REIS.

\begin{tabular}{|c|c|c|c|}
\hline South and West & Coeff. & Northeast and Midwest & Corr. \\
\hline Washington, DC (PMSA) & 0.79 & New York, NY (CMSA) & 0.84 \\
Baltimore, MD (PMSA) & 0.42 & Philadelphia, PA (CMSA) & 0.82 \\
Atlanta, GA (MSA) & 0.73 & Boston, MA (CMSA) & 0.73 \\
Miami, FL (CMSA) & -0.18 & Pittsburgh, PA (MSA) & 0.57 \\
Dallas, TX (CMSA) & 0.63 & Buffalo, NY (MSA) & 0.77 \\
Houston, TX (CMSA) & 0.86 & Chicago, IL (CMSA) & 0.76 \\
\cline { 4 - 4 } Los Angeles, CA (CMSA) & 0.85 & Detroit, MI (CMSA) & 0.74 \\
San Francisco, CA (CMSA) & 0.65 & Milwaukee, WI (CMSA) & 0.12 \\
San Diego, CA (MSA) & 0.75 & Minneapolis-St, Paul, MN (MSA) & 0.70 \\
Portland, OR (CMSA) & 0.57 & Cleveland, OH (CMSA) & 0.90 \\
Seattle, WA (CMSA) & 0.60 & Cincinnati, OH (CMSA) & -0.23 \\
Honolulu, HI (MSA) & 0.84 & St. Louis, MO (MSA) & 0.54 \\
Anchorage, AK (MSA) & 0.80 & Kansas City, MO-KS (MSA) & 0.57 \\
Phoenix, AZ (MSA) & 0.83 & & \\
Denver, CO (CMSA) & 0.67 & Average \\
\cline { 3 - 4 }
\end{tabular}

Table 12: Median Home Value and Home-Ownership Rate.

The table shows median home values for 1980 and 2000 (in thousands of nominal dollars) and the home ownership rate for 1980 and 2000. All data are from the US Bureau of the Census, Decennial Survey 1980 and 2000

\begin{tabular}{|l|cc|cc||}
\hline \multicolumn{1}{|c|}{ MSA } & $\mathrm{V}_{80}$ & $\mathrm{~V}_{00}$ & $\mathrm{HO}_{80}$ & $\mathrm{HO}_{00}$ \\
\hline Washington, DC (PMSA) & 79.9 & 178.9 & 54.3 & 64.0 \\
Baltimore, MD (PMSA) & 51.4 & 134.9 & 60.0 & 66.9 \\
Atlanta, GA (MSA) & 47.7 & 135.3 & 61.4 & 66.4 \\
Miami, FL (CMSA) & 57.0 & 126.1 & 61.5 & 63.2 \\
Dallas-Fort Worth, TX (CMSA) & 45.6 & 100.0 & 64.7 & 60.4 \\
Houston, TX (CMSA) & 52.8 & 89.7 & 59.1 & 60.7 \\
Tampa, FL (MSA) & 39.9 & 93.8 & 71.7 & 70.8 \\
\hline \hline San Francisco, CA (CMSA) & 98.4 & 353.5 & 55.8 & 57.8 \\
Los Angeles, CA (CMSA) & 87.6 & 203.3 & 53.8 & 54.8 \\
San Diego, CA (MSA) & 90.0 & 227.2 & 55.1 & 55.4 \\
Portland, OR (CMSA) & 60.8 & 165.4 & 63.2 & 63.0 \\
Seattle, WA (CMSA) & 66.0 & 195.4 & 63.8 & 62.9 \\
Honolulu, HI (MSA) & 129.5 & 309.0 & 49.9 & 54.6 \\
Anchorage, AK (MSA) & 89.2 & 160.7 & 56.6 & 60.1 \\
Denver, CO (CMSA) & 69.1 & 179.5 & 63.0 & 66.4 \\
Phoenix, AZ (MSA) & 59.2 & 127.9 & 68.7 & 68.0 \\
\hline \hline New York, NY (CMSA) & 62.5 & 203.1 & 44.2 & 53.0 \\
Philadelphia, PA (CMSA) & 42.2 & 122.3 & 67.7 & 69.9 \\
Boston, MA (CMSA) & 52.0 & 203.0 & 54.8 & 60.6 \\
Pittsburgh, PA (MSA) & 42.7 & 68.1 & 69.0 & 71.3 \\
Buffalo, NY (MSA) & 39.7 & 89.1 & 63.7 & 66.2 \\
\hline \hline Chicago, IL (CMSA) & 62.8 & 159.0 & 58.5 & 65.2 \\
Detroit, MI (CMSA) & 43.5 & 132.6 & 70.2 & 72.2 \\
Milwaukee, WI (CMSA) & 59.2 & 131.9 & 61.1 & 62.1 \\
Minneapolis-St, Paul, MN (MSA) & 62.3 & 141.2 & 67.2 & 72.4 \\
Cleveland, OH (CMSA) & 52.1 & 117.9 & 66.6 & 68.8 \\
Cincinnati, OH (CMSA) & 47.9 & 116.5 & 63.8 & 67.1 \\
St. Louis, MO (MSA) & 41.8 & 99.4 & 68.2 & 71.4 \\
Kansas City, MO-KS (MSA) & 43.5 & 104.7 & 66.4 & 67.9 \\
Tampa, FL (MSA) & 59.9 & 85.2 & 73.0 & 71.0 \\
\hline & & & & \\
\hline
\end{tabular}

